\title{
DNA-Compatible Copper-Catalyzed Oxidative Amidation of Aldehydes with Non-Nucleophilic Arylamines
}

$\mathrm{Ke} \mathrm{Li}^{\dagger \S}$, Yi Qu ${ }^{\dagger \S}$, Yulong An ${ }^{\dagger}$, Eric Breinlinger ${ }^{\ddagger}$, Matthew P. Webster ${ }^{\psi}$, Huanan Wen ${ }^{\dagger}$, Duanchen Ding ${ }^{\dagger}$, Meng Zhao ${ }^{\dagger}$, Xiaodong Shi ${ }^{\dagger}$, Jiangong Wang ${ }^{\dagger}$, Wenji Su${ }^{\dagger}$, Weiren Cui ${ }^{\dagger}$, Alexander L. Satz ${ }^{\dagger}$, Hongfang Yang $^{\dagger}$, Letian Kuai ${ }^{\dagger}$, Andrew Little ${ }^{\ddagger *}$ and Xuanjia Peng ${ }^{\dagger *}$

†WuXiAppTec (Shanghai) Co., Ltd. 288 Middle Fu Te Road, Shanghai 200131, China

*AbbVie Bioresearch Center, 381 Plantation Street, Worcester, MA 01605, United States

${ }^{\psi}$ Research and Development, AbbVie, 1 North Waukegan Road, North Chicago, Illinois 60064, United States

Supporting Information 


\section{Contents}

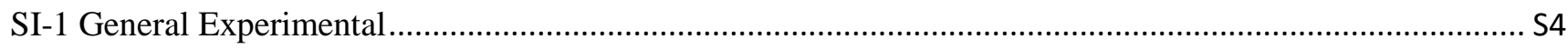

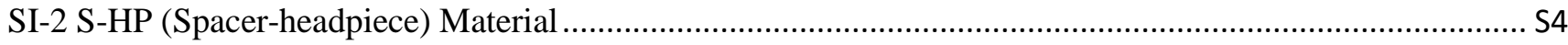

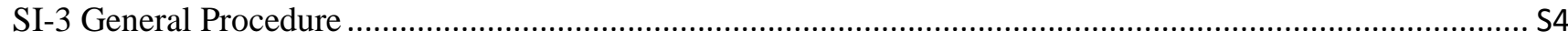

SI-3-1 Ethanol Precipitation for DNA Compatible Reactions …............................................................... S4

SI-3-2 General Procedure 1 for DNA conjugated aryl aldehydes ...........................................................S5

SI-3-3 General Procedure 2 for DNA conjugated aliphatic aldehyde 1q .................................................S5

SI-3-4 General Procedure 3 for Oxidative Amidation. ............................................................................ S6

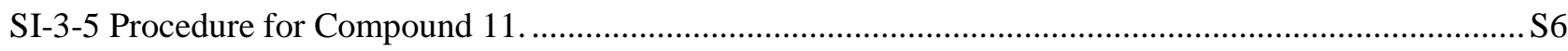

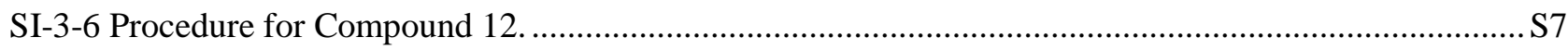

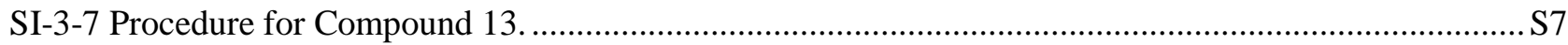

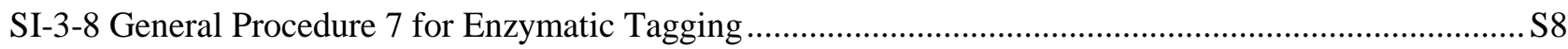

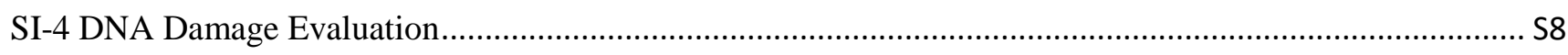

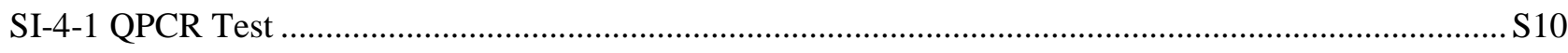

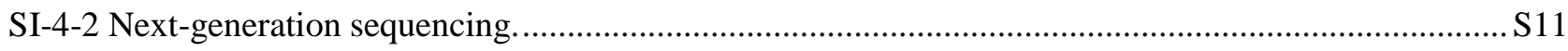

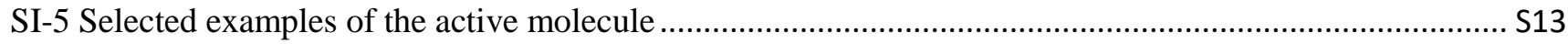

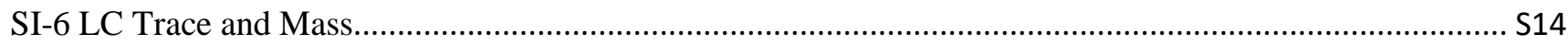

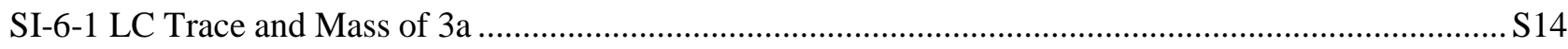

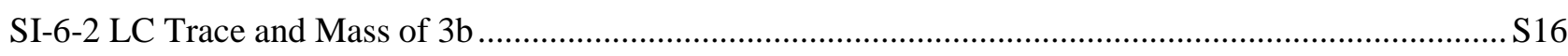

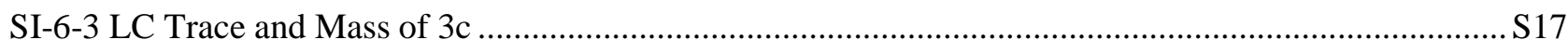

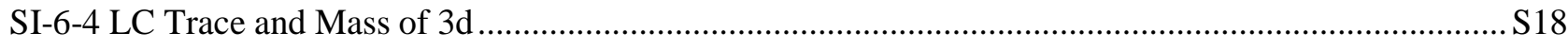

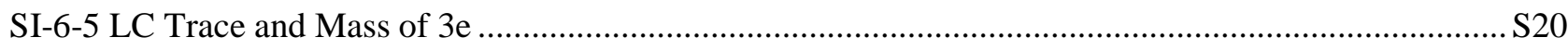

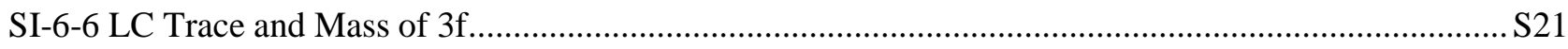

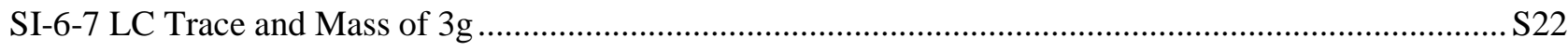

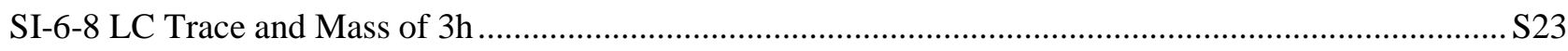

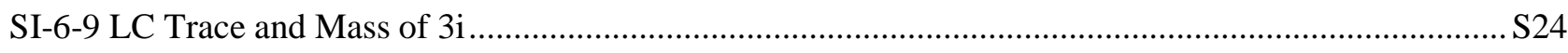

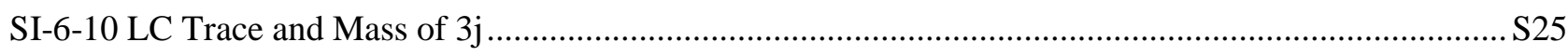

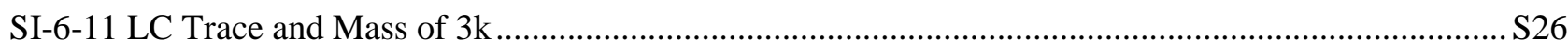

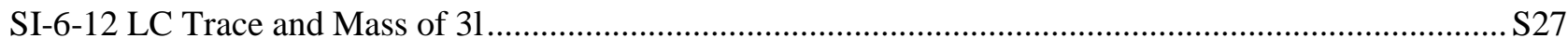

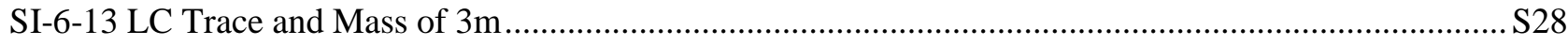

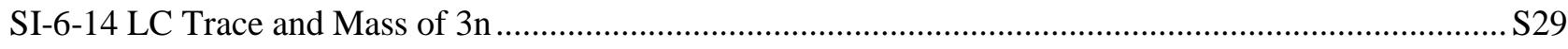

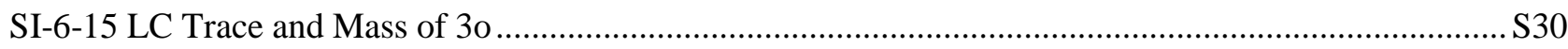

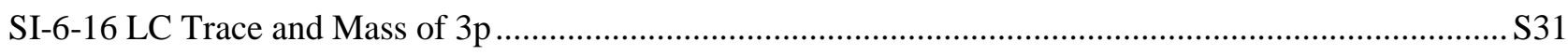

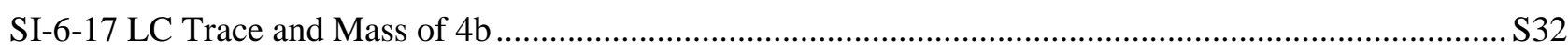


SI-6-18 LC Trace and Mass of 4c S33

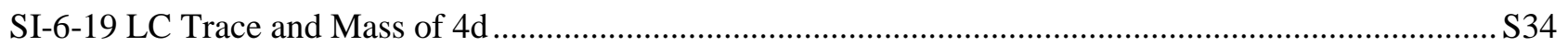

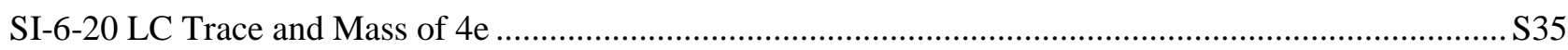

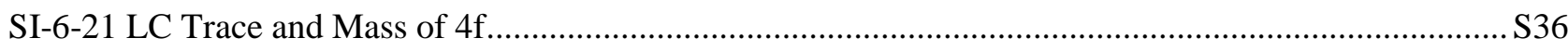

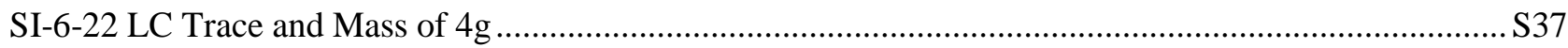

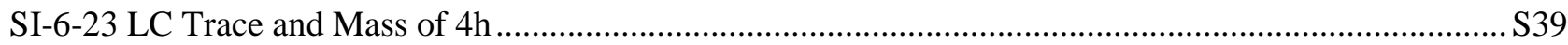

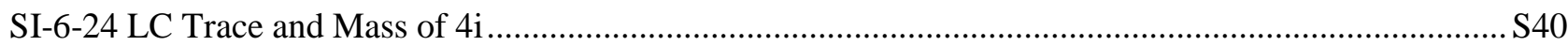

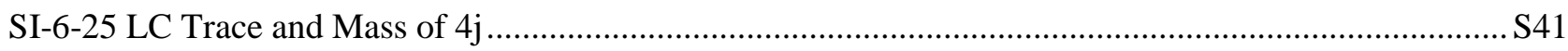

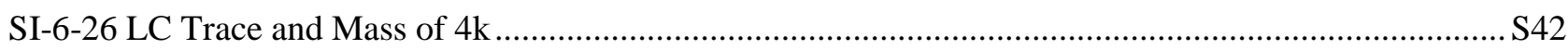

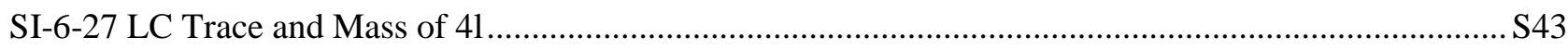

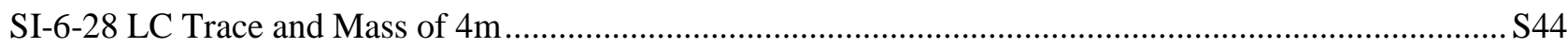

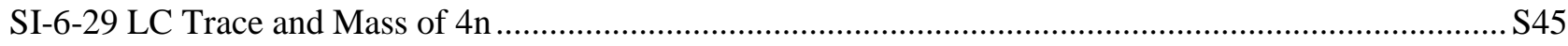

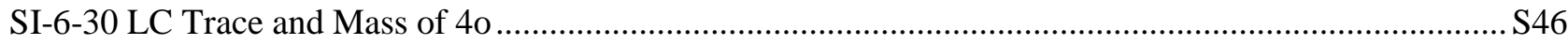

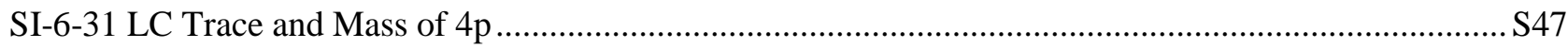

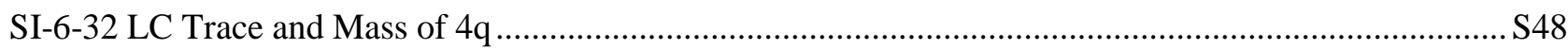

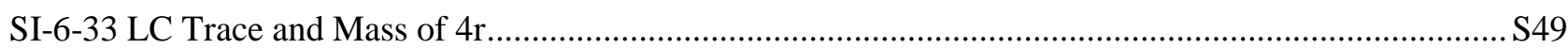

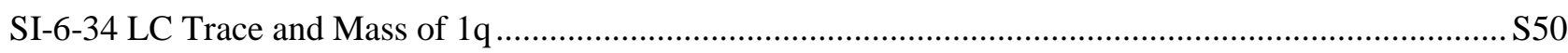

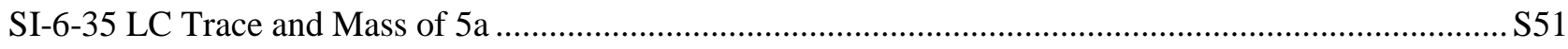

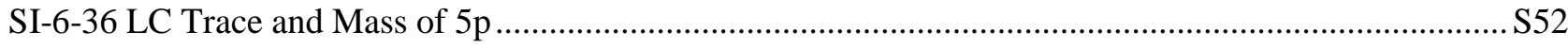

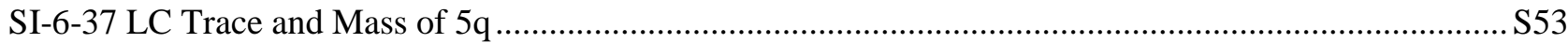

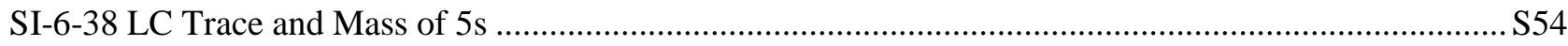

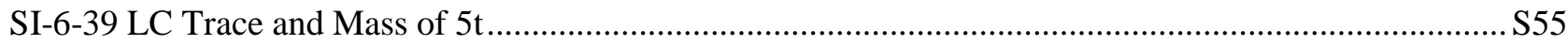

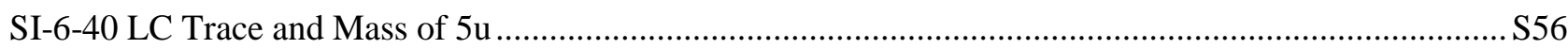

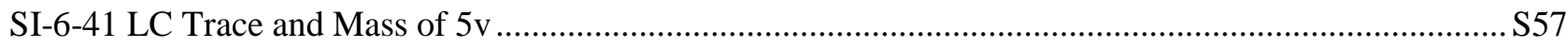

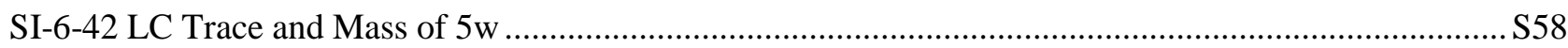

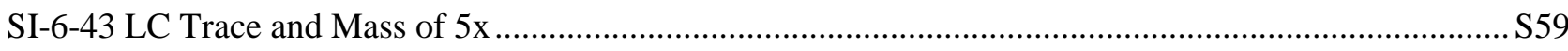

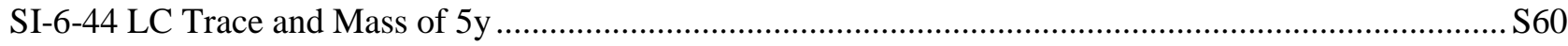

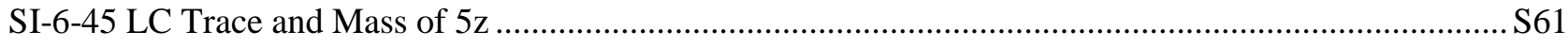

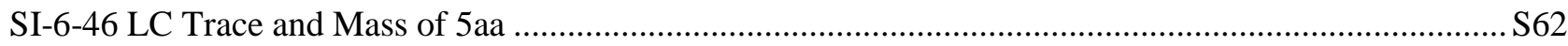

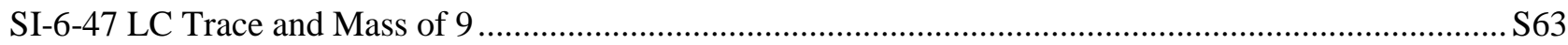

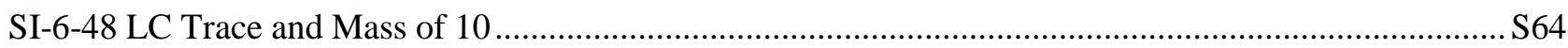

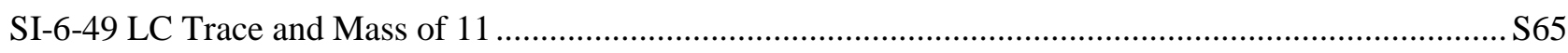

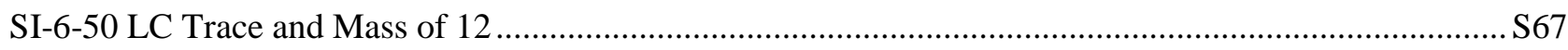

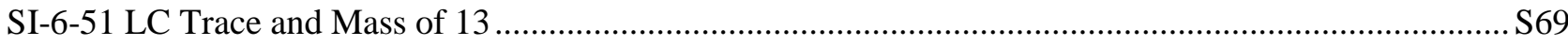




\section{SI-1 General Experimental}

Dimethylsulfoxide (DMSO), 1-methyl-2-pyrrolidinone (NMP), $N, N$-dimethylacetamide (DMAc), acetonitrile $\left(\mathrm{CH}_{3} \mathrm{CN}\right)$, and EtOH were purchased from Sigma-Aldrich. EDCI (CAS: 25952-53-8), $N$-hydroxysulfosuccinimide sodium salt (s-NHS, CAS: 106627-54-7), tert-butyl-hydroperoxide (TBHP, 70\% in water, 75-91-2), and $\mathrm{NaCl}$ were purchased from TCI. The $\mathrm{H}_{2} \mathrm{O}$ used was obtained by passing through the Milli-Q Direct. The reaction buffers were purchased from Vazyme and the ligase and ligation buffer were purchased from Thermo. The other reagents were purchased from domestic vendors unless mentioned otherwise. On-DNA reaction conversions were determined by UV traces of LC/MS analysis. The centrifuge instruments were Allegra X-15R, eppendorf-5424R. The peak at 0.27 min sometimes seen in the provided LC/MS traces is attributed to inorganic salts and small molecules contaminants, according to our experience.

\section{SI-2 S-HP (Spacer-headpiece) Material}

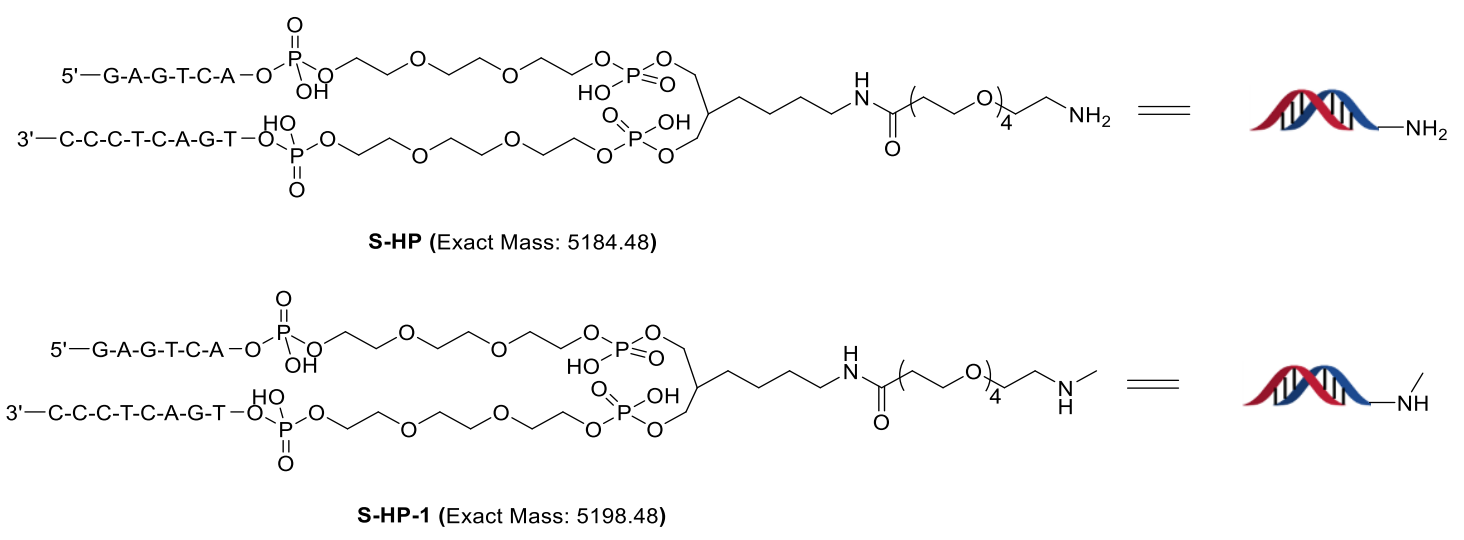

S-HP is composed of headpiece and PEG4 linker.

\section{SI-3 General Procedure}

\section{SI-3-1 Ethanol Precipitation for DNA Compatible Reactions}

To the reaction mixture was added $10 \%$ (v/v) $5 \mathrm{M} \mathrm{NaCl}$ aqueous solutions and 2.5-3 fold the volume of cold ethanol (stored at $-20^{\circ} \mathrm{C}$ before use). The colloidal solution was then allowed to sit at $-80{ }^{\circ} \mathrm{C}$ for more than 2 hours. The solutions were centrifuged at $4{ }^{\circ} \mathrm{C}$ for $30 \mathrm{~min}$ at $4000 \mathrm{~g}$. The supernatants were discarded, and the DNA pellet was dried at $30{ }^{\circ} \mathrm{C}$ for 1 hour in vacuo. Generally, ethanol precipitation was performed after each chemical reaction. 


\section{SI-3-2 General Procedure 1 for DNA conjugated aryl aldehydes}

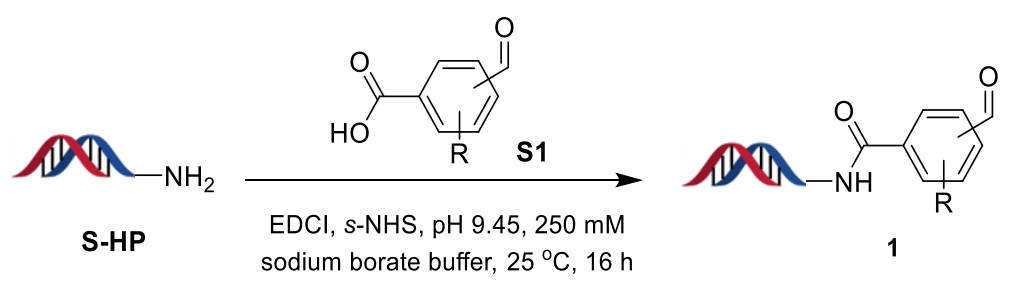

To a $15 \mathrm{~mL}$ tube was added a solution of EDCI (200 mM in DMSO, $125 \mu \mathrm{L}, 50$ equiv), $s$-NHS (200 mM in DMSO/ $\mathrm{H}_{2} \mathrm{O}=1 / 1,75 \mu \mathrm{L}, 30$ equiv) and $\mathbf{S 1}$ (200 mM in DMAc, $150 \mu \mathrm{L}, 60$ equiv). This solution was mixed and left to stand at $20^{\circ} \mathrm{C}$ for 15 min to make the active ester.

Next, S-HP solution (1 mM in pH 9.5 sodium borate buffer $(250 \mathrm{mM}), 500 \mu \mathrm{L}, 1$ equiv) was added to the freshly prepared active ester solution. The solution was mixed and left to stand at $25^{\circ} \mathrm{C}$ for $16 \mathrm{~h}(\mathrm{pH} 9)$, with reaction conversion monitored by LCMS. The reaction mixture was then precipitated with ethanol (see General Procedure SI-3-1).

\section{SI-3-3 General Procedure 2 for DNA conjugated aliphatic aldehyde 1q}

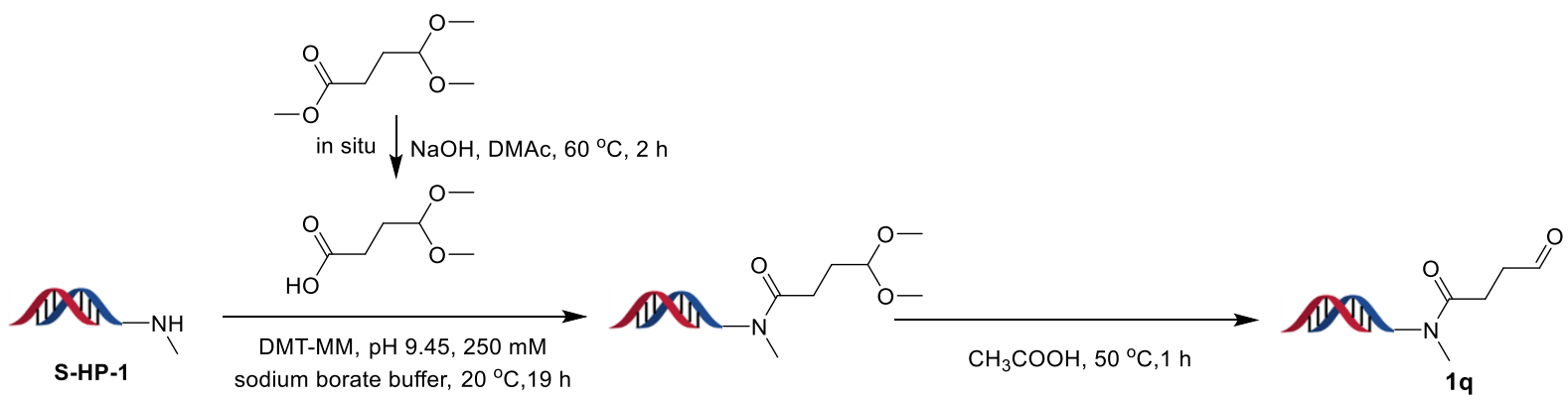

The DNA-linked material S-HP-1 (500 nmol) was dissolved in sodium borate buffer (pH 9.45, $250 \mathrm{mM}$, $500 \mu \mathrm{L}$ ) to make a $1 \mathrm{mM}$ solution. To 4,4-dimethoxybutanoic acid methyl ester (200 mM in DMAc, 106.25 $\mu \mathrm{L}, 42.5$ equiv) was added $\mathrm{NaOH}\left(200 \mathrm{mM}\right.$ in $\mathrm{H}_{2} \mathrm{O}, 106.25 \mu \mathrm{L}, 42.5$ equiv); the solution was mixed and then stood at $60{ }^{\circ} \mathrm{C}$ for $2 \mathrm{~h}$. To the DNA material S-HP-1 was added the above solution and DMT-MM (200 mM in $\mathrm{H}_{2} \mathrm{O}, 100 \mu \mathrm{L}, 40$ equiv). The solution was mixed and left to stand at $20{ }^{\circ} \mathrm{C}$ for another $3 \mathrm{~h}(\mathrm{pH}$ ) ) to make the precursor for $\mathbf{1 q}$ in situ. The reaction conversion monitored by LCMS. The reaction mixture was then precipitated with ethanol (see General Procedure SI-3-1). 
Next, the material was redissoved in $\mathrm{H}_{2} \mathrm{O}(500 \mu \mathrm{L})$ and freshly prepared acetic acid solution (300 Mm in $\left.\mathrm{H}_{2} \mathrm{O}, 166 \mu \mathrm{L}\right)$ was added. The solution was mixed and left to stand at $50{ }^{\circ} \mathrm{C}$ for $1 \mathrm{~h}(\mathrm{pH} 9)$, with reaction conversion monitored by LCMS. The reaction mixture was then precipitated with ethanol (see General Procedure SI-3-1).

\section{SI-3-4 General Procedure 3 for Oxidative Amidation.}

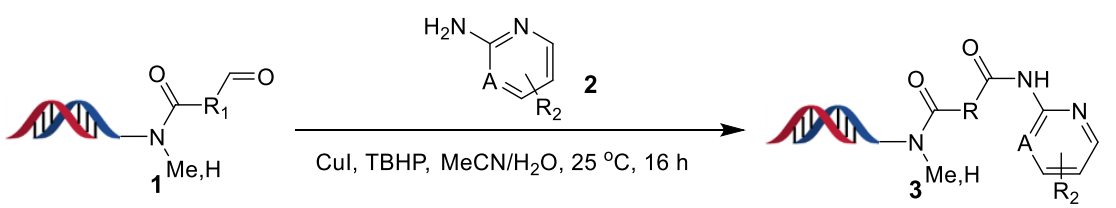

To the DNA-linked material 1 (10 nmol, $1 \mathrm{mM}$ in $\mathrm{H}_{2} \mathrm{O}, 10 \mu \mathrm{L}, 1$ equiv) was added aniline 2 (400.0 mM in $\mathrm{CH}_{3} \mathrm{CN}, 5 \mu \mathrm{L}, 200$ equiv), $\mathrm{CuI}\left(50.0 \mathrm{mM}\right.$ in $\mathrm{CH}_{3} \mathrm{CN}, 16 \mu \mathrm{L}, 80$ equiv) and TBHP (200 mM in $\mathrm{H}_{2} \mathrm{O}$, $5 \mu \mathrm{L}, 100$ equiv). The solution was mixed at $25{ }^{\circ} \mathrm{C}$ for $16 \mathrm{~h}$ in a shaker (pH 6 7). Next, to the solution was added ethyldithiocarbamate trihydrate $\left(200.0 \mathrm{mM}\right.$ in $\mathrm{H}_{2} \mathrm{O}, 12 \mu \mathrm{L}, 240.0$ equiv). The solution was mixed and left to stand at $80{ }^{\circ} \mathrm{C}$ for $30 \mathrm{~min}$, with reaction conversion monitored by LCMS. The reaction mixture was then precipitated with ethanol (see General Procedure SI-3-1).

\section{SI-3-5 Procedure for Compound 11.}

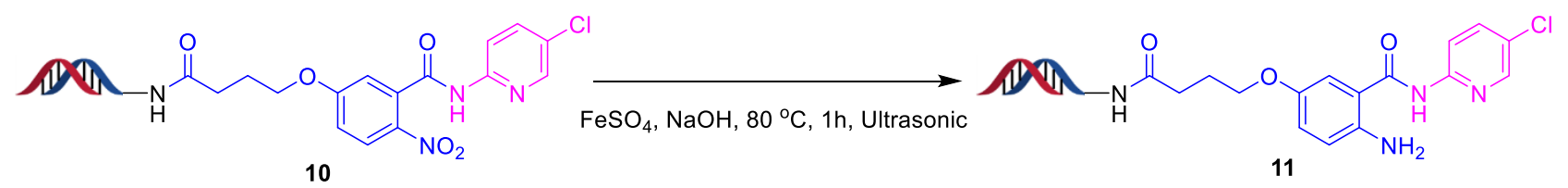

To the DNA starting material 10 (946 nmol, $1 \mathrm{mM}$ in $\mathrm{H}_{2} \mathrm{O}, 946 \mu \mathrm{L}, 1$ equiv) was added $\mathrm{FeSO}_{4} .7 \mathrm{H}_{2} \mathrm{O}$ (200.0 mM in $\mathrm{H}_{2} \mathrm{O}, 378.4 \mu \mathrm{L}, 80.0$ equiv), and $\mathrm{NaOH}\left(2500.0 \mathrm{mM}\right.$ in $\mathrm{H}_{2} \mathrm{O}, 189.2 \mu \mathrm{L}, 500.0$ equiv). The solutions was mixed at $80{ }^{\circ} \mathrm{C}$ for $1 \mathrm{~h}$ in an ultrasonic unit ( $\mathrm{pH}$ 12). Next, to the solution was added ethyldithiocarbamate trihydrate $\left(100.0 \mathrm{mM}\right.$ in $\mathrm{H}_{2} \mathrm{O}, 567.6 \mu \mathrm{L}, 60$ equiv). The solution was mixed and left to stand at $80{ }^{\circ} \mathrm{C}$ for $30 \mathrm{~min}$, with reaction conversion monitored by LCMS. The reaction mixture was then precipitated with ethanol (see General Procedure SI-3-1). The crude product was purified by reversephase HPLC to give $167.8 \mathrm{nmol}$ of desired product 11. Yield (17.7\%). 


\section{SI-3-6 Procedure for Compound 12.}

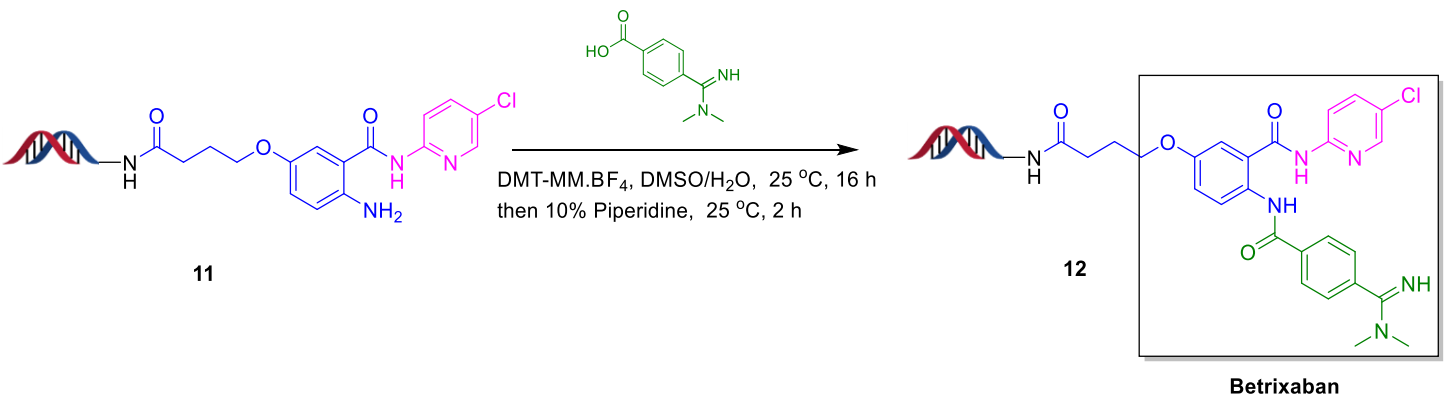

The DNA starting material 11 (5 nmol) was dissolved in MOPS buffer (pH 8.2, $50 \mathrm{mM}, 5 \mu \mathrm{L}) .4-(N, N-$ Dimethylcarbamimidoyl)benzoic acid (400.0 mM in $\mathrm{H}_{2} \mathrm{O}, 2.5 \mu \mathrm{L}, 200.0$ equiv) and DMT-MM.BF $4(400.0$ $\mathrm{mM}$ in DMSO, $2.5 \mu \mathrm{L}, 200$ equiv) were then added. After the addition, the tube was centrifuged, eddied and re-centrifuged. The reaction mixture was kept at $25^{\circ} \mathrm{C}$ for $16 \mathrm{~h}(\mathrm{pH} 8)$. After EtOH precipitation, $\mathrm{H}_{2} \mathrm{O}(5 \mu \mathrm{L})$ and $20 \%$ piperidine $(5 \mu \mathrm{L})$ were added. The tube was centrifuged, eddied and re-centrifuged. The solution was mixed and left to stand at $25^{\circ} \mathrm{C}$ for $2 \mathrm{~h}$, with reaction conversion monitored by LCMS. The reaction mixture was then precipitated with ethanol (see General Procedure SI-3-1).

\section{SI-3-7 Procedure for Compound 13.}

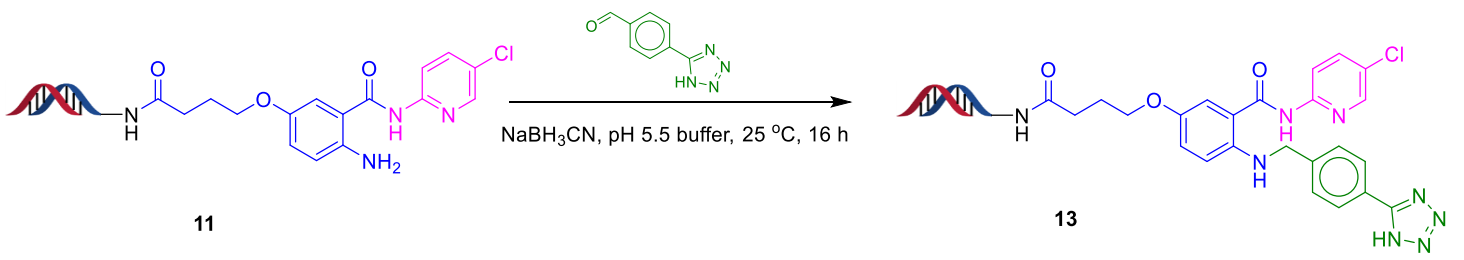

The DNA starting material $11(5 \mathrm{nmol})$ was dissolved in phosphoric buffer (pH 5.5, $250 \mathrm{mM}, 5 \mu \mathrm{L})$. 4(1H-Tetrazol-5-yl) benzaldehyde (200.0 mM in DMAc, $3 \mu \mathrm{L}, 20.0$ equiv) and $\mathrm{NaBH}_{3} \mathrm{CN}(400.0 \mathrm{mM}$ in DMAc, $1.5 \mu \mathrm{L}, 120$ equiv) were then added. After the addition, the tube was centrifuged, eddied and recentrifuged. The solution was mixed and left to stand at $20^{\circ} \mathrm{C}$ for $16 \mathrm{~h}(\mathrm{pH} 6)$, with reaction conversion monitored by LCMS. The reaction mixture was then precipitated with ethanol (see General Procedure SI3-1). 


\section{SI-3-8 General Procedure 7 for Enzymatic Tagging}

To DNA-linked starting materials (100 nmol, $1 \mathrm{mM}$ in $\mathrm{H}_{2} \mathrm{O}, 100 \mu \mathrm{L}, 1$ equiv) were added DNA tags (160 nmol, $1 \mathrm{mM}$ in $\mathrm{H}_{2} \mathrm{O}, 160 \mu \mathrm{L}, 1.6$ equiv), 10x T4 DNA ligation buffer (40 $\left.\mu \mathrm{L}\right)$, T4 DNA ligase (4 $\mu \mathrm{L}$, $30 \mathrm{U} / \mu \mathrm{L})$ and $\mathrm{H}_{2} \mathrm{O}(96 \mu \mathrm{L})$. The solutions were mixed and stirred at $16{ }^{\circ} \mathrm{C}$ for $16 \mathrm{~h}$. The reaction mixtures were precipitated with ethanol, according to General Procedure SI-3-1, and the samples were analyzed by $4 \%$ gel picture.

\section{SI-4 DNA Damage Evaluation}

Copper-mediated oxidative amidation of aldehyde reactions (abbreviated as "the oxidative amidation reaction" below) were performed with DNA conjugated compound with a double stranded DNA coding region to mimic the library component. The DNA conjugated compound was subjected to the oxidative amidation reaction under different conditions (Table S1) to determine DNA damage.

Table S1, sampling logic of the comparison.

\begin{tabular}{cccc}
\hline ID & Condition No. & Condition Info. & $\begin{array}{c}\text { Theoretical In- } \\
\text { put }\end{array}$ \\
\hline A1 & 1 & Normal reaction & $5 \mathrm{nmol}$ \\
A2 & 2 & No CuI/TBHP & $5 \mathrm{nmol}$ \\
A3 & 3 & No CuI & $5 \mathrm{nmol}$ \\
A4 & 4 & No TBHP & $5 \mathrm{nmol}$ \\
A5 & $5^{a}$ & formaldehyde(PC1) & $5 \mathrm{nmol}$ \\
A6 & $6^{b}$ & No reaction(NC) & $5 \mathrm{nmol}$ \\
A7 & $7^{c}$ & No reaction (Ab NC) & $5 \mathrm{nmol}$ \\
\hline
\end{tabular}


Note: ${ }^{a}$ Compounds in this group act as positive control. ${ }^{[1] b}$ Compounds in this group act as negative control and go through the basic liquid transfer processes in the oxidative amidation reaction, but no reagent or material was added. ${ }^{c}$ Compounds in this group don't go through the oxidative amidation reaction and are kept as an absolute negative control.

[1] Huang, H., Hopkins, P. B. (1993) DNA interstrand cross-linking by formaldehyde: nucleotide sequence preference and covalent struc-ture of the predominant cross-link formed in synthetic oligonucleo-tides. J. Am. Chem. Soc. 115, 9402-9408.

The products of each reaction were visualized by an Agilent 2100 Bioanalyzer (Fig S1), then ligated to an oligonucleotide to generate a full-length DNA fragment, similar to DEL molecules. If there is DNA damage in the oxidative amidation reaction, the band of the experimental group may become vague or turn into a smear compared with the negative control. The shape of the band from the experimental group A1 is similar to the negative group A7, while the band of positive control of the formaldehyde treated group A5 is disappearing. These results indicate that normal reaction conditions will not affect the DNA as observed in condition A5. As the band of A2 to A4 are quite similar, it is clear that the different reagents in the oxidative amidation reaction will not affect the DNA. For subsequent qPCR analysis, only the groups of A1 (oxidative amidation reaction group), A5 (formaldehyde treated, positive control) and A7 (negative control) were used.

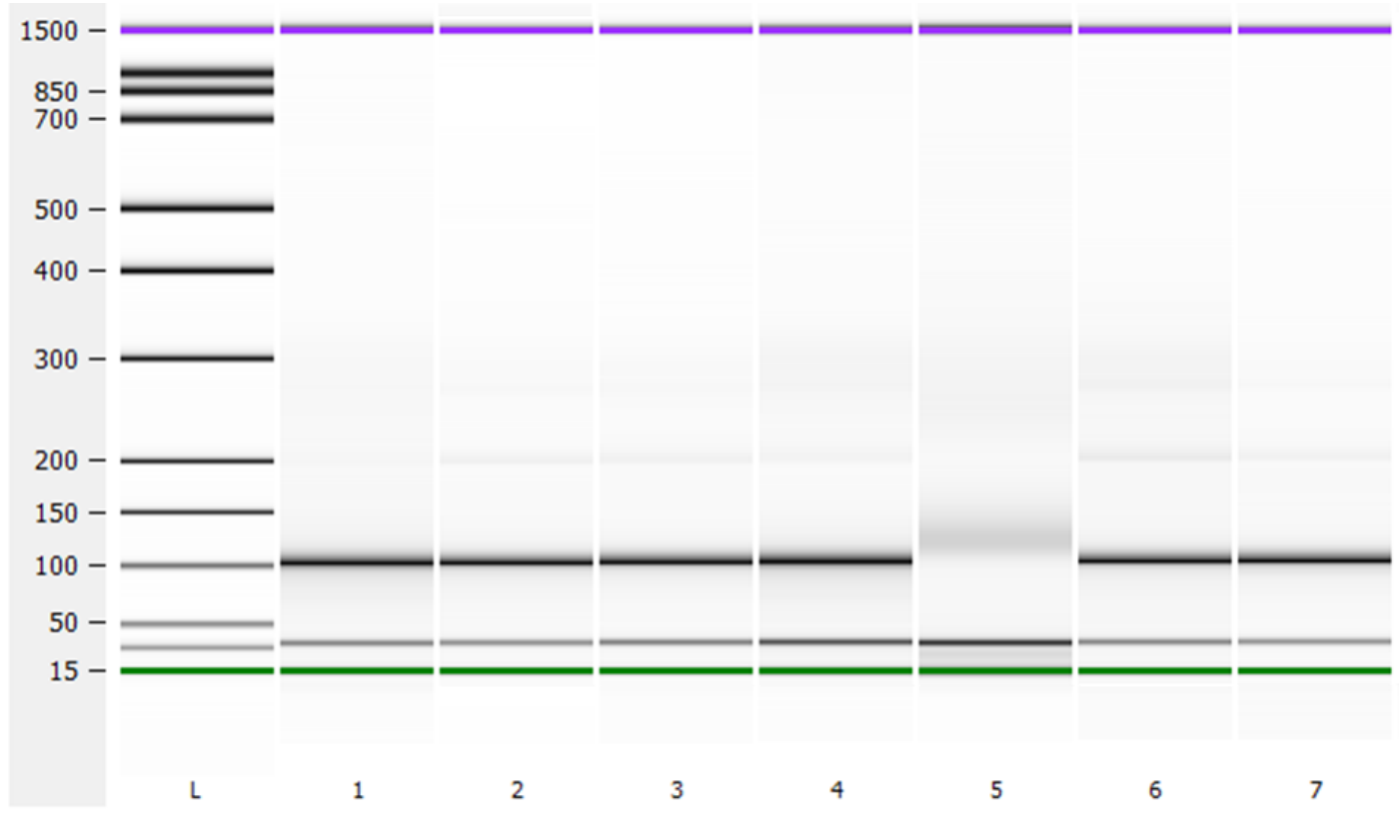


Figure S1. Gel image of different comparison groups. Lane 1 to 7 is the condition A1 to A7.

\section{SI-4-1 QPCR Test}

After EtOH Precipitation, according to General Procedure SI-3-1, the ligation products of A1 (oxidative amidation), A5 (formaldehyde treated) and A7 (negative control) were step-wise diluted 10 fold to a final 1e4 fold dilution. The serial dilutions were used as templates for qPCR testing using a SYBR Green Master Mix kit (Thermo) and a Real-Time PCR System (QuantStudio 7 Flex) (Table S2). All samples were run in triplicate and subjected to PCR cycles as follows: $95{ }^{\circ} \mathrm{C}$ heat activation for 5 min followed by 40 cycles of $95{ }^{\circ} \mathrm{C}$ denaturation for 10 seconds, $55^{\circ} \mathrm{C}$ annealing for 15 seconds and extension at $72{ }^{\circ} \mathrm{C}$ for 30 seconds.

Table S2. Summary of qPCR Data Analysis.

\begin{tabular}{|c|c|c|c|c|c|c|}
\hline \multicolumn{2}{|c|}{$\begin{array}{c}\text { qPCR Standard (Copy } \\
\text { Number) }\end{array}$} & \multicolumn{3}{|c|}{ LOG10(Copy Number) } & \multicolumn{2}{|c|}{ Average(Ct) } \\
\hline \multicolumn{2}{|c|}{$1.00 \mathrm{E}+09$} & \multicolumn{3}{|c|}{9.00} & \multicolumn{2}{|l|}{5.46} \\
\hline \multicolumn{2}{|c|}{$1.00 \mathrm{E}+08$} & \multicolumn{3}{|c|}{8.00} & \multicolumn{2}{|l|}{8.67} \\
\hline \multicolumn{2}{|c|}{$1.00 \mathrm{E}+07$} & \multicolumn{3}{|c|}{7.00} & \multicolumn{2}{|l|}{12.49} \\
\hline \multicolumn{2}{|c|}{$1.00 \mathrm{E}+06$} & \multicolumn{3}{|c|}{6.00} & \multicolumn{2}{|l|}{15.68} \\
\hline \multicolumn{2}{|c|}{$1.00 \mathrm{E}+05$} & \multicolumn{3}{|c|}{5.00} & \multicolumn{2}{|l|}{18.96} \\
\hline \multicolumn{2}{|c|}{$1.00 \mathrm{E}+04$} & \multicolumn{3}{|c|}{4.00} & \multicolumn{2}{|l|}{22.64} \\
\hline \multicolumn{2}{|c|}{$1.00 \mathrm{E}+03$} & \multicolumn{3}{|c|}{3.00} & \multicolumn{2}{|l|}{26.18} \\
\hline \multirow{2}{*}{$\begin{array}{l}\text { LOG10(Dilution } \\
\text { Fold) }\end{array}$} & \multicolumn{2}{|c|}{ Group A1 } & \multicolumn{2}{|c|}{ Group A5 } & \multicolumn{2}{|c|}{ Group A7 } \\
\hline & Average $(\mathrm{Ct})$ & Copies/ $/ \mathrm{L}$ & Average $(\mathrm{Ct})$ & Copies/ $\mu \mathrm{L}$ & - Average $(\mathrm{Ct})$ & Copies $/ \mu \mathrm{L}$ \\
\hline 3.00 & 7.64 & $1.10 E+08$ & 9.61 & $2.97 E+07$ & 6.23 & $2.83 \mathrm{E}+08$ \\
\hline 4.00 & 10.63 & $1.50 \mathrm{E}+07$ & 13.36 & $2.43 E+06$ & 10.26 & $1.92 \mathrm{E}+07$ \\
\hline 5.00 & 14.14 & $1.44 E+06$ & 17.00 & $2.14 \mathrm{E}+05$ & 14.34 & $1.26 \mathrm{E}+06$ \\
\hline 6.00 & 18.21 & $9.55 \mathrm{E}+04$ & 20.36 & $2.27 E+04$ & 17.08 & $2.02 \mathrm{E}+05$ \\
\hline
\end{tabular}
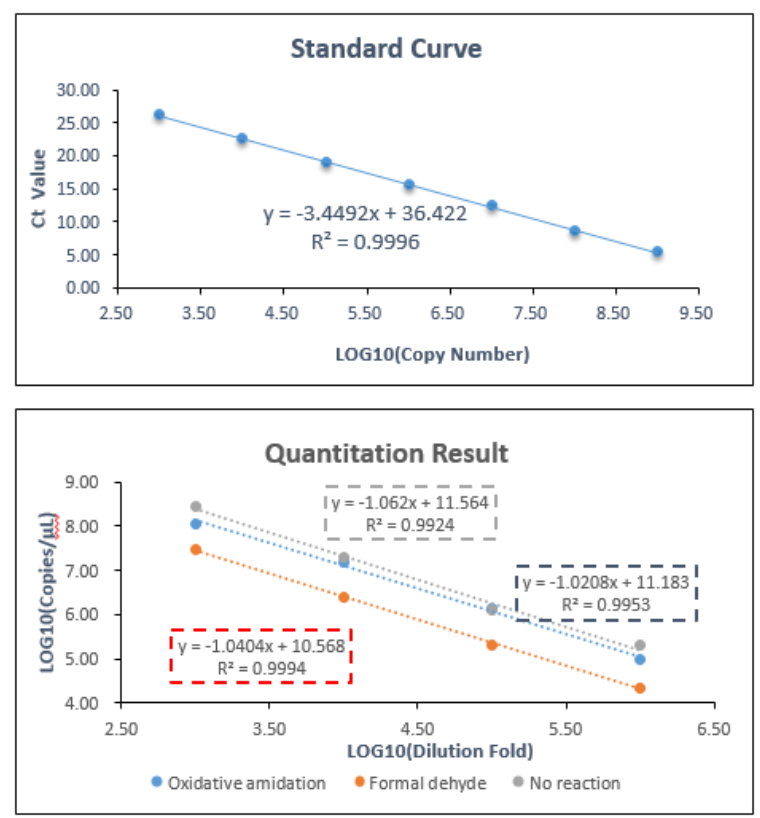

The results showed that no obvious concentration difference was observed between oxidative amidation and no reaction, but the concentration of formaldehyde at the same dilution ratio is significantly lower. The $\mathrm{R}^{2}$ value are all above 0.99 in these three groups. This indicates that the oxidative amidation reaction did not affect the detectability of DNA tags. 


\section{SI-4-2 Next-generation sequencing.}

1e7 copies of the three groups mentioned above were used as template for PCR amplification. To a PCR tube was added diluted sample $(2 \mu \mathrm{L}), 10 x$ high fidelity PCR buffer $(5 \mu \mathrm{L}), 50 \mathrm{mM} \mathrm{MgSO}_{4}(2 \mu \mathrm{L})$, 10 mM dNTP mix $(1 \mu \mathrm{L})$, Platinum ${ }^{\mathrm{TM}}$ Taq DNA Polymerase $(0.2 \mu \mathrm{L}), 10 \mu \mathrm{M}$ forward primer $(2 \mu \mathrm{L}), 10$ $\mu \mathrm{M}$ reverse primer $(2 \mu \mathrm{L})$, and nuclease-free water $(35.8 \mu \mathrm{L})$. After 20 cycles, the PCR products $(204 \mathrm{bp}$, forward primer brought in additional $20 \mathrm{bp}$ at $5^{\prime}$ terminal, reverse primer brought in additional 66 bp at 3' terminal) were purified by the Agencourt AMPure XP Beads method. The purified samples were quantified by Qubit 4.0 to appear at $1.2 \mathrm{ng} / \mu \mathrm{L}$. PCR products were diluted to $3 \mathrm{nM}$ and pooled together according to the ratio of PCR input copies, then provided for next-generation sequencing (Illumina HiSeq XTen). Bowtie 2 were used to mapping the sequenced reads to reference by local alignment. The detailed mapping identity were extracted from CIGAR string and XM flag in the SAM format. The results of NGS showed that all samples retained the right sequence as expected (Fig. S2), indicating that the chemical reactions did not affect the encodability of DNA tags.

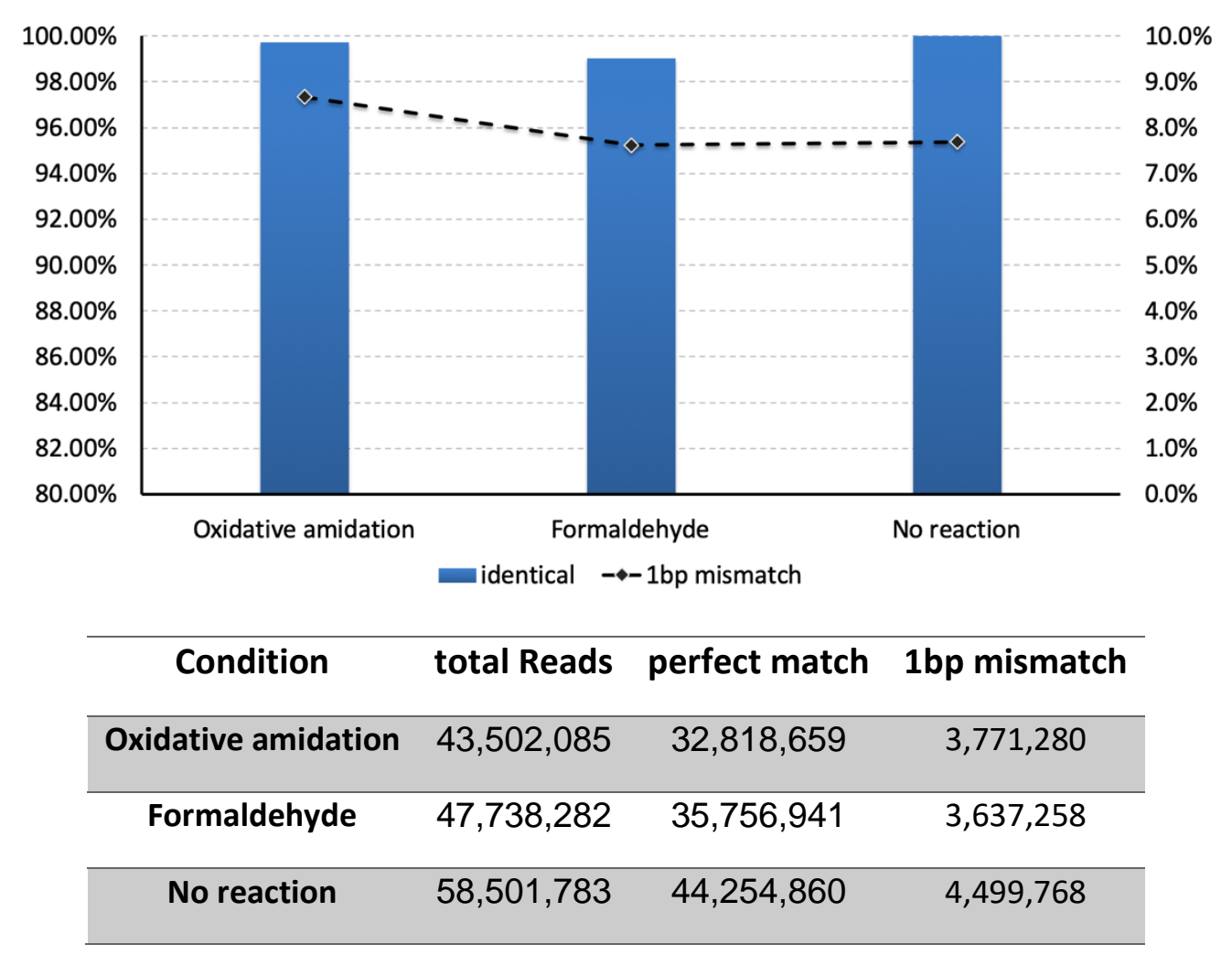


Figure S2. Statistics of next-generation sequencing results. The left Y-axis is the ratio of perfect match read count normalized by the negative control, while the right $\mathrm{Y}$-axis is the fraction of $1 \mathrm{bp}$ mismatch.

In conclusion, our data revealed that the oxidative amidation reaction used in this paper caused no damage to DNA, and thus could be used for the encoded library construction. 


\section{SI-5 Selected examples of the active molecule}
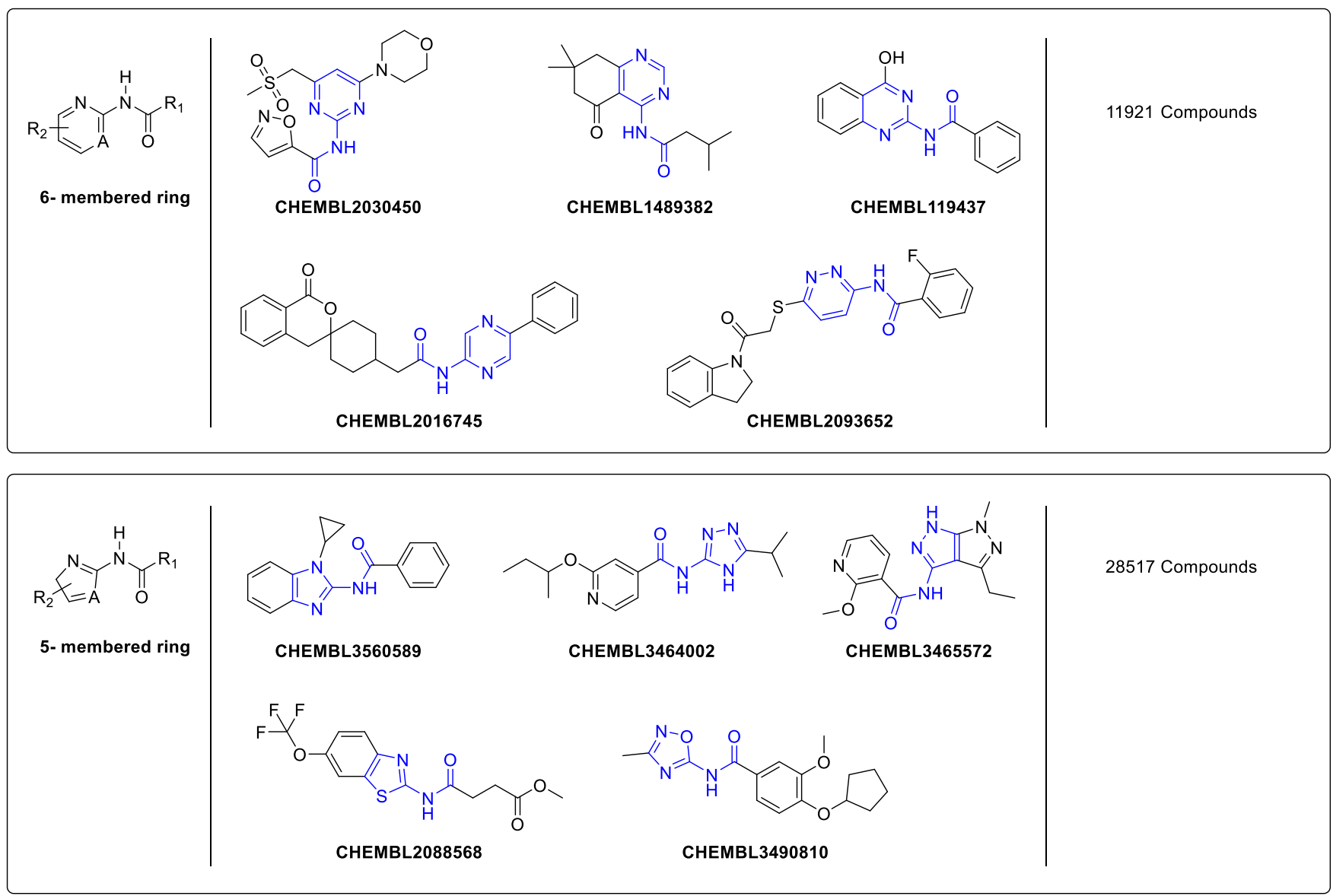

Figure S3. Selected examples of building blocks used in the Cu-catalyzed oxidative amidation reactions.

To investigate the molecules that could potentially be synthesized with the oxidative amidation reaction, the library of CHEMBL_25.sdf was searched through. 11921 (0.64\% of the total) pyridin-2-yl analogous amides and 28517 (1.52\% of the total) pyrrol-2-yl analogous amides were found, among which 283 molecules were counted in both of the categories. The total coverage of molecules that could be synthesized with the newly developed method is $2.15 \%$. (CHEMBL database (CHEMBL 25) accessed on 2020. Feb. 26th under https://www.ebi.ac.uk/chembl/) 


\section{SI-6 LC Trace and Mass}

\section{SI-6-1 LC Trace and Mass of 3a}

\section{Following General Procedure 3}

Yield: $92.31 \%$

Exact mass: 5438.56

Triply charged mass [M-3]/3, calculated: 1811.9; observed: 1812.1.
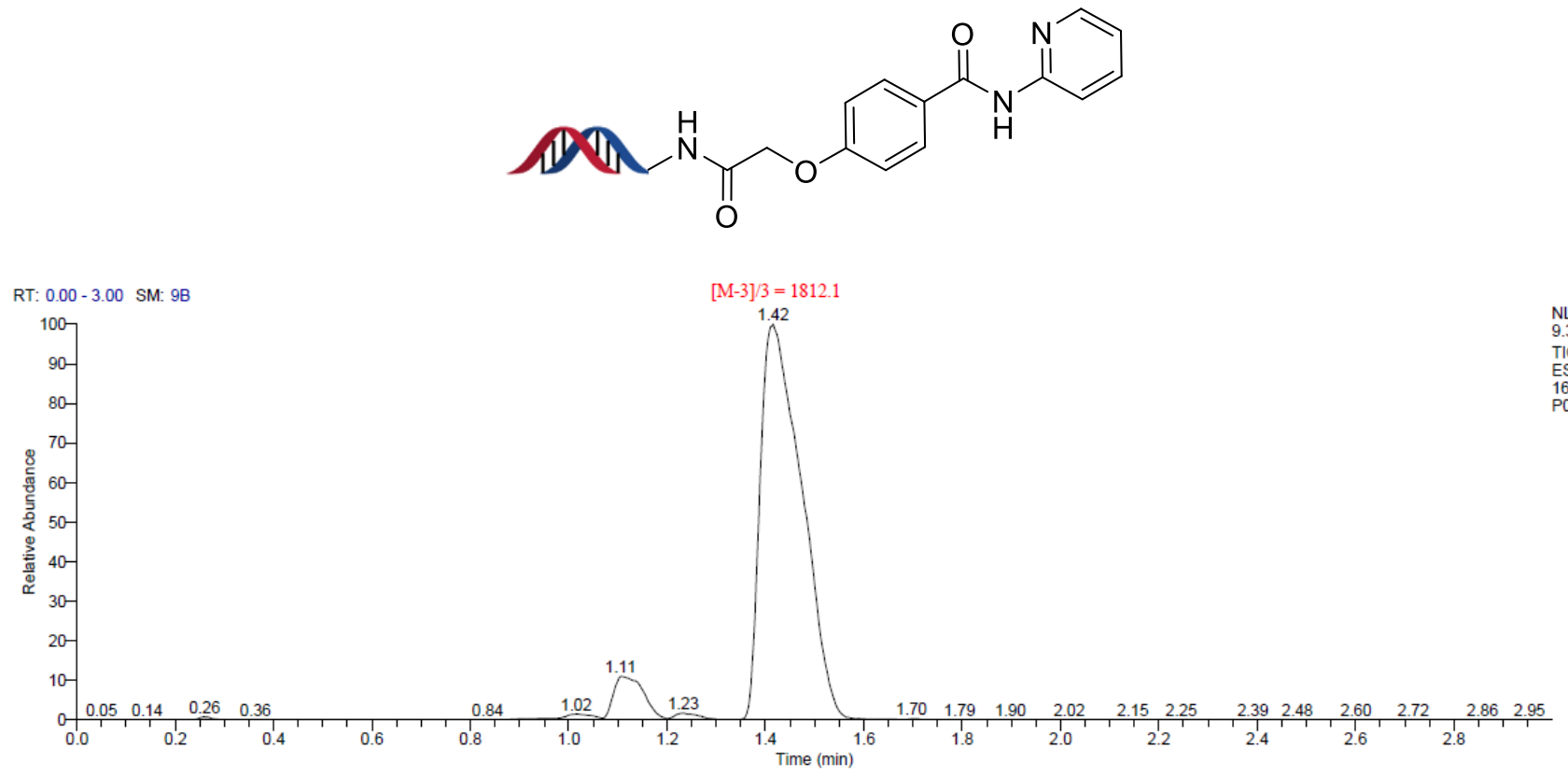

\begin{tabular}{|c|c|c|c|c|}
\hline RT & Peak Height & Peak Width & Peak Area & Area \% \\
\hline 1.11 & 10532.76 & 0.05 & 22617.59 & 3.85 \\
\hline 1.13 & 9454.39 & 0.08 & 19430.23 & 3.30 \\
\hline 1.22 & 1549.48 & 0.03 & 1600.16 & 0.27 \\
\hline 1.24 & 1387.02 & 0.02 & 1543.74 & 0.26 \\
\hline 1.42 & 95603.18 & 0.25 & 542717.33 & 92.31 \\
\hline
\end{tabular}

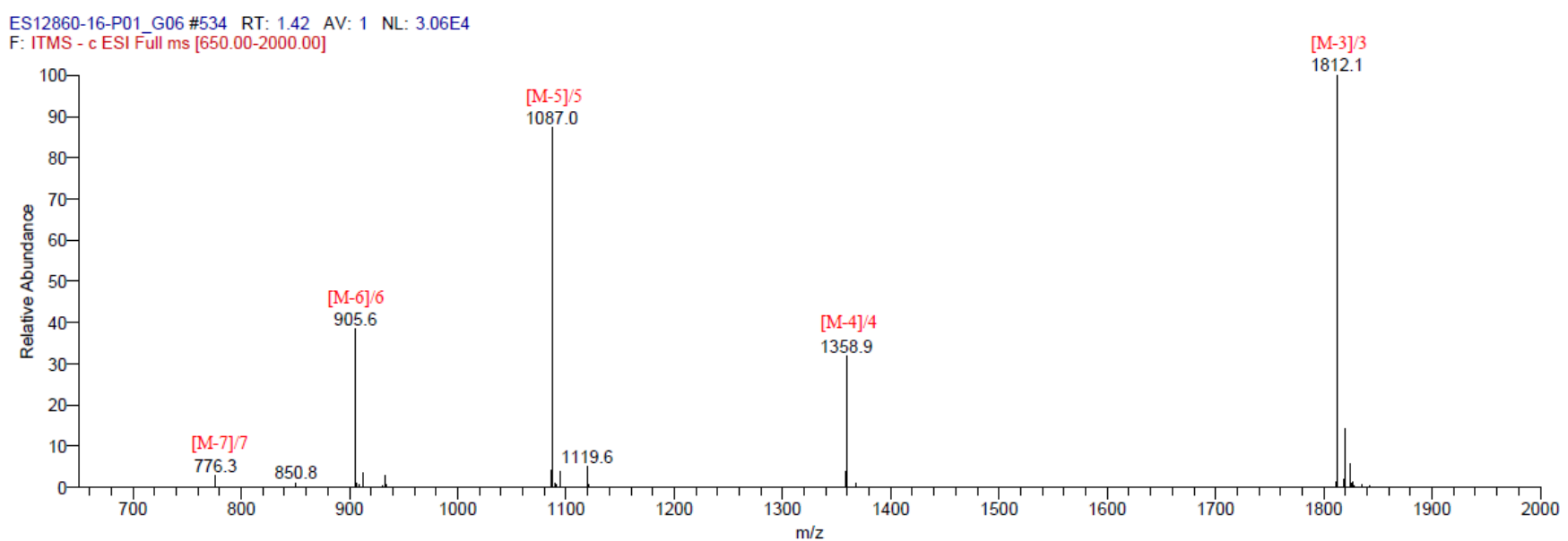

Figure S4. LC trace and mass of $\mathbf{3 a}$ 


\section{SI-6-2 LC Trace and Mass of 3b}

Yield: $>99 \%$

Exact mass: 5623.77

Triply charged mass [M-3]/3, calculated: 1873.6; observed: 1873.4 .<smiles>COc1ccc(CC(=O)NC2C3CCC2C3C)cc1Oc1cc(Br)ccc1C(=O)Nc1ccccn1</smiles>
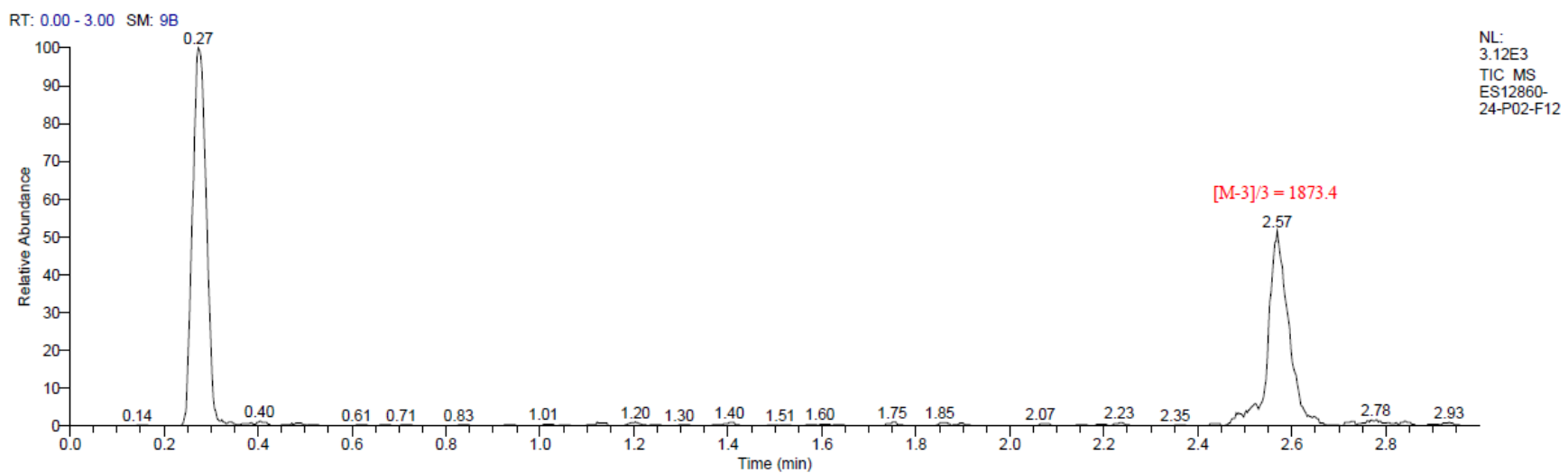

\begin{tabular}{|c|c|c|c|c|}
\hline RT & Peak Height & Peak Width & Peak Area & Area \% \\
\hline 2.56 & 1704.14 & 0.06 & 3089.89 & 100.00 \\
\hline
\end{tabular}

ES12860-24-P02-F12 \#966 RT: 2.56 AV: 1 NL: 9.17E2

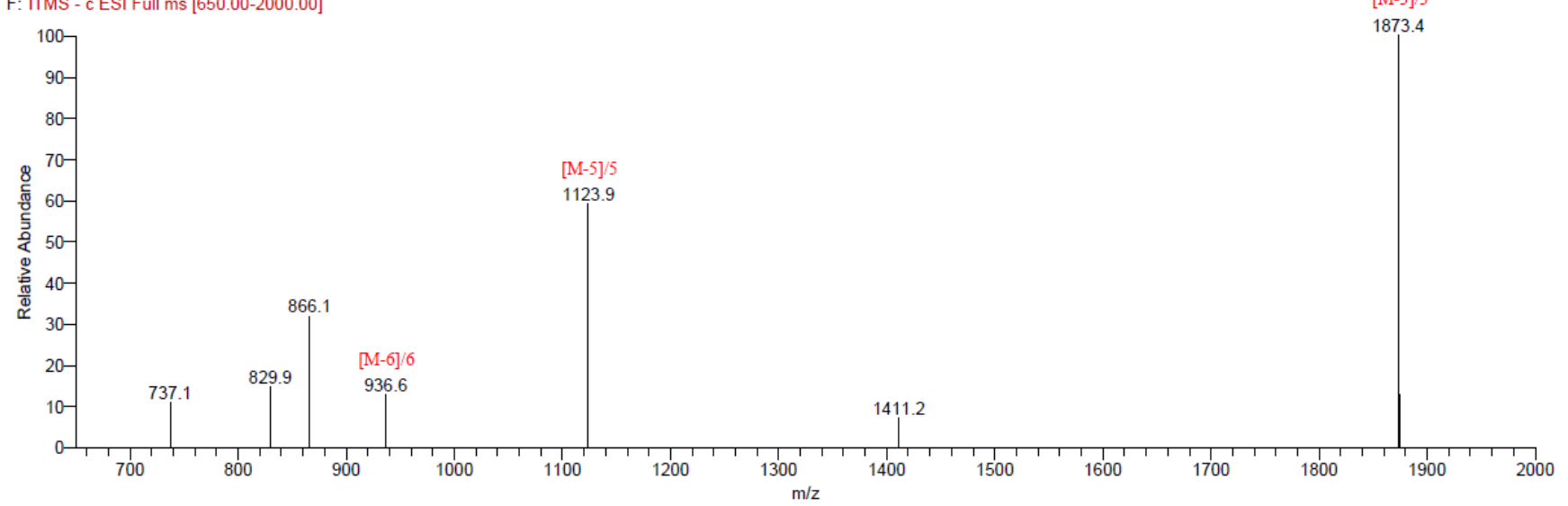

Figure S5. LC trace and mass of $\mathbf{3 b}$ 


\section{SI-6-3 LC Trace and Mass of 3c}

Yield: $77.13 \%$

Exact mass: 5675.77

Triply charged mass [M-3]/3, calculated: 1890.9; observed: 1891.2.<smiles>O=C(CCc1ccc(Oc2c(C(=O)Nc3ccccn3)cccc2C(F)(F)F)c(Br)c1)NC1CC2CCC1C2</smiles>
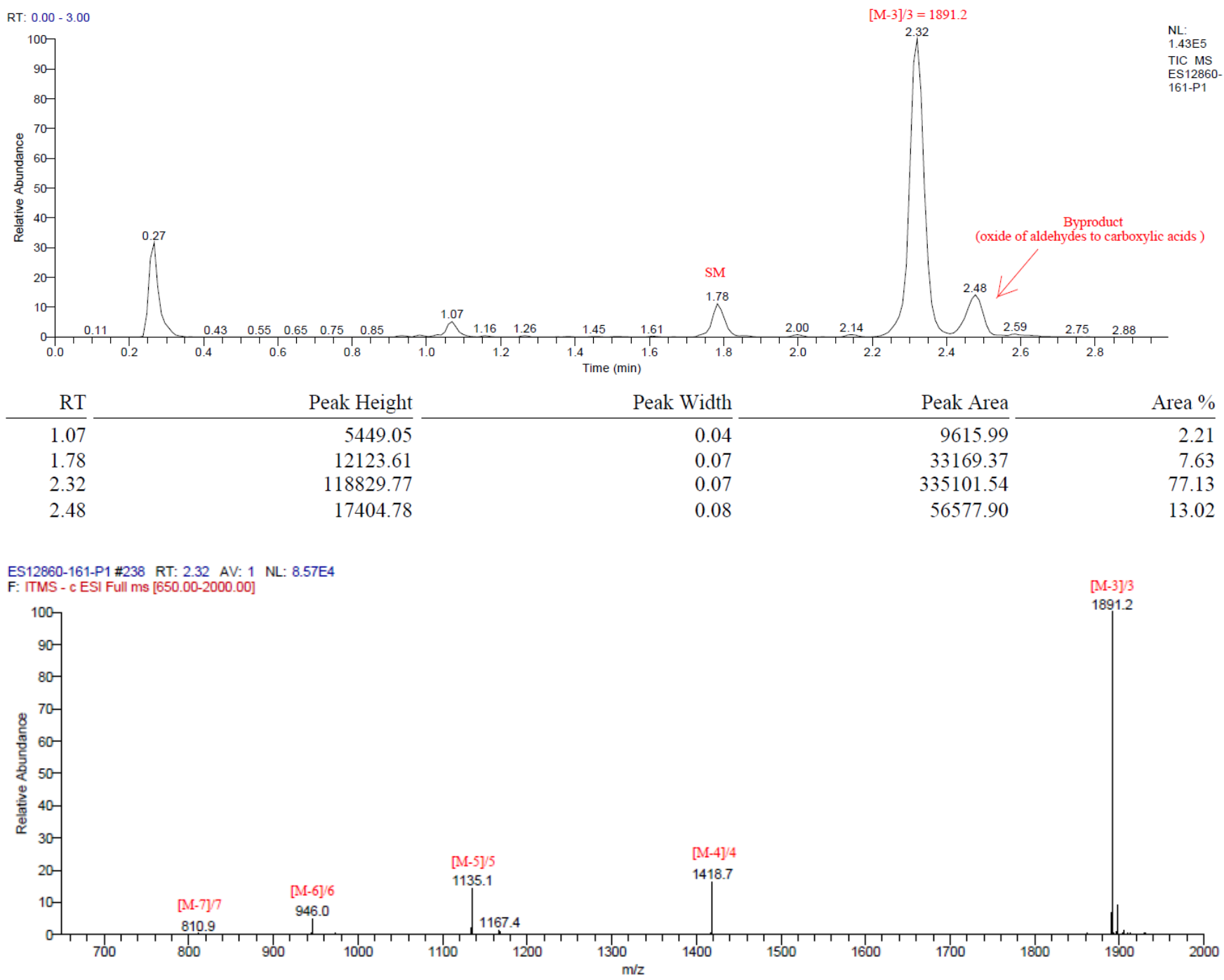

Figure S6. LC trace and mass of $\mathbf{3 c}$ 


\section{SI-6-4 LC Trace and Mass of 3d}

Following General Procedure 3

Yield: $69.87 \%$

Exact mass: 5597.71

Triply charged mass [M-3]/3, calculated: 1864.9; observed: 1865.2.<smiles>O=C(NCc1ccccc1)c1ccc(Br)c(Oc2ccc(F)cc2C(=O)Nc2ccccn2)c1</smiles>

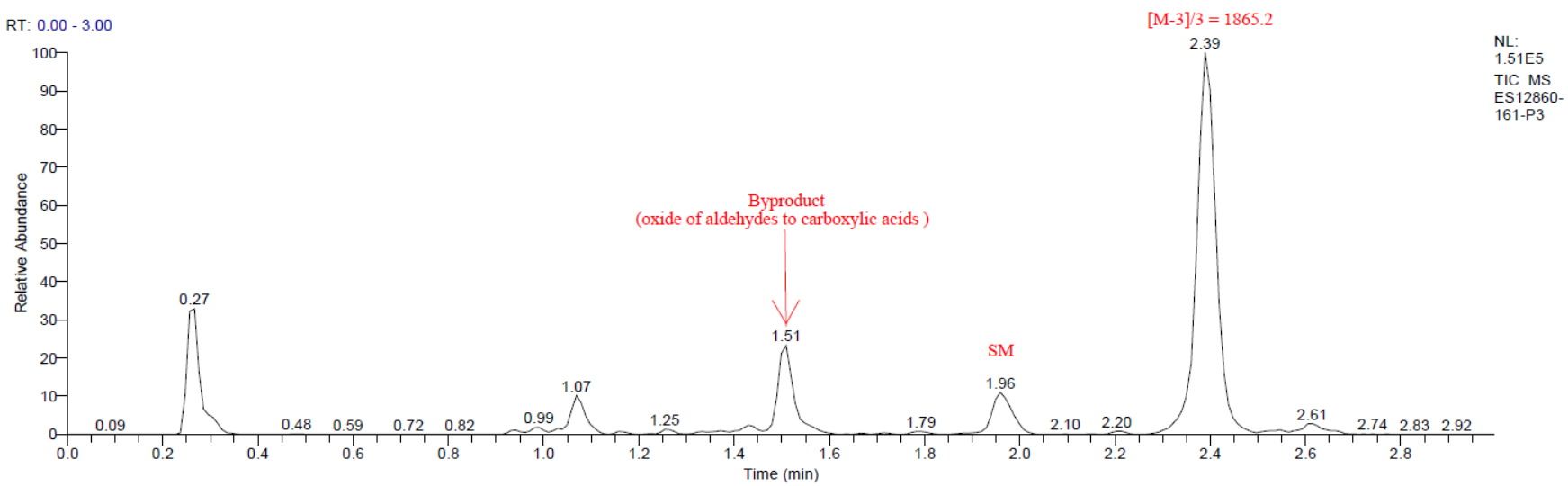

\begin{tabular}{|c|c|c|c|c|}
\hline $\mathrm{RT}$ & Peak Height & Peak Width & Peak Area & Area $\%$ \\
\hline 1.07 & 11266.70 & 0.07 & 30809.80 & 5.99 \\
\hline 1.43 & 2867.77 & 0.02 & 3209.72 & 0.62 \\
\hline 1.51 & 27035.24 & 0.06 & 67443.01 & 13.11 \\
\hline 1.96 & 13789.12 & 0.07 & 41047.37 & 7.98 \\
\hline 2.39 & 124240.47 & 0.07 & 359501.08 & 69.87 \\
\hline 2.61 & 3490.03 & 0.09 & 12486.26 & 2.43 \\
\hline
\end{tabular}

ES12860-161-P3 \#245 RT: 2.39 AV: 1 NL: $9.62 E 4$

F: ITMS - c ESI Full ms [650.00-2000.00]

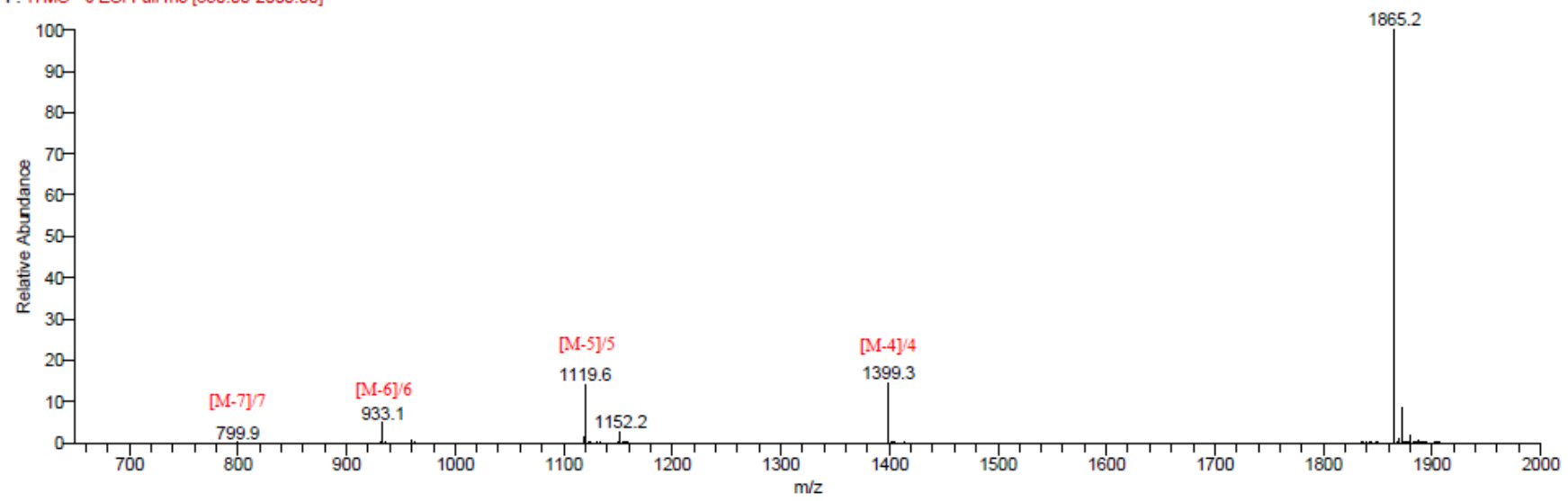

Figure S7. LC trace and mass of 3d 


\section{SI-6-5 LC Trace and Mass of 3e}

\section{Following General Procedure 3}

Yield: $99.12 \%$

Exact mass: 5593.8

Triply charged mass [M-3]/3, calculated: 1863.6; observed: 1863.8 .<smiles>Cc1cc(Br)cc(C(=O)Nc2ccccn2)c1Oc1ccc(C(=O)NC2C3C=C[C@H]2C3C)cc1</smiles>

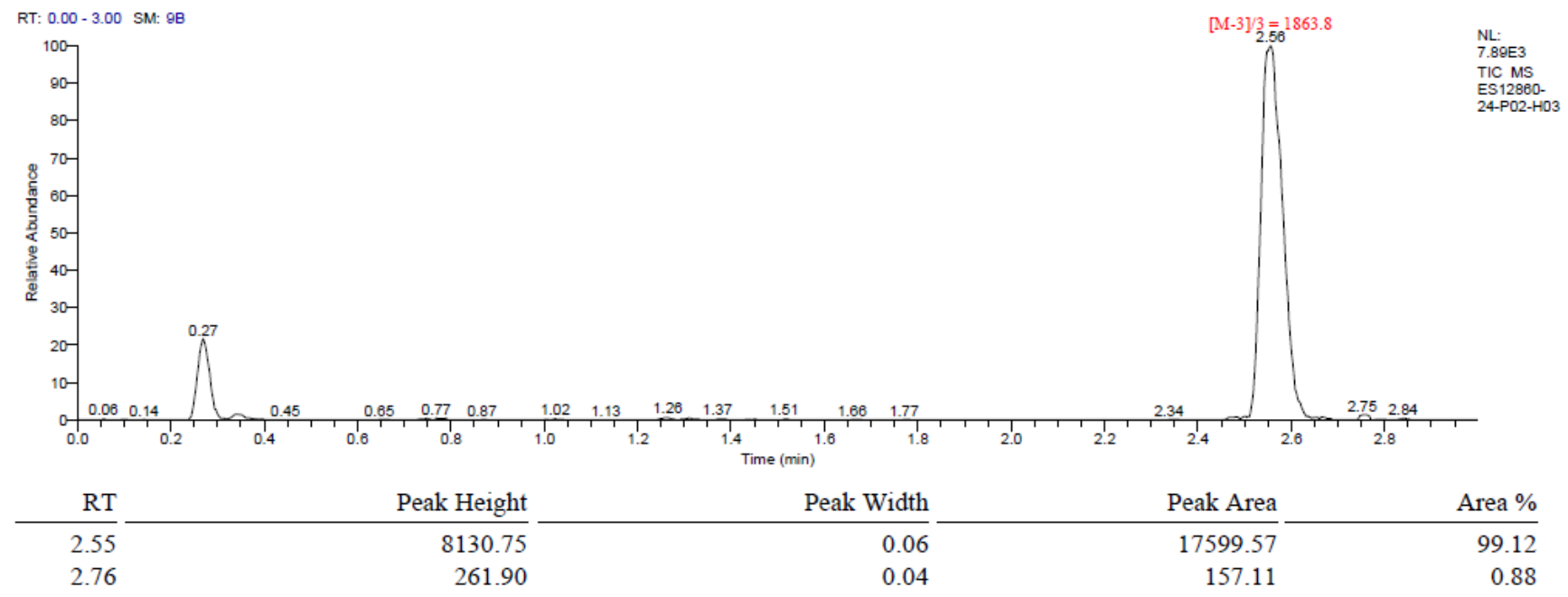

ES12860-24-P02-H03 \#962 RT: 2.55 AV: 1 NL: $3.12 E 3$

F: ITMS - c ESI Full ms [650.00-2000.00]

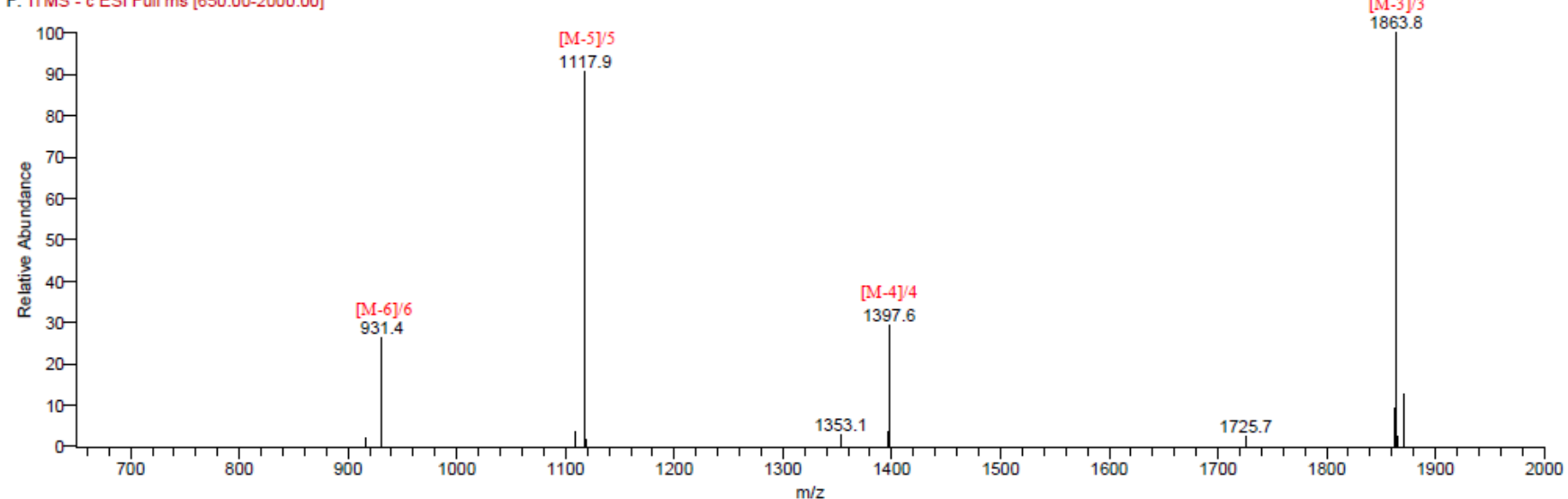

Figure S8. LC trace and mass of $\mathbf{3 e}$ 


\section{SI-6-6 LC Trace and Mass of 3f}

\section{Following General Procedure 3}

Yield: $88.75 \%$

Exact mass: 5579.72

Triply charged mass [M-3]/3, calculated: 1858.9; observed: 1858.5.<smiles>O=C(NC[C@@H]1C[C@@H]2C=C[C@@H]21)c1cccc(Oc2ccc(C(=O)Nc3ccccn3)c(Br)c2)c1</smiles>

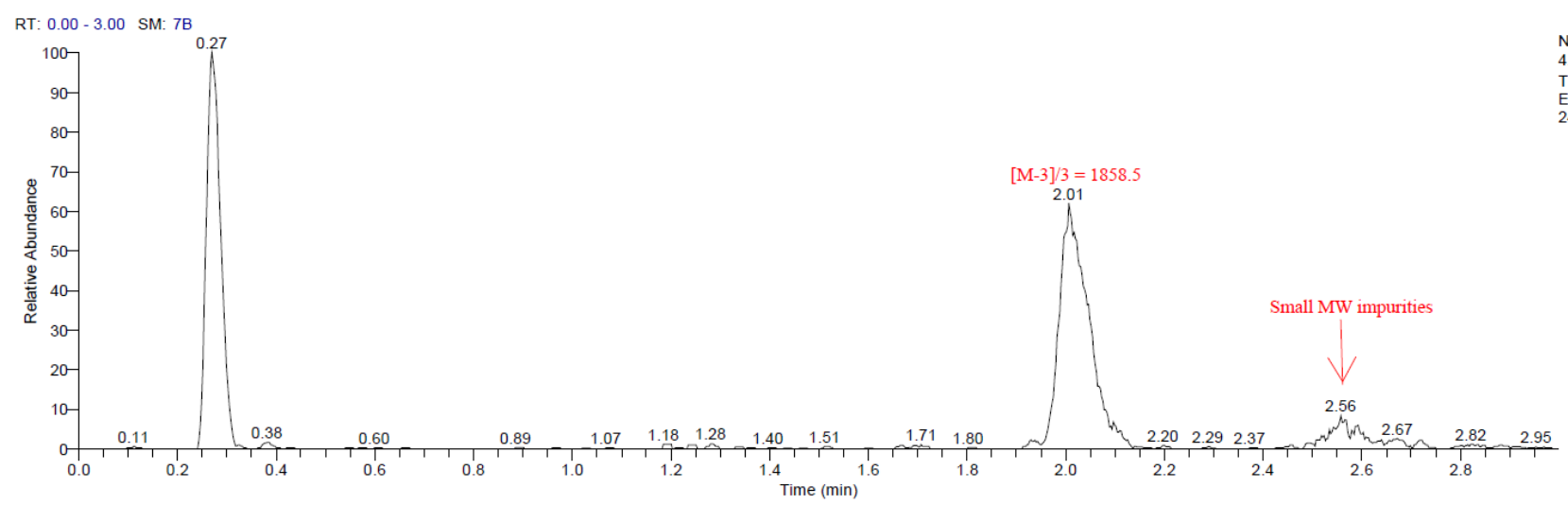

\begin{tabular}{|c|c|c|c|c|}
\hline RT & Peak Height & Peak Width & Peak Area & Area \% \\
\hline 2.00 & 2431.68 & 0.23 & 10241.32 & 88.75 \\
\hline 2.54 & 225.76 & 0.03 & 298.98 & 2.59 \\
\hline 2.56 & 365.75 & 0.02 & 356.11 & 3.09 \\
\hline 2.59 & 247.01 & 0.05 & 412.33 & 3.57 \\
\hline 2.68 & 110.12 & 0.05 & 231.04 & 2.00 \\
\hline
\end{tabular}

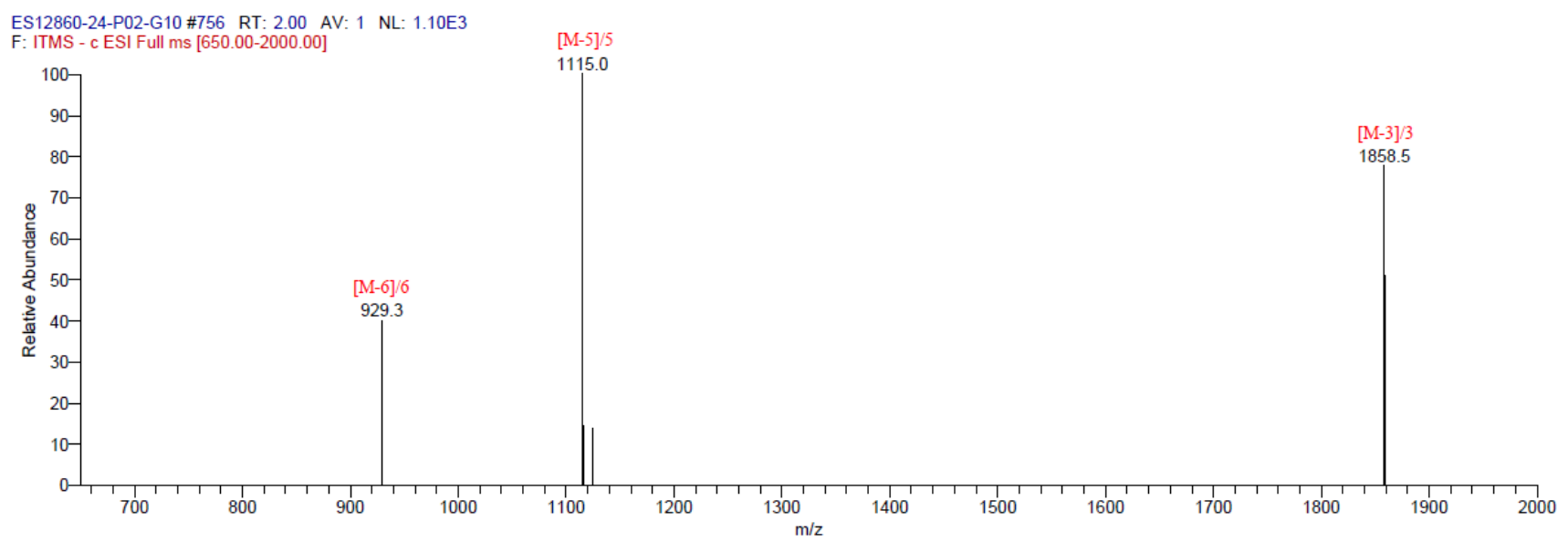

Figure S9. LC trace and mass of $\mathbf{3 f}$ 


\section{SI-6-7 LC Trace and Mass of 3g}

\section{Following General Procedure 3}

Yield: $80.94 \%$

Exact mass: 5514.85

Triply charged mass [M-3]/3, calculated: 1837.3; observed: 1837.4.

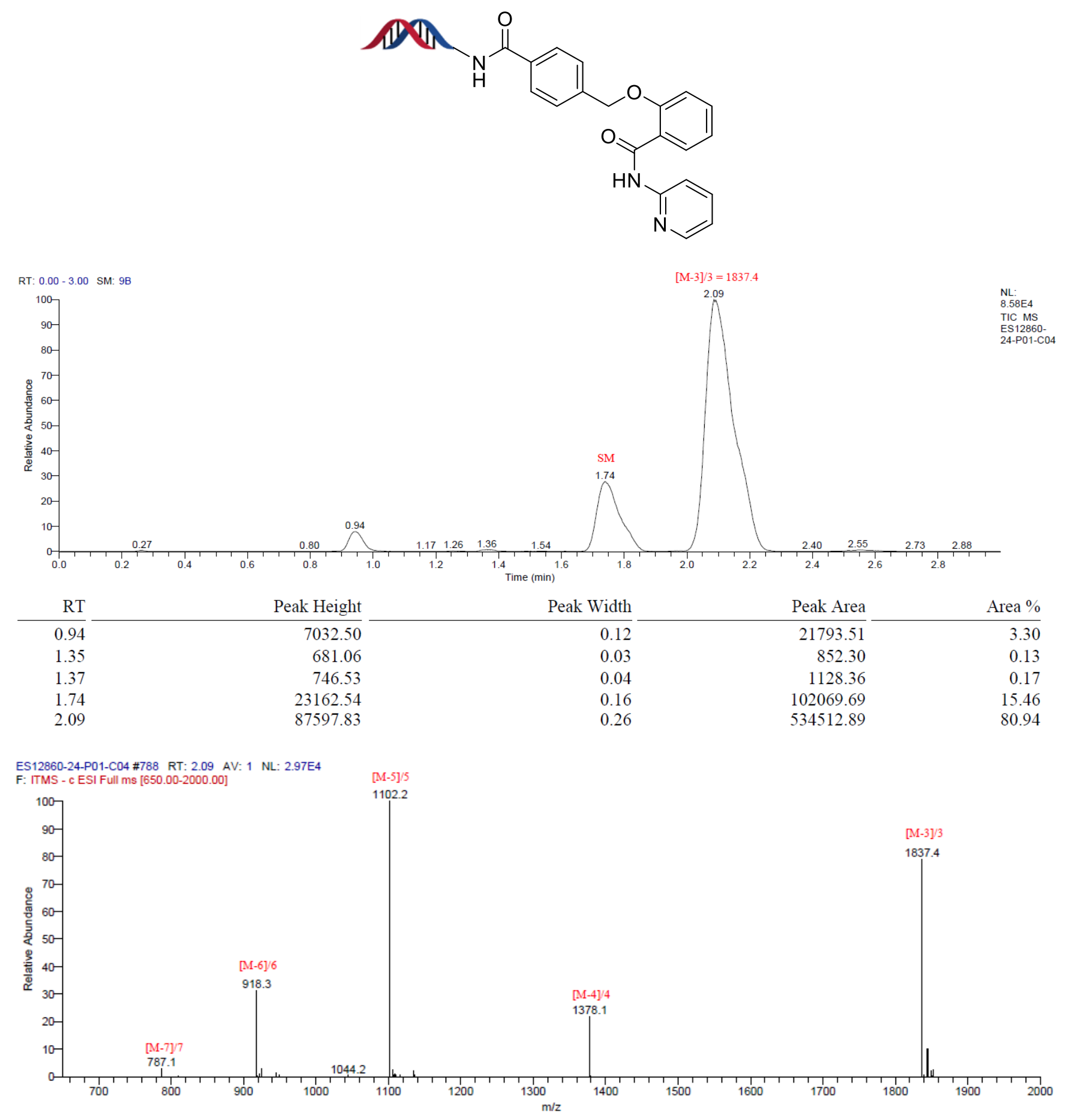

Figure S10. LC trace and mass of $\mathbf{3 g}$ 


\section{SI-6-8 LC Trace and Mass of $3 \mathrm{~h}$}

\section{Following General Procedure 3}

Yield: $66.01 \%$

Exact mass: 5496.83

Triply charged mass [M-3]/3, calculated: 1831.3; observed: 1831.2.<smiles>COc1cc(OCC(=O)NCC2C3CCC2C3C)ccc1C(=O)Nc1ccccn1</smiles>
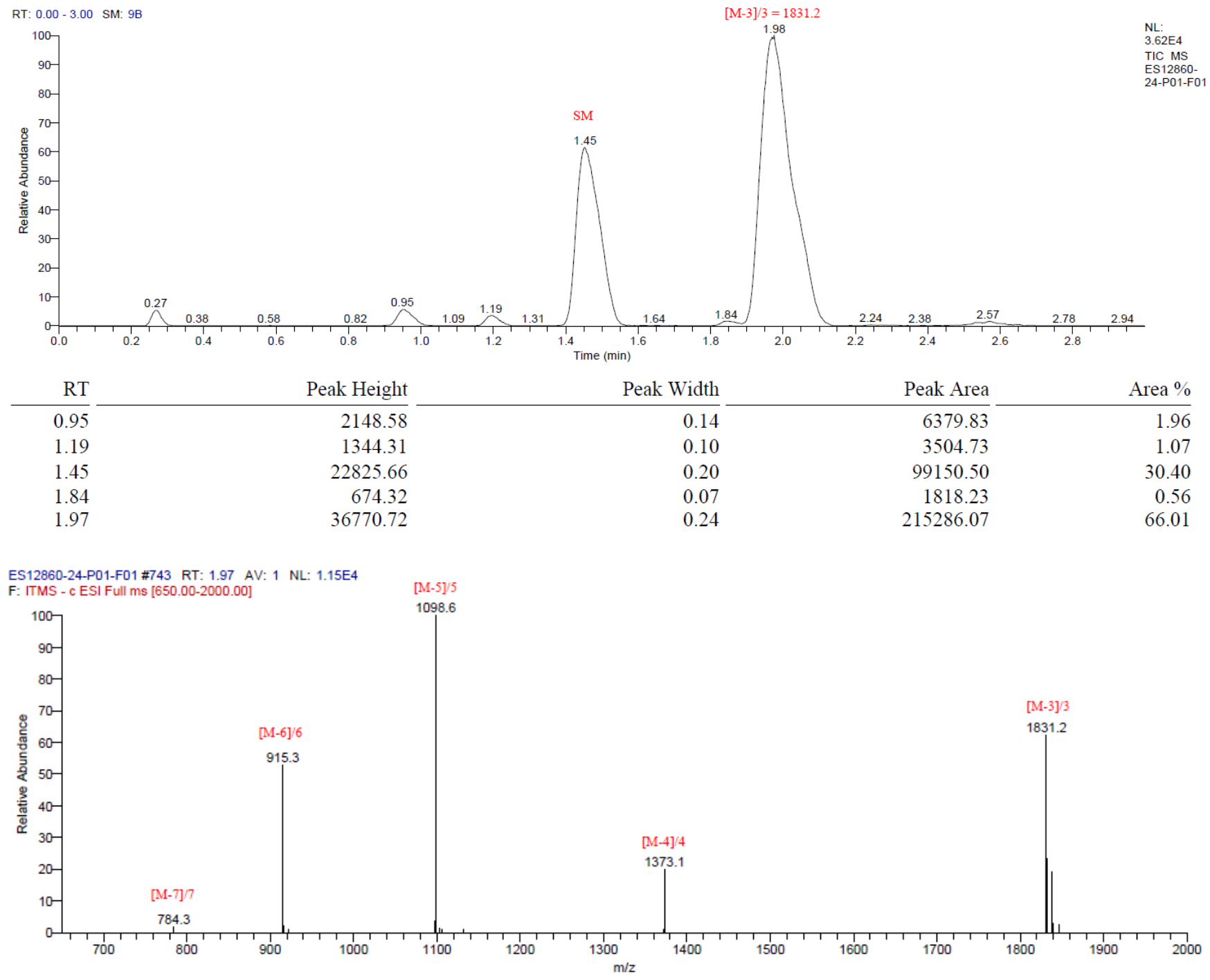

Figure S11. LC trace and mass of $\mathbf{3 h}$ 


\section{SI-6-9 LC Trace and Mass of 3i}

Following General Procedure 3

Yield: $74.54 \%$

Exact mass: 5438.75

Triply charged mass [M-3]/3, calculated: 1811.9; observed: 1812.2.
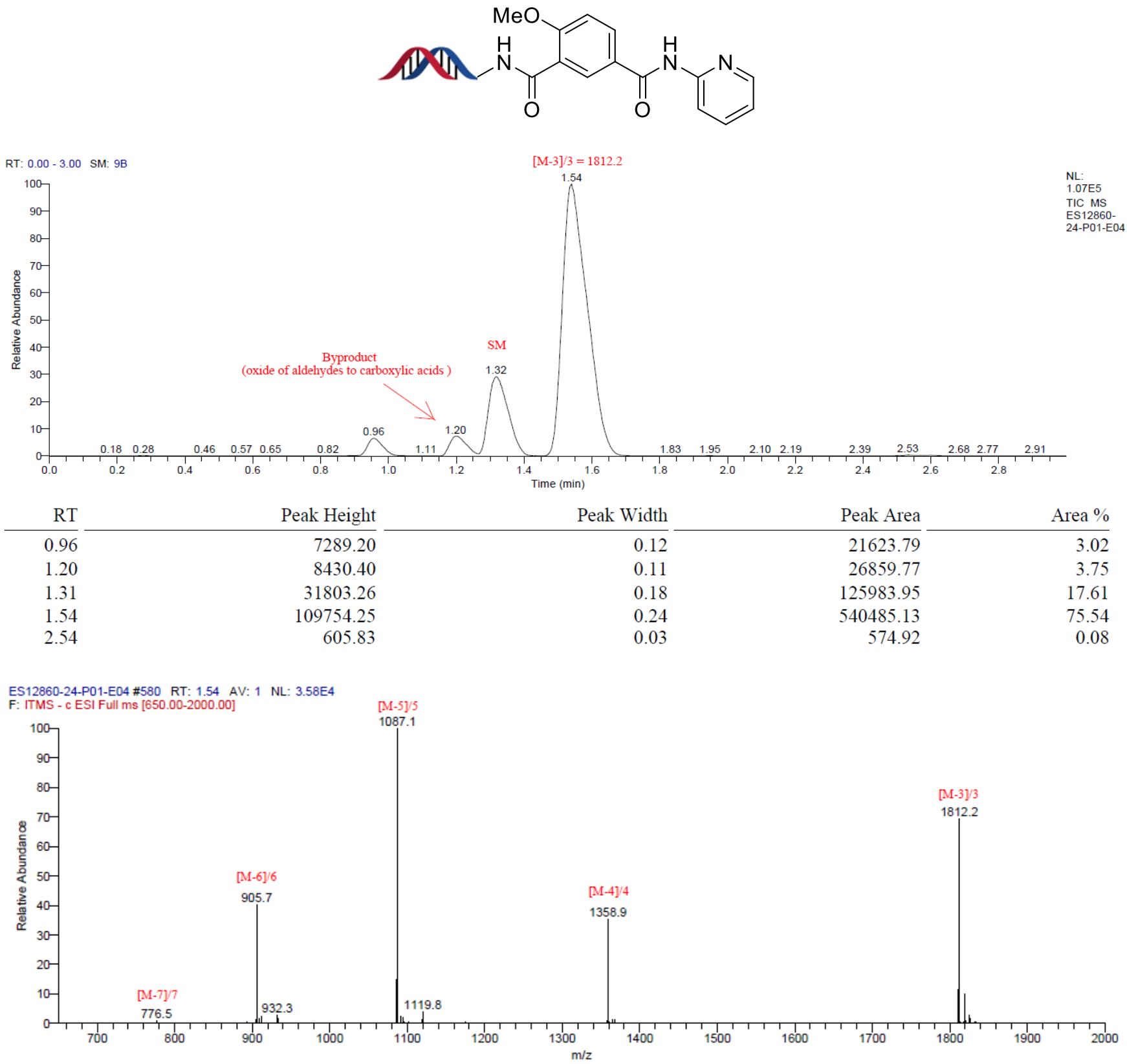

Figure S12. LC trace and mass of $\mathbf{3 i}$ 


\section{SI-6-10 LC Trace and Mass of 3j}

Following General Procedure 3

Yield: $79.33 \%$

Exact mass: 5408.72

Triply charged mass [M-3]/3, calculated: 1801.9; observed: 1802.1.<smiles>CC1C2CCC1C2NC(=O)c1cccc(C(=O)Nc2ccccn2)c1</smiles>

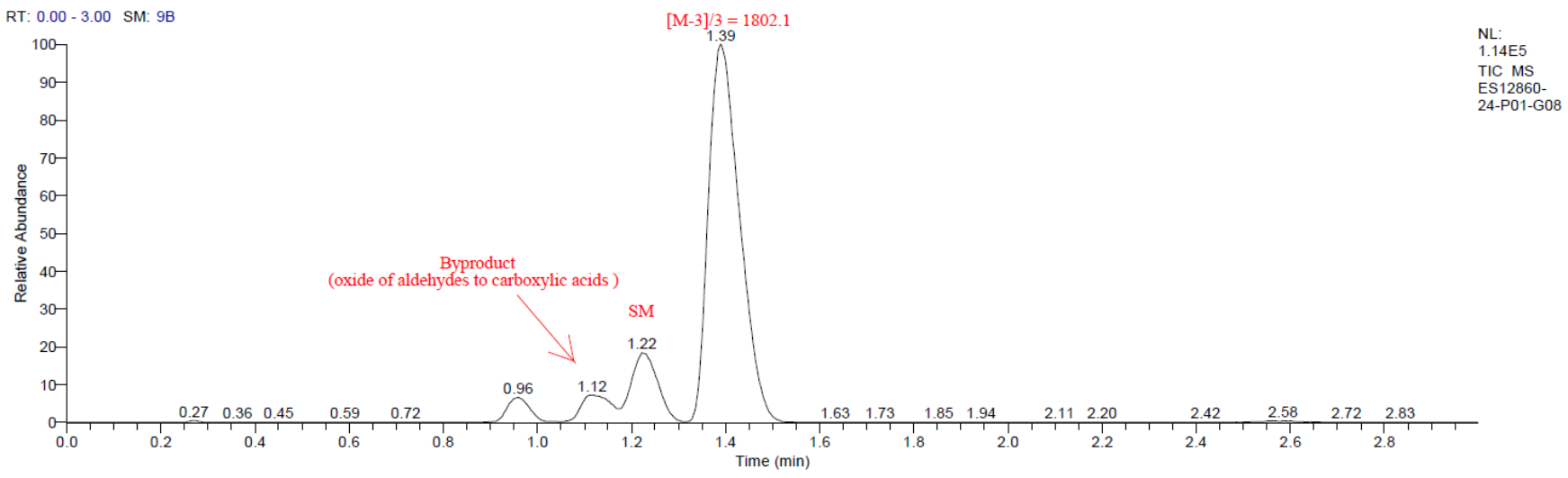

\begin{tabular}{|c|c|c|c|c|}
\hline RT & Peak Height & Peak Width & Peak Area & Area \% \\
\hline 0.96 & 7887.26 & 0.09 & 15781.26 & 2.38 \\
\hline 1.11 & 8647.07 & 0.09 & 21916.69 & 3.30 \\
\hline 1.14 & 7914.56 & 0.05 & 16100.88 & 2.43 \\
\hline 1.23 & 21720.58 & 0.14 & 83325.71 & 12.56 \\
\hline 1.39 & 117877.47 & 0.23 & 526263.18 & 79.33 \\
\hline
\end{tabular}

ES12860-24-P01-G08 \#526 RT: 1.39 AV: 1 NL: 4.51E4

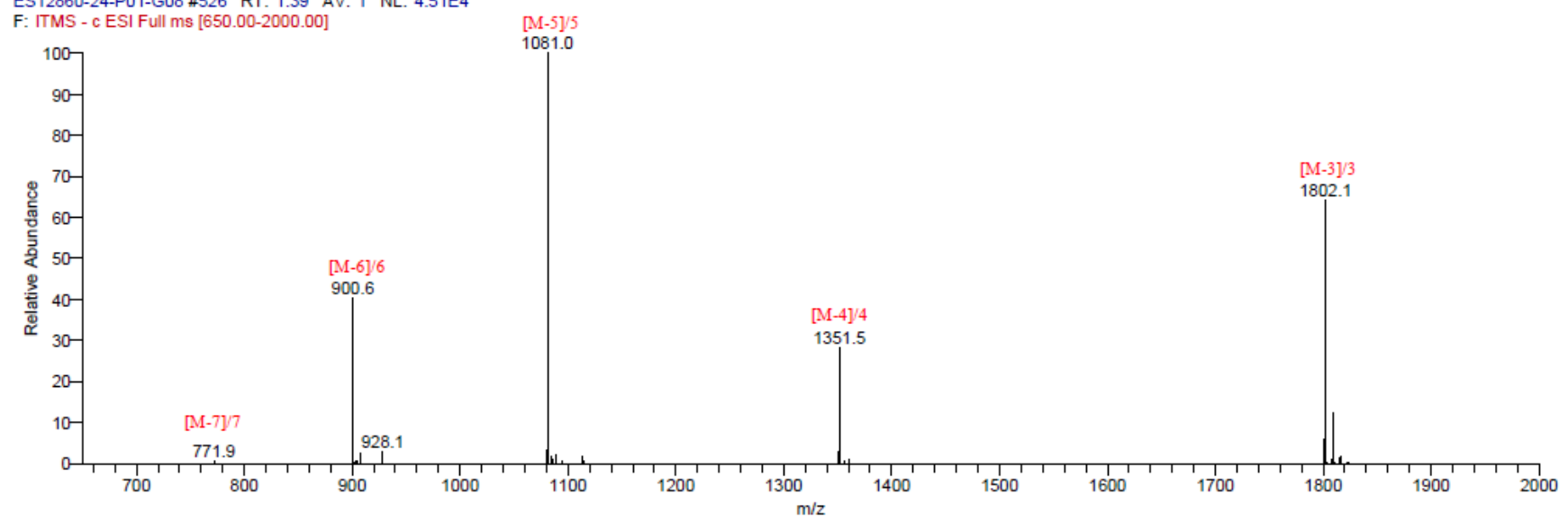

Figure S13. LC trace and mass of $\mathbf{3 j}$ 


\section{SI-6-11 LC Trace and Mass of 3k}

\section{Following General Procedure 3}

Yield: $74.7 \%$

Exact mass: 5422.75

Triply charged mass [M-3]/3, calculated: 1806.6; observed: 1806.9.
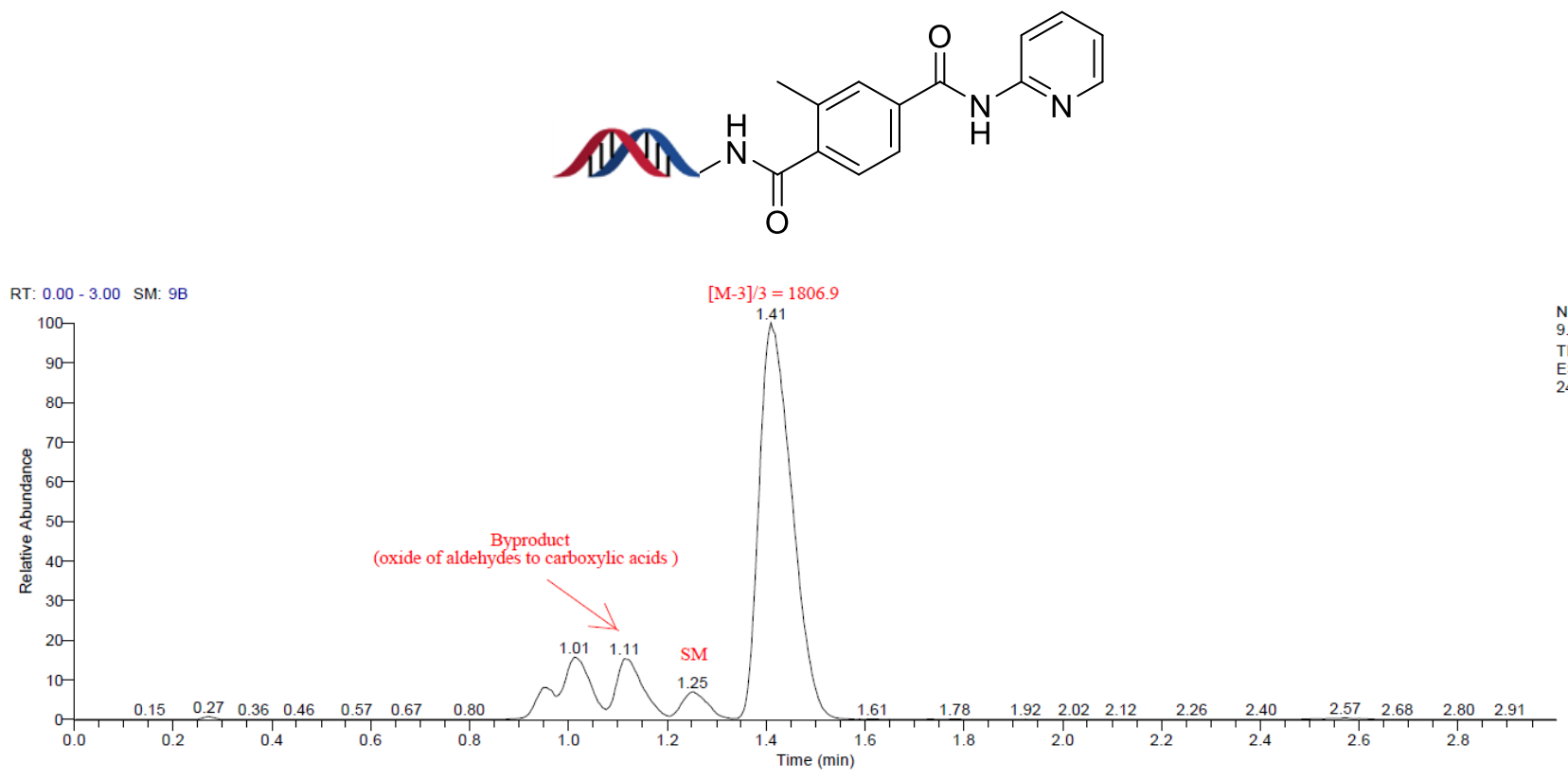

\begin{tabular}{|c|c|c|c|c|}
\hline RT & Peak Height & Peak Width & Peak Area & Area \% \\
\hline 0.96 & 8508.54 & 0.09 & 22352.75 & 3.72 \\
\hline 1.01 & 16147.25 & 0.10 & 55164.62 & 9.19 \\
\hline 1.11 & 15442.75 & 0.12 & 56342.17 & 9.39 \\
\hline 1.26 & 7186.23 & 0.06 & 17965.96 & 2.99 \\
\hline 1.41 & 99061.92 & 0.23 & 448276.14 & 74.70 \\
\hline
\end{tabular}

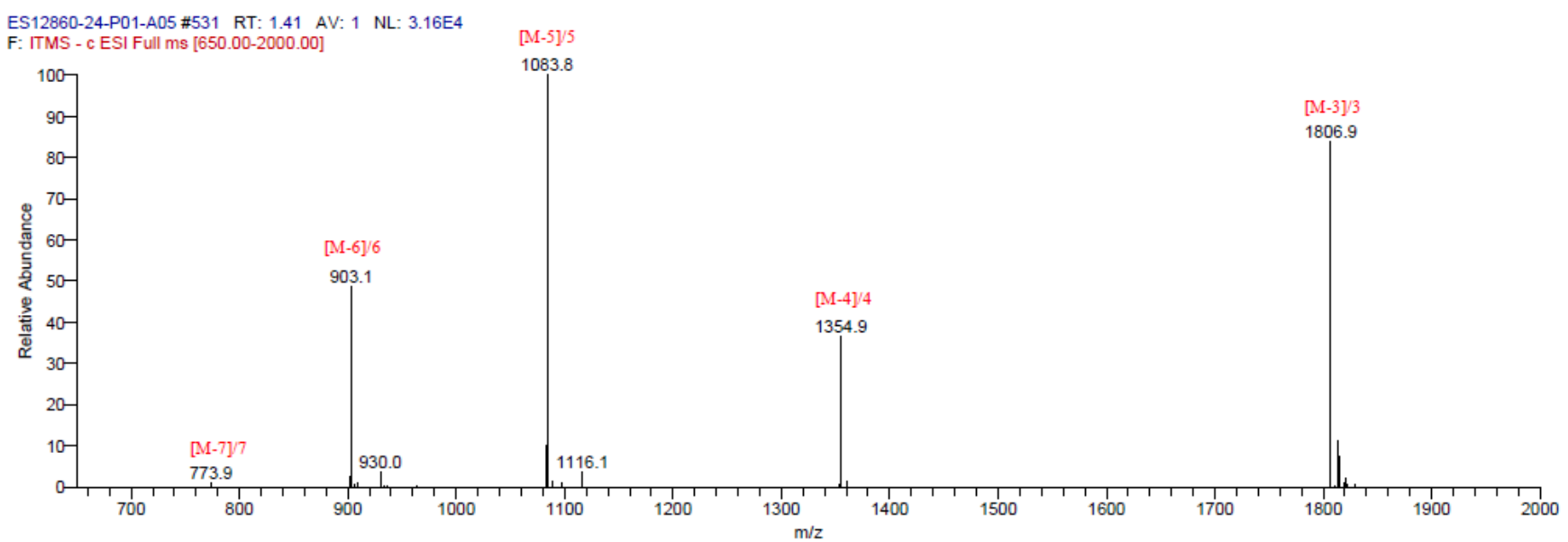

Figure S14. LC trace and mass of $\mathbf{3 k}$ 


\section{SI-6-12 LC Trace and Mass of 31}

Following General Procedure 3

Yield: $48.70 \%$

Exact mass: 5498.85

Triply charged mass [M-3]/3, calculated: 1832.0; observed: 1832.2.<smiles>O=C(Cc1cc(C(=O)Nc2ccccn2)ccc1-c1ccccc1)NC[C@@H]1CC[C@@H]2CC[C@@H]21</smiles>
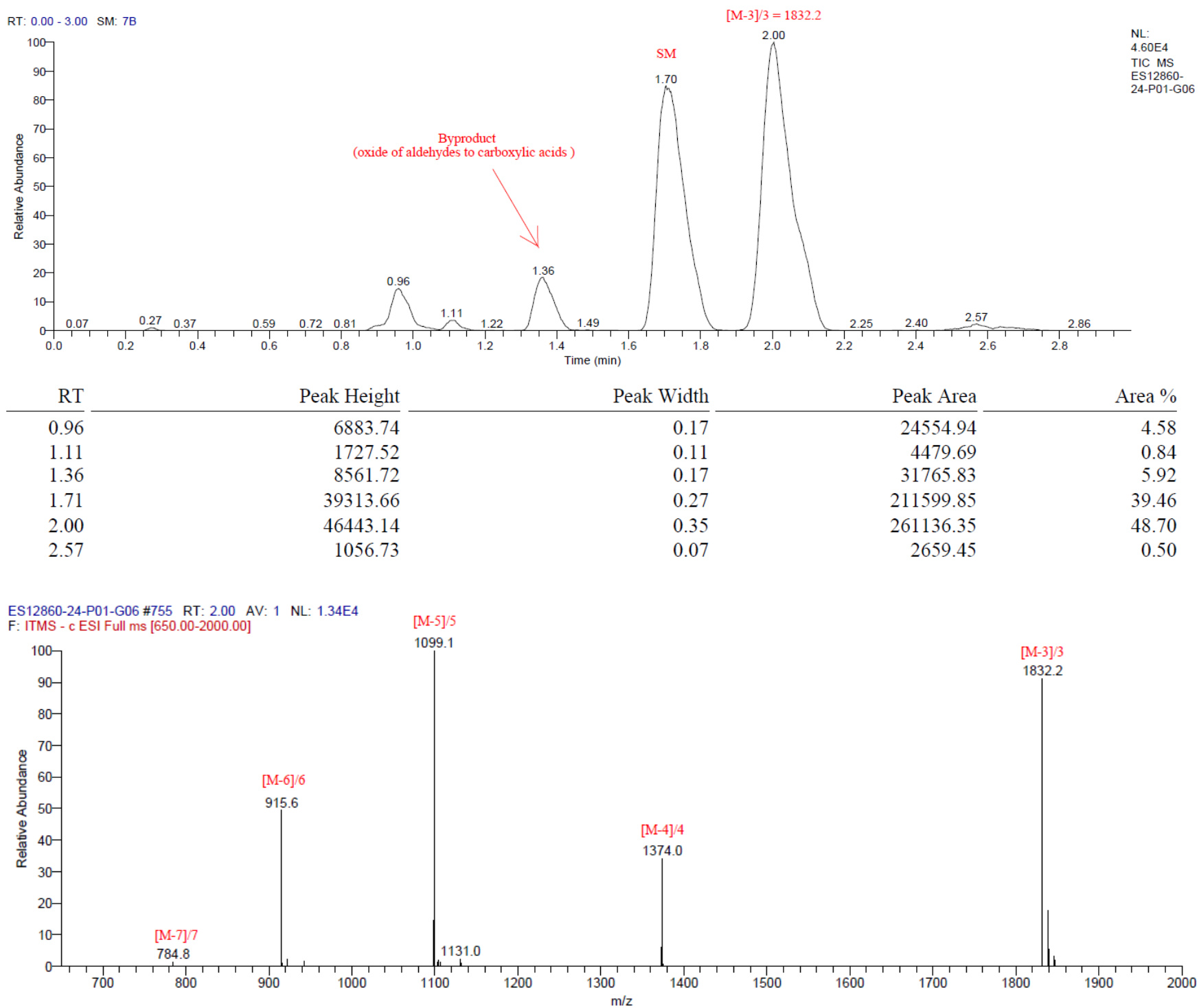

Figure S15. LC trace and mass of $\mathbf{3 1}$ 


\section{SI-6-13 LC Trace and Mass of 3m}

Following General Procedure 3

Yield: $51.06 \%$

Exact mass: 5485.81

Triply charged mass [M-3]/3, calculated: 1827.6; observed: 1827.4.
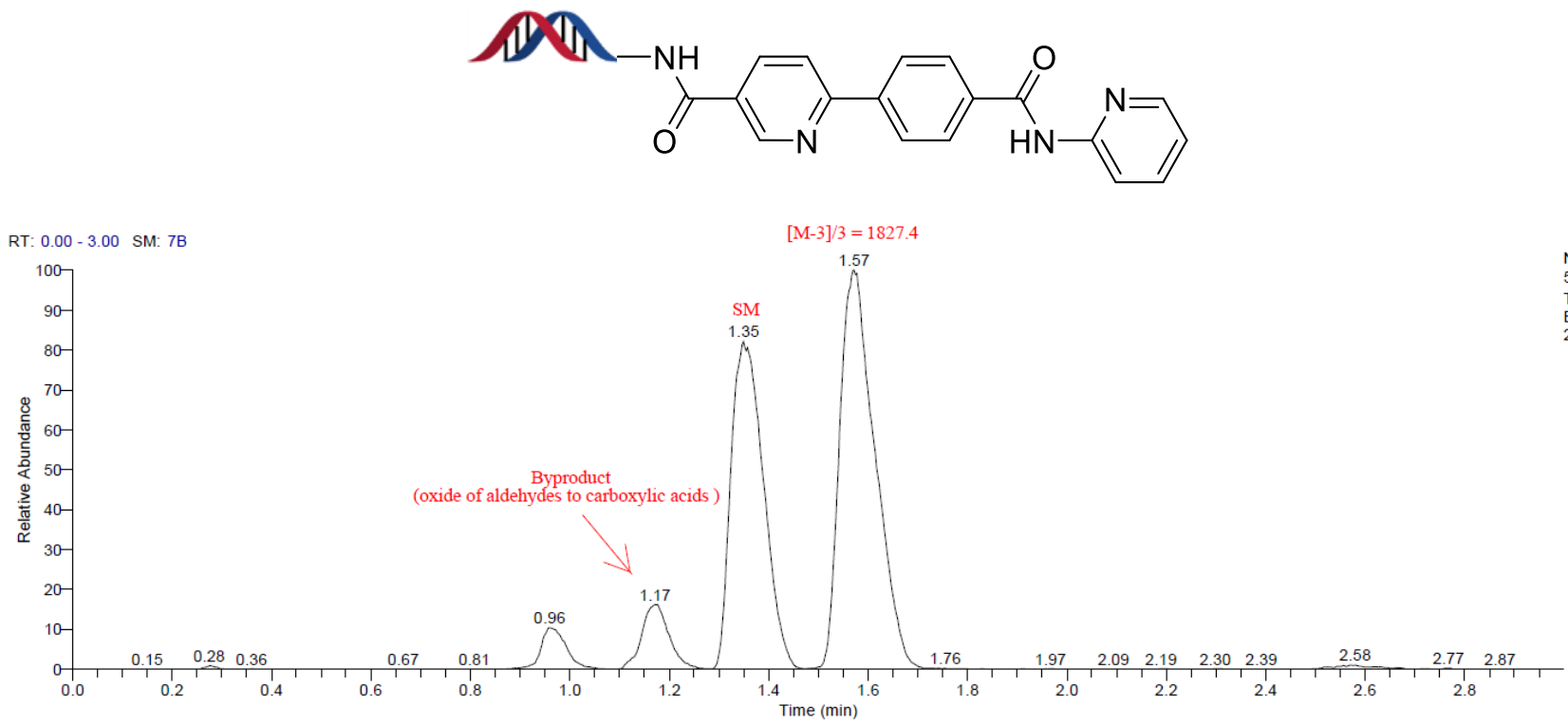

\begin{tabular}{|c|c|c|c|c|}
\hline RT & Peak Height & Peak Width & Peak Area & Area \% \\
\hline 0.96 & 5342.52 & 0.16 & 18825.87 & 3.77 \\
\hline 1.17 & 8535.55 & 0.18 & 32126.23 & 6.44 \\
\hline 1.35 & 42700.50 & 0.17 & 193164.33 & 38.73 \\
\hline 1.57 & 52206.65 & 0.23 & 254674.69 & 51.06 \\
\hline
\end{tabular}

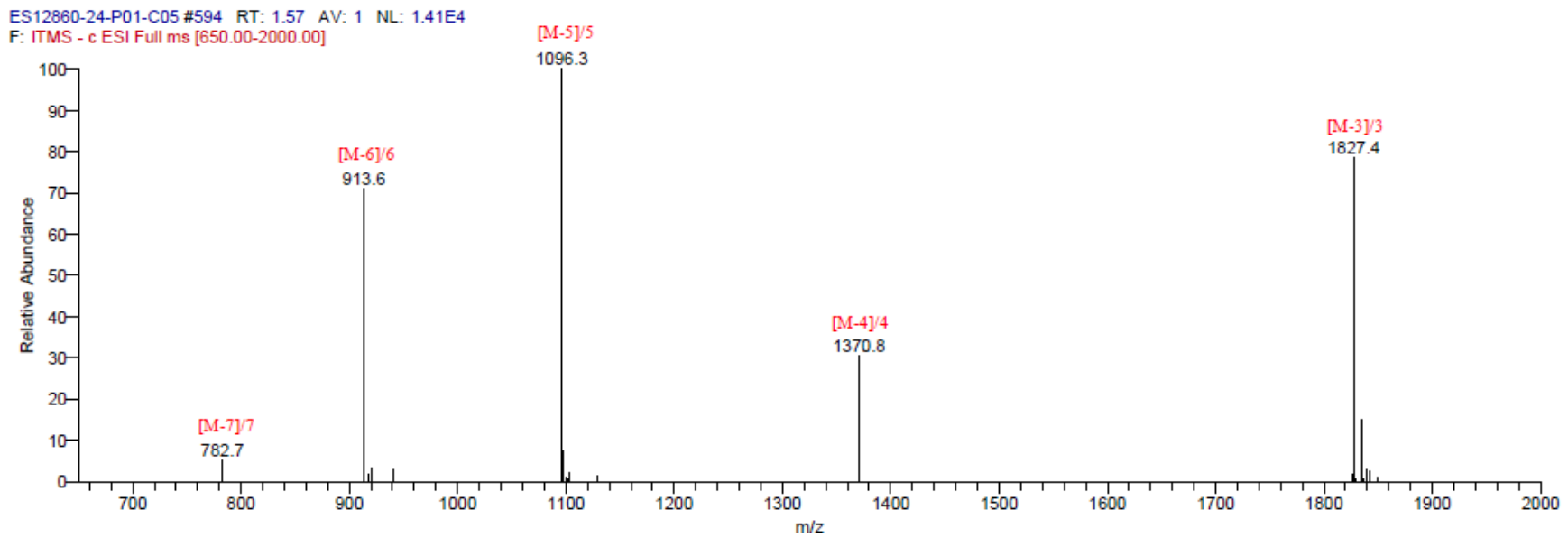

Figure S16. LC trace and mass of $\mathbf{3 m}$ 


\section{SI-6-14 LC Trace and Mass of 3n}

Following General Procedure 3

Yield: $85.95 \%$

Exact mass: 5555.7

Triply charged mass [M-3]/3, calculated: 1850.9; observed: 1851.3.
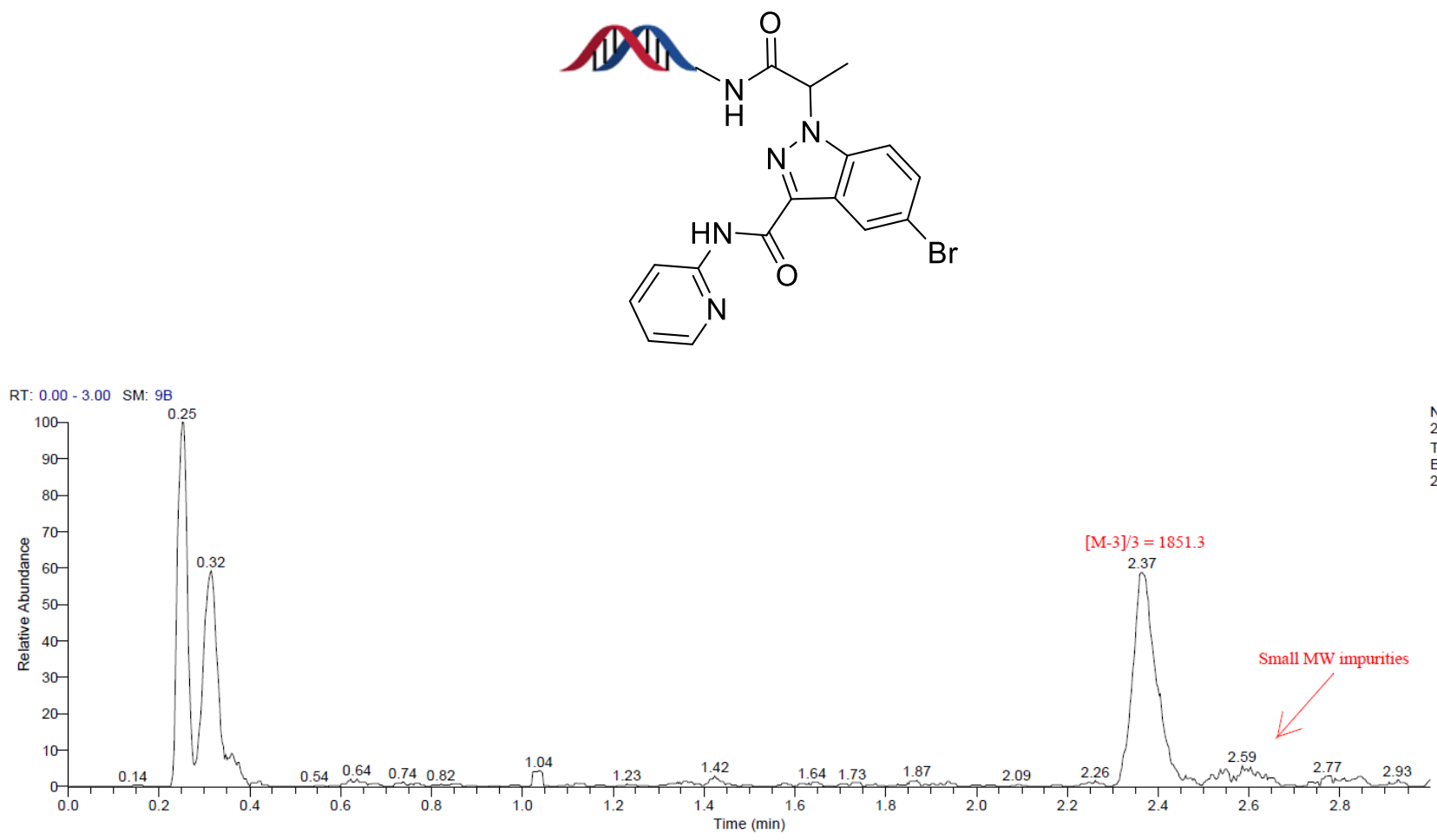

\begin{tabular}{|c|c|c|c|c|}
\hline RT & Peak Height & Peak Width & Peak Area & Area \% \\
\hline 2.33 & 424.52 & 0.03 & 357.44 & 6.26 \\
\hline 2.37 & 1648.07 & 0.11 & 4906.42 & 85.95 \\
\hline 2.55 & 208.60 & 0.03 & 174.72 & 3.06 \\
\hline 2.60 & 183.75 & 0.04 & 270.08 & 4.73 \\
\hline
\end{tabular}

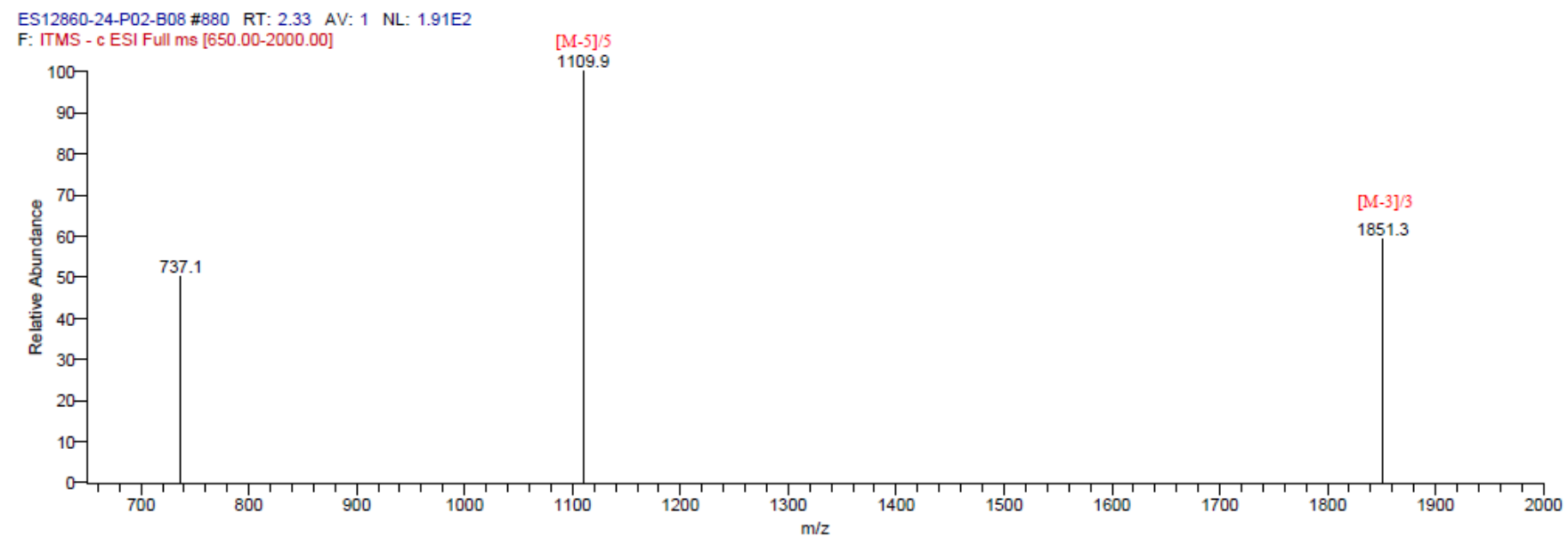

Figure S17. LC trace and mass of $\mathbf{3 n}$ 


\section{SI-6-15 LC Trace and Mass of 3o}

Following General Procedure 3

Yield: $17.14 \%$

Exact mass: 5448.75

Triply charged mass [M-3]/3, calculated: 1815.3; observed: 1815.0.<smiles>O=C(Nc1ccccn1)c1ccn2ncc(C(=O)NCC3CCCC3)c2c1</smiles>

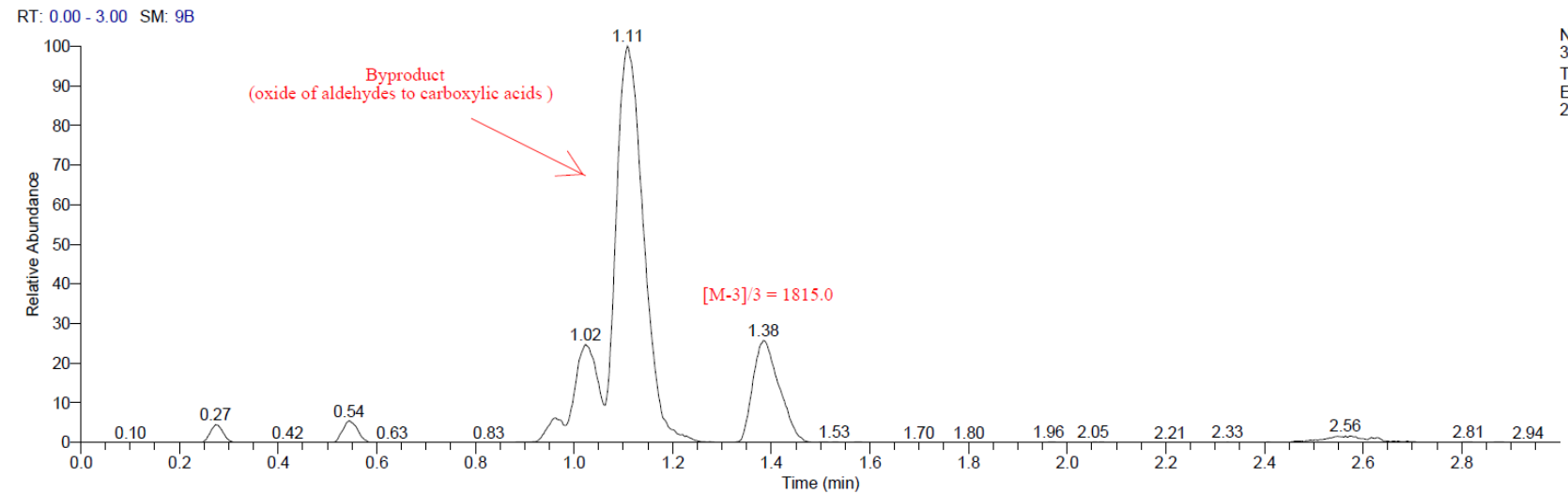

\begin{tabular}{|c|c|c|c|c|}
\hline RT & Peak Height & Peak Width & Peak Area & Area \% \\
\hline 0.97 & 2407.84 & 0.08 & 4628.29 & 2.47 \\
\hline 1.02 & 8502.55 & 0.08 & 25459.67 & 13.59 \\
\hline 1.11 & 33789.24 & 0.12 & 124103.62 & 66.25 \\
\hline 1.20 & 1128.32 & 0.03 & 1020.74 & 0.54 \\
\hline 1.39 & 8927.77 & 0.16 & 32116.53 & 17.14 \\
\hline
\end{tabular}

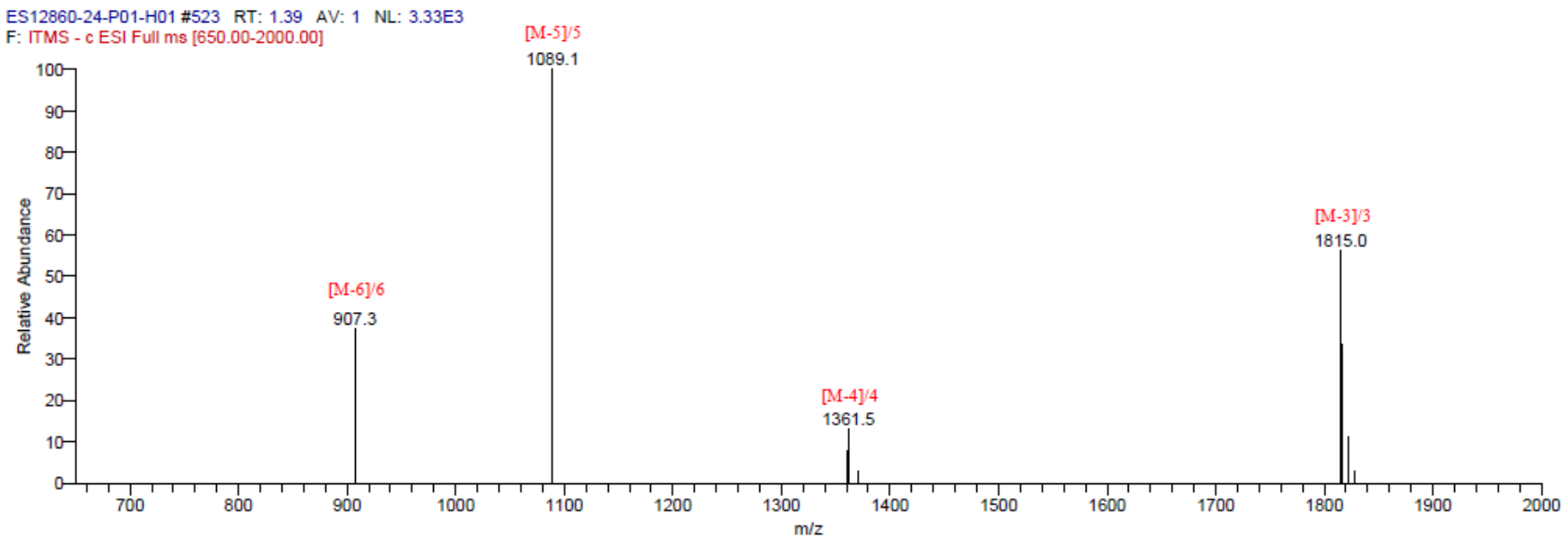

Figure S18. LC trace and mass of $\mathbf{3 o}$ 


\section{SI-6-16 LC Trace and Mass of 3p}

Following General Procedure 3

Yield: $76.37 \%$

Exact mass: 5448.74

Triply charged mass [M-3]/3, calculated: 1815.3; observed: 1815.6.
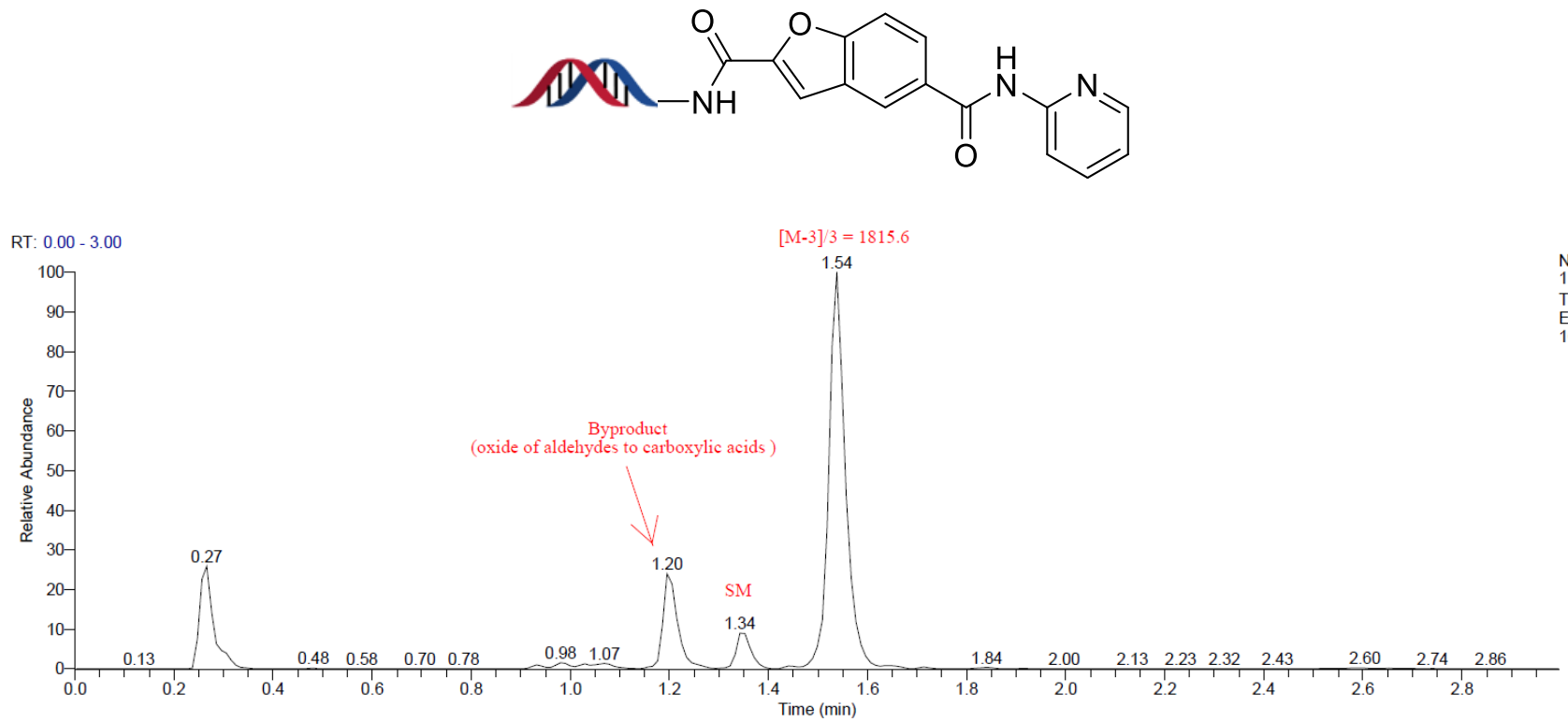

\begin{tabular}{|c|c|c|c|c|}
\hline RT & Peak Height & Peak Width & Peak Area & Area \% \\
\hline 1.21 & 33952.81 & 0.06 & 83807.04 & 16.91 \\
\hline 1.35 & 13692.19 & 0.06 & 33300.39 & 6.72 \\
\hline 1.54 & 151616.92 & 0.06 & 378394.39 & 76.37 \\
\hline
\end{tabular}

ES12860-161-P2 \#158 RT: 1.54 AV: 1 NL: $1.26 E 5$

F: ITMS - c ESI Full ms [650.00-2000.00]
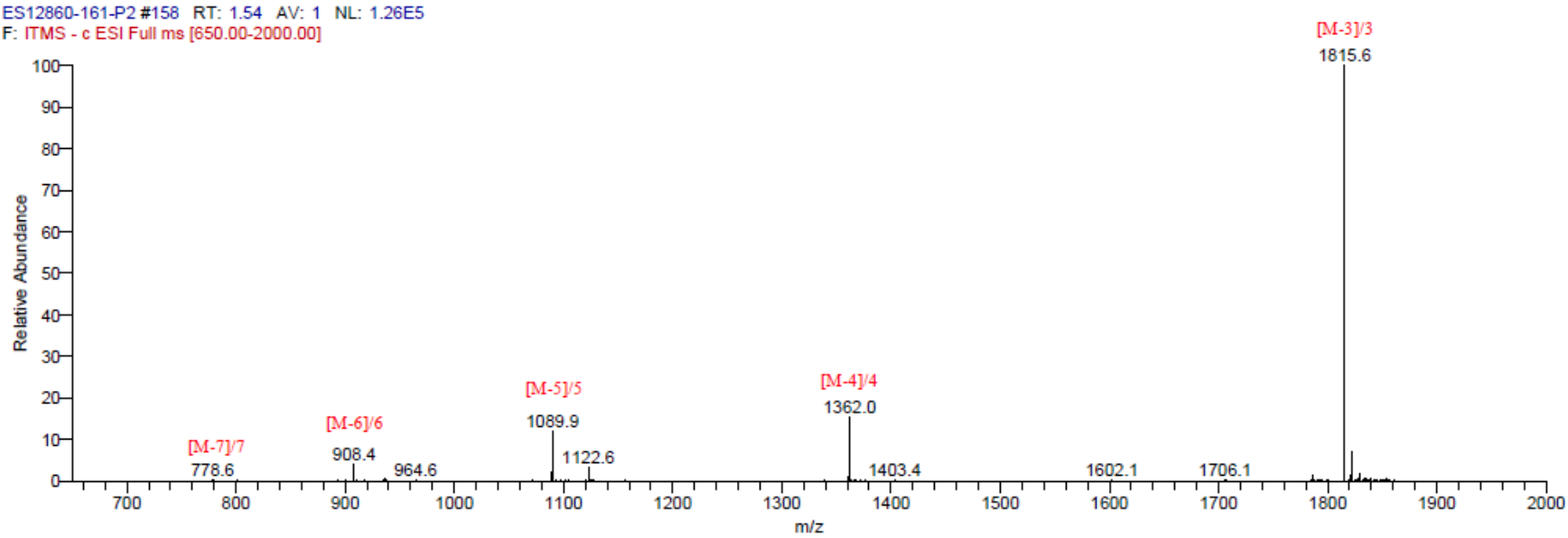

Figure S19. LC trace and mass of $\mathbf{3 p}$ 


\section{SI-6-17 LC Trace and Mass of 4b}

Following General Procedure 3

Yield: $92.75 \%$

Exact mass: 5547.89

Triply charged mass [M-3]/3, calculated: 1848.3; observed: 1848.3.<smiles>CC1C2CC[C@@H]1C2CNC(=O)COc1ccc(C(=O)Nc2cccc(-c3nncn3C(C)C)n2)cc1</smiles>

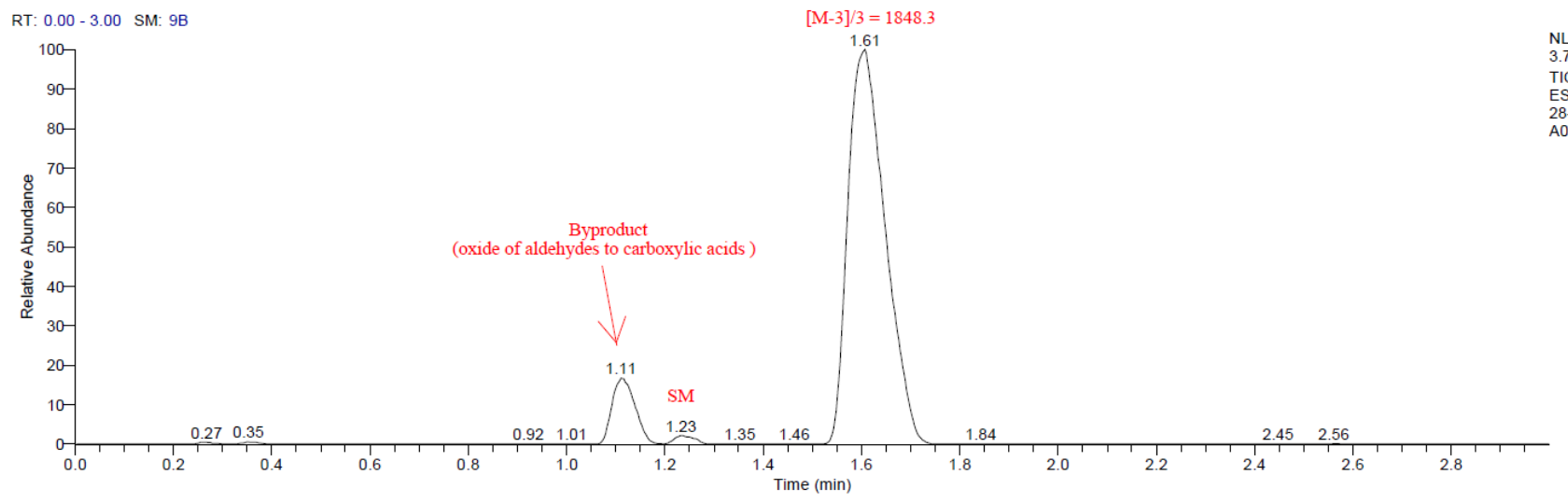

\begin{tabular}{|c|c|c|c|c|}
\hline $\mathrm{RT}$ & Peak Height & Peak Width & Peak Area & Area $\%$ \\
\hline 1.11 & 5654.43 & 0.06 & 12940.67 & 6.14 \\
\hline 1.23 & 893.52 & 0.05 & 1555.02 & 0.74 \\
\hline 1.26 & 715.89 & 0.03 & 793.59 & 0.38 \\
\hline 1.60 & 37398.53 & 0.24 & 195595.26 & 92.75 \\
\hline
\end{tabular}

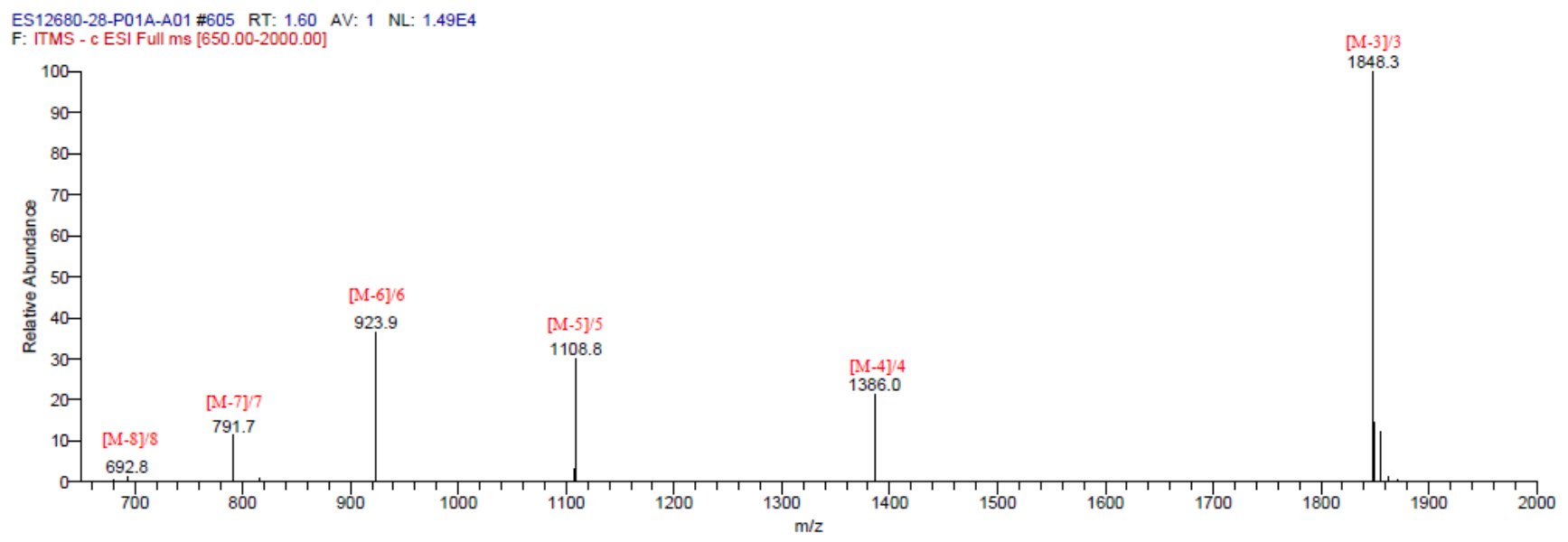

Figure S20. LC trace and mass of $\mathbf{4 b}$ 


\section{SI-6-18 LC Trace and Mass of 4c}

Following General Procedure 3

Yield: $42.26 \%$

Exact mass: 5506.75

Triply charged mass [M-3]/3, calculated: 1834.6; observed: 1834.5.<smiles>O=C(COc1ccc(C(=O)Nc2ccc(C(F)(F)F)cn2)cc1)NCC1CC2CCC1C2</smiles>

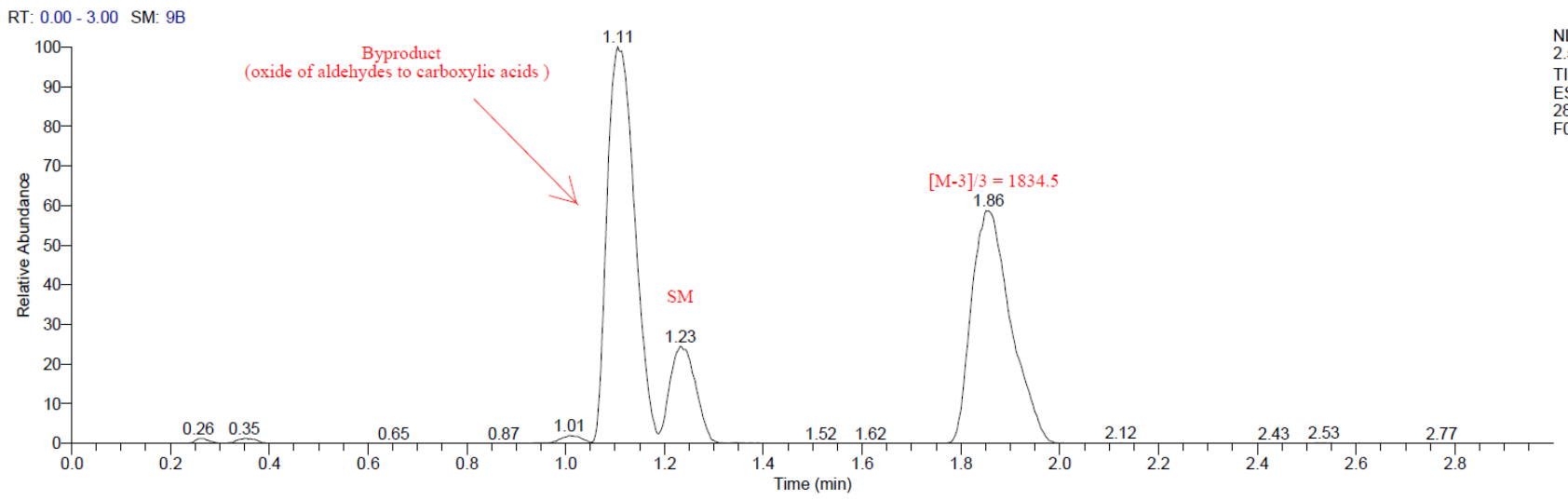

\begin{tabular}{|c|c|c|c|c|}
\hline RT & Peak Height & Peak Width & Peak Area & Area \% \\
\hline 1.01 & 187.29 & 0.04 & 295.54 & 0.15 \\
\hline 1.11 & 25181.37 & 0.14 & 96169.81 & 49.96 \\
\hline 1.24 & 5112.23 & 0.07 & 14686.05 & 7.63 \\
\hline 1.86 & 15531.02 & 0.24 & 81337.51 & 42.26 \\
\hline
\end{tabular}

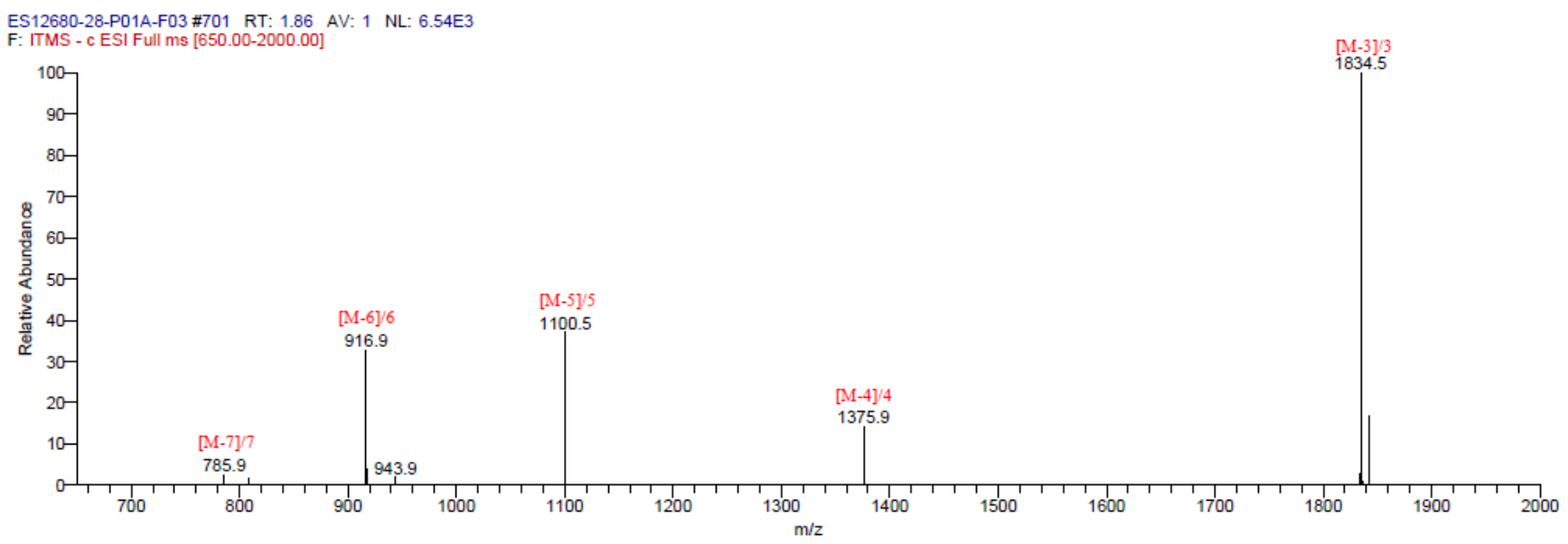

Figure S21. LC trace and mass of $\mathbf{4 c}$ 


\section{SI-6-19 LC Trace and Mass of 4d}

Yield: $90.67 \%$

Exact mass: 5456.75

Triply charged mass [M-3]/3, calculated: 1817.9; observed: 1818.2.<smiles>O=C(COc1ccc(C(=O)Nc2ccc(F)cn2)cc1)NC[C@@H]1C2C=C[C@H]1C2</smiles>

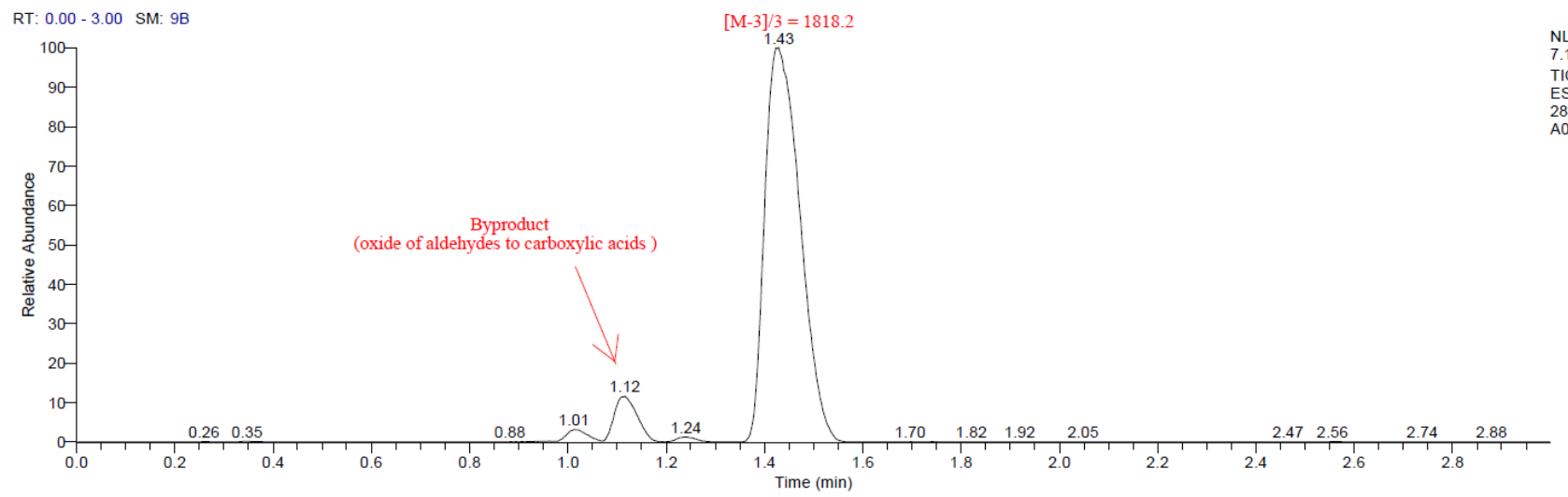

\begin{tabular}{|c|c|c|c|c|}
\hline RT & Peak Height & Peak Width & Peak Area & Area $\%$ \\
\hline 1.01 & 2544.67 & 0.10 & 6866.92 & 1.76 \\
\hline 1.11 & 8726.11 & 0.12 & 26922.17 & 6.89 \\
\hline 1.23 & 1104.40 & 0.05 & 1255.36 & 0.32 \\
\hline 1.25 & 933.00 & 0.07 & 1381.28 & 0.35 \\
\hline 1.42 & 71949.44 & 0.24 & 354047.05 & 90.67 \\
\hline
\end{tabular}

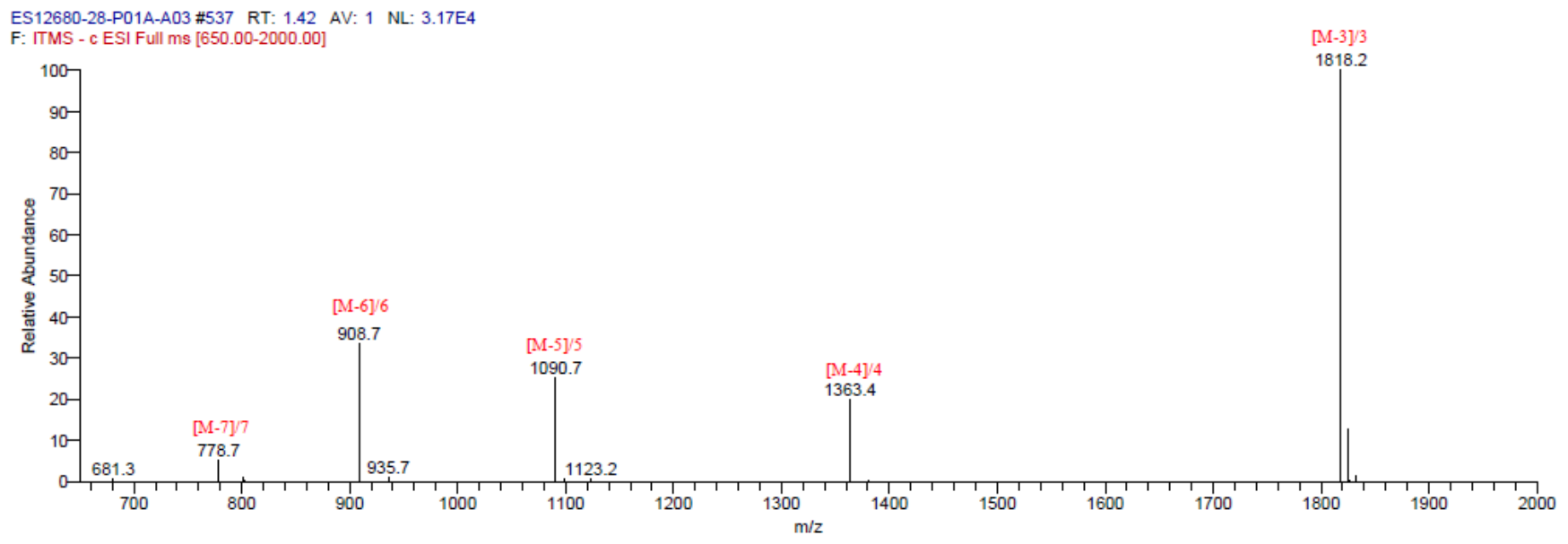

Figure S22. LC trace and mass of the mixture of $\mathbf{4 d}$ 


\section{SI-6-20 LC Trace and Mass of 4e}

Following General Procedure 3

Yield: $80.83 \%$

Exact mass: 5452.78

Triply charged mass [M-3]/3, calculated: 1816.6; observed: 1816.3.
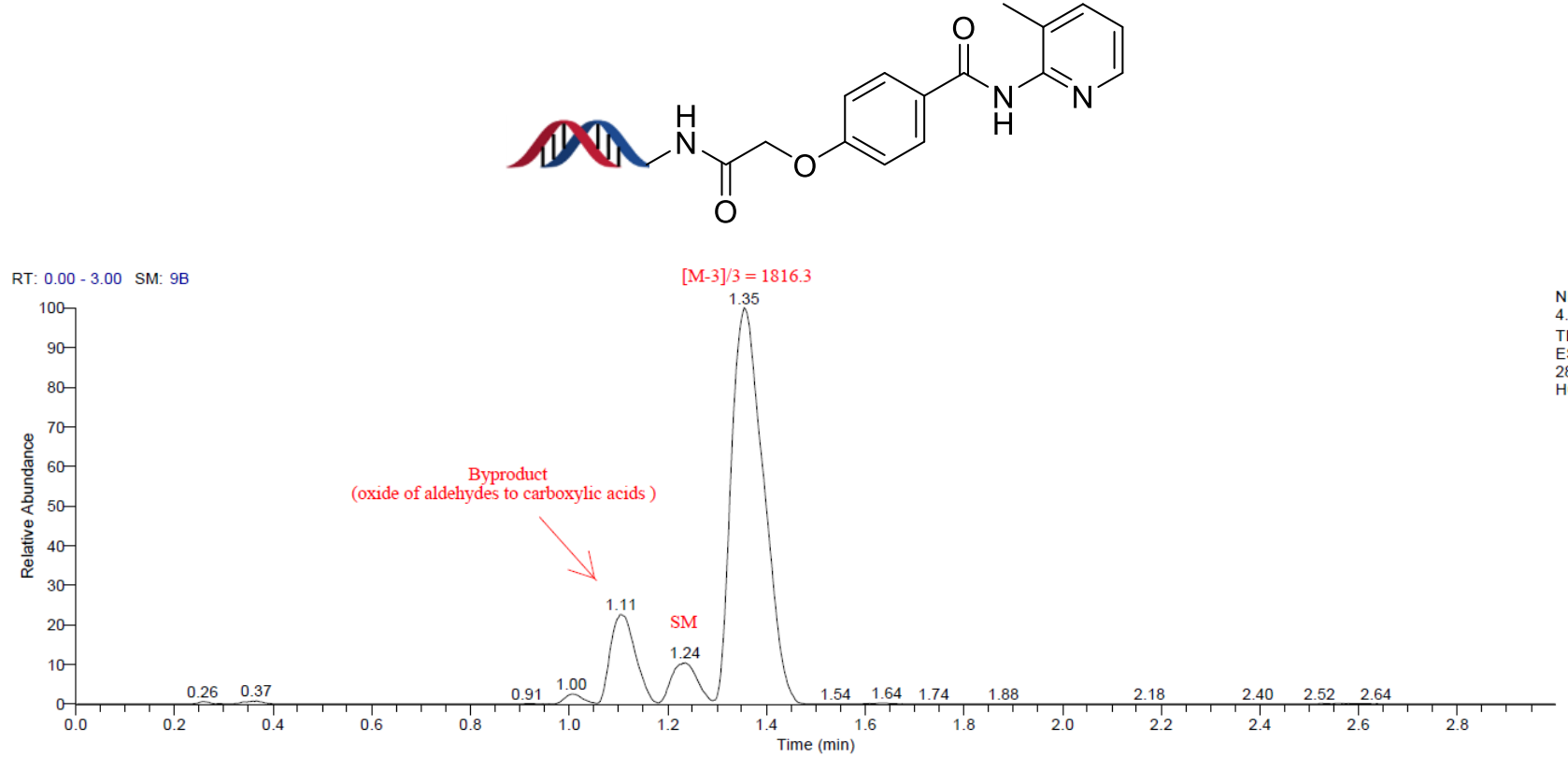

\begin{tabular}{|c|c|c|c|c|}
\hline RT & Peak Height & Peak Width & Peak Area & Area \% \\
\hline 1.01 & 1134.92 & 0.10 & 2610.65 & 1.16 \\
\hline 1.11 & 9313.19 & 0.12 & 31896.02 & 14.16 \\
\hline 1.23 & 3017.73 & 0.07 & 8661.97 & 3.85 \\
\hline 1.36 & 41077.77 & 0.20 & 182032.78 & 80.83 \\
\hline
\end{tabular}

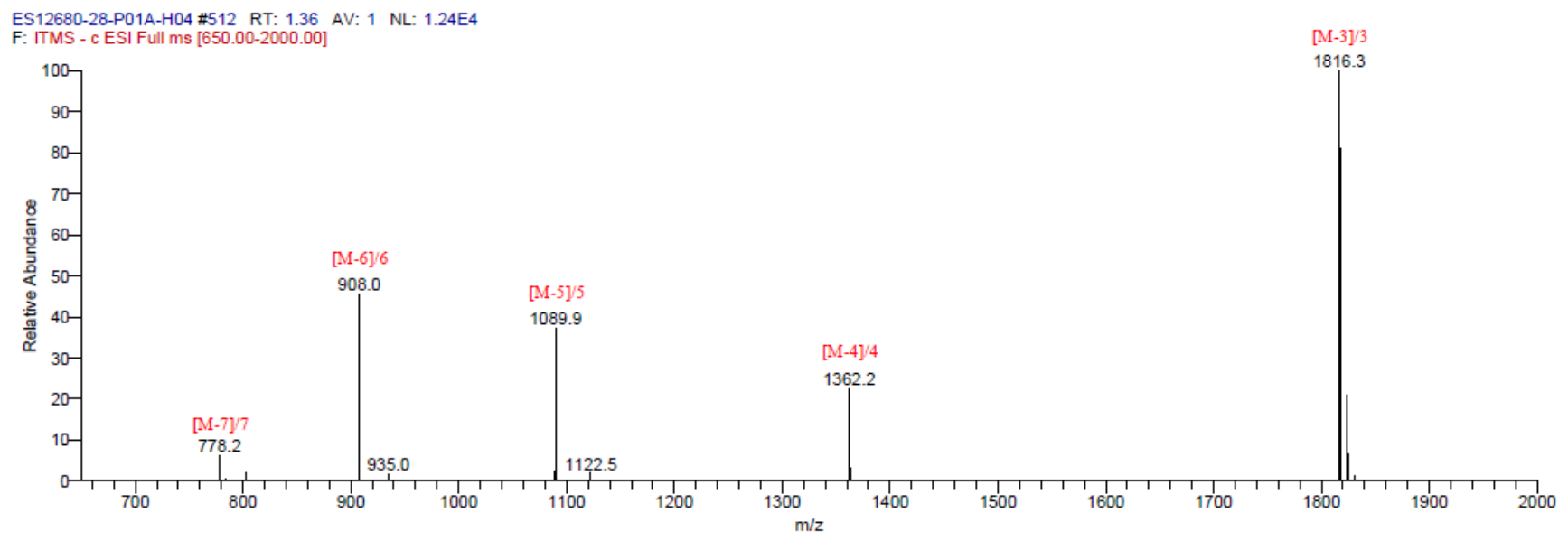

Figure S23. LC trace and mass of $4 \mathbf{e}$ 


\section{SI-6-21 LC Trace and Mass of $4 f$}

Following General Procedure 3

Yield: $51.46 \%$

Exact mass: 5517.65

Triply charged mass [M-3]/3, calculated: 1838.2; observed: 1838.4.
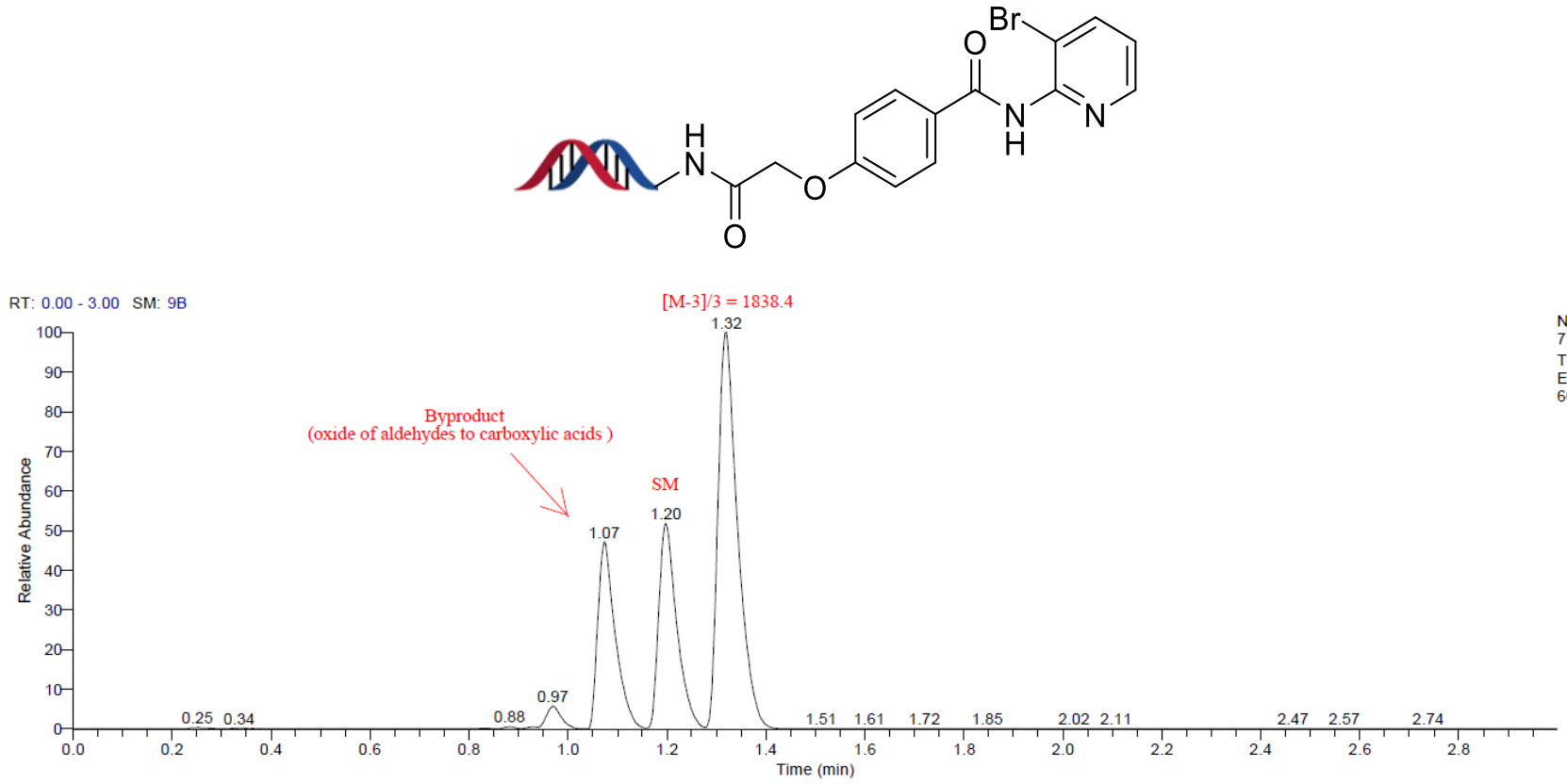

\begin{tabular}{|c|c|c|c|c|}
\hline RT & Peak Height & Peak Width & Peak Area & Area \% \\
\hline 0.88 & 577.48 & 0.05 & 671.58 & 0.16 \\
\hline 0.97 & 5145.44 & 0.08 & 9563.64 & 2.26 \\
\hline 1.07 & 42676.07 & 0.11 & 91521.25 & 21.67 \\
\hline 1.20 & 45873.01 & 0.12 & 103248.85 & 24.45 \\
\hline 1.32 & 86032.43 & 0.16 & 217366.65 & 51.46 \\
\hline
\end{tabular}

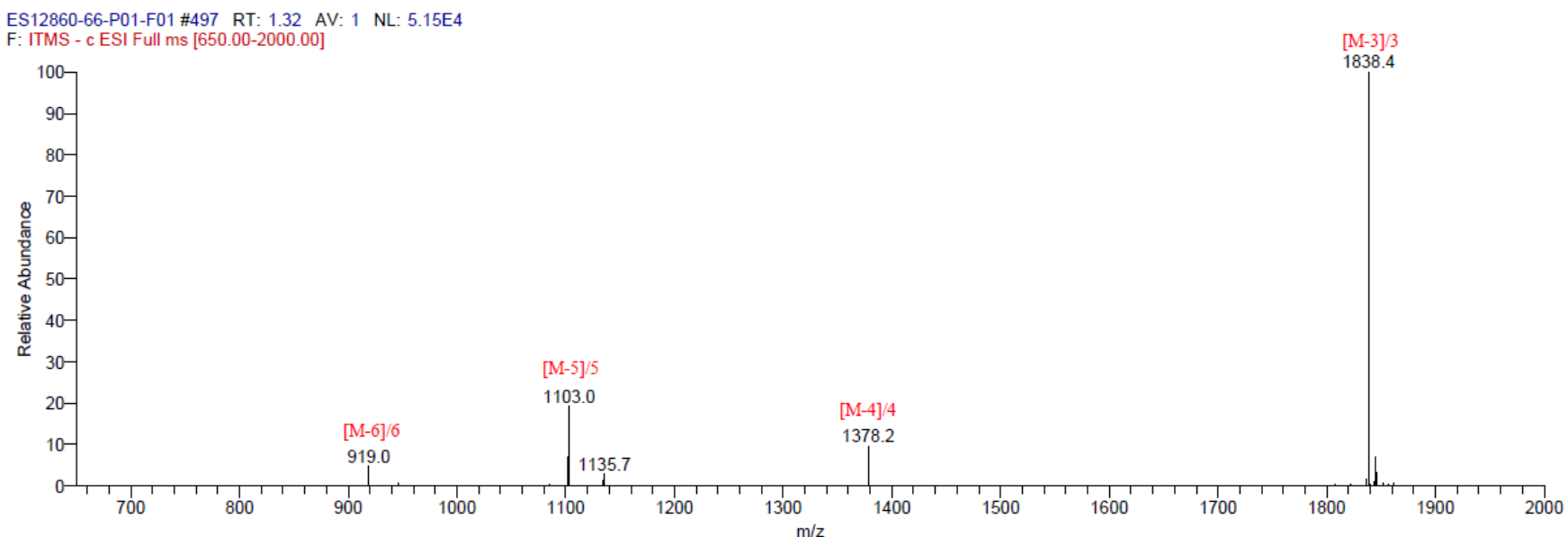

Figure S24. LC trace and mass of $\mathbf{4 f}$ 


\section{SI-6-22 LC Trace and Mass of 4g}

Following General Procedure 3

Yield: $88.49 \%$

Exact mass: 5509.83

Triply charged mass [M-3]/3, calculated: 1835.6; observed: 1835.9.
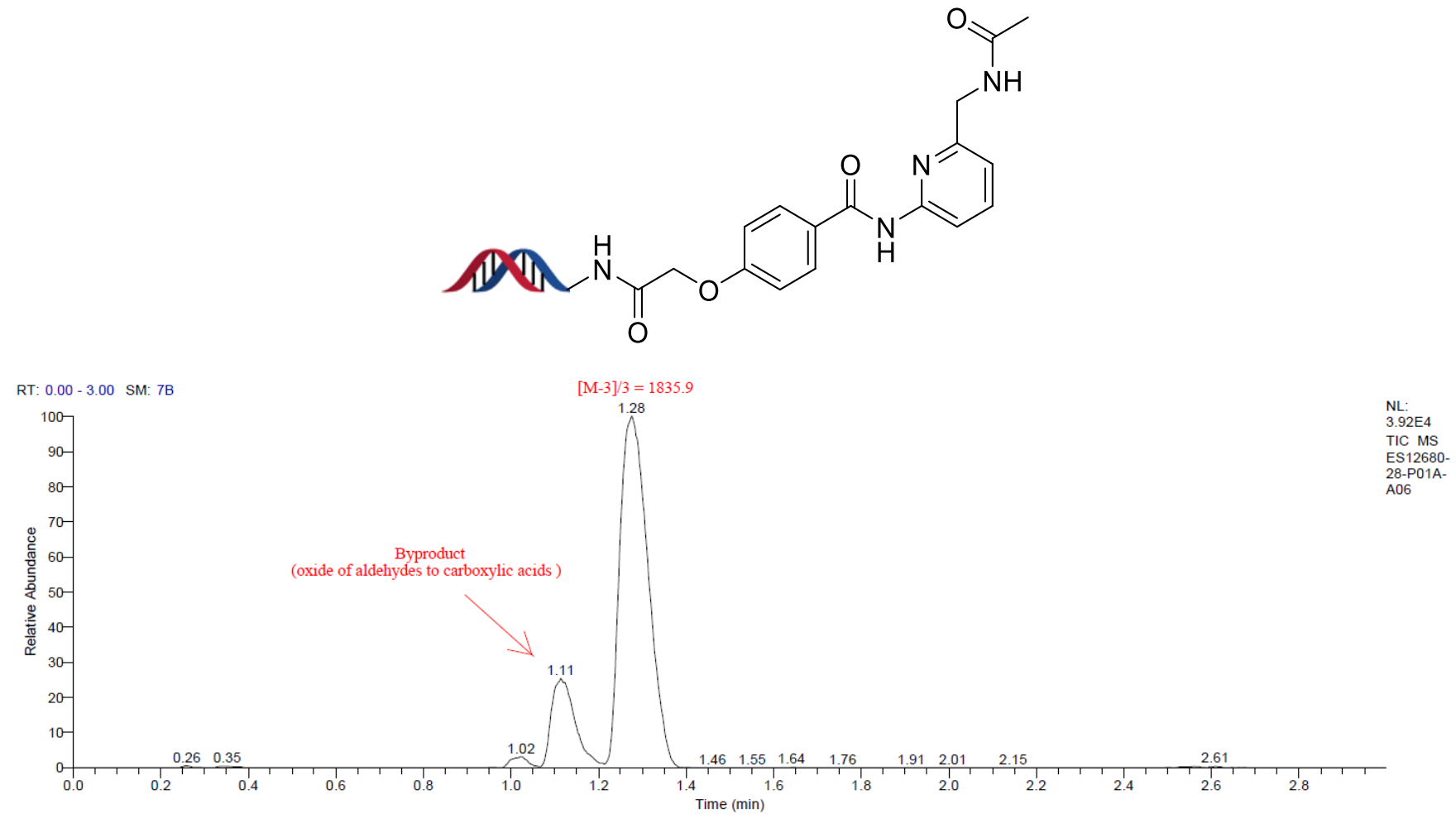

\begin{tabular}{rrrrr} 
RT & Peak Height & Peak Width & Peak Area & Area \% \\
\cline { 2 - 4 } 1.00 & 715.35 & 0.03 & 681.15 & 0.35 \\
1.02 & 679.35 & 0.03 & 795.76 & 0.41 \\
1.12 & 8233.04 & 0.06 & 20430.53 & 10.60 \\
1.27 & 38737.88 & 0.16 & 170590.80 & 88.49 \\
2.53 & 82.06 & 0.06 & 281.38 & 0.15
\end{tabular}

ES12680-28-P01A-A06 \#480 RT: 1.27 AV: 1 NL: $2.14 E 4$

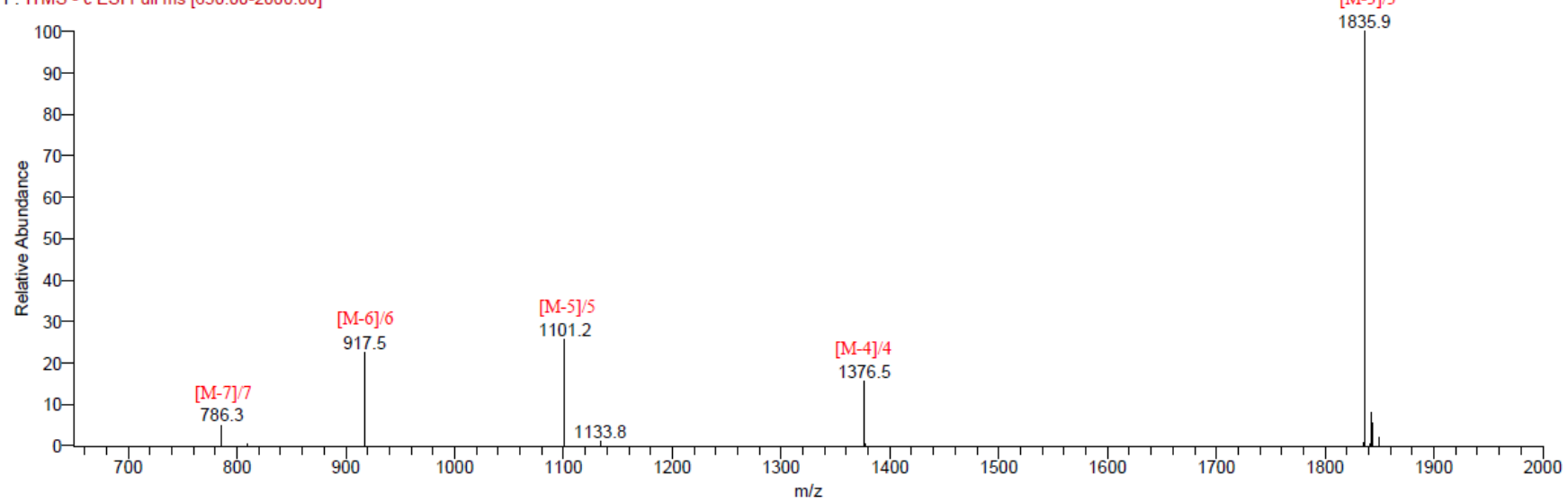

Figure S25. LC trace and mass of $\mathbf{4 g}$ 


\section{SI-6-23 LC Trace and Mass of 4h}

Following General Procedure 3

Yield: $77.95 \%$

Exact mass: 5622.98

Triply charged mass [M-3]/3, calculated: 1873.3; observed: 1873.7.<smiles>CC1C2CC[C@@H]1C2NC(=O)COc1ccc(C(=O)Nc2cc(N3CCN(C(=O)OC(C)(C)C)CC3)ccn2)cc1</smiles>

RT: $0.00-3.00$ SM: $9 B$
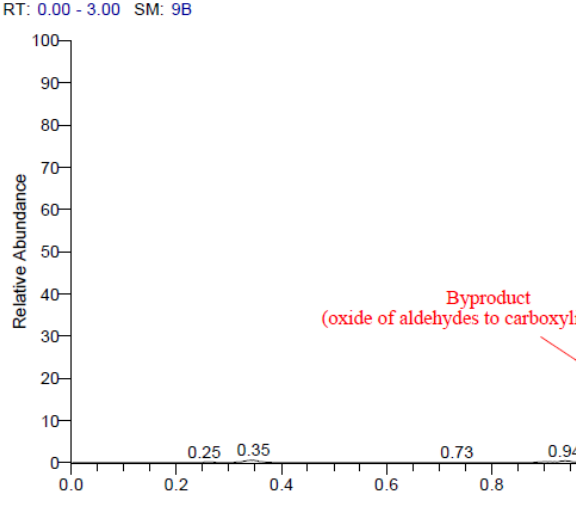

\begin{tabular}{rr} 
RT & Peak Height \\
\hline 0.94 & 312.87 \\
1.11 & 5496.11 \\
1.23 & 15639.75 \\
2.20 & 230.97 \\
2.62 & 48222.98
\end{tabular}
Peak Width

0.04

0.11

0.06

0.04

0.17

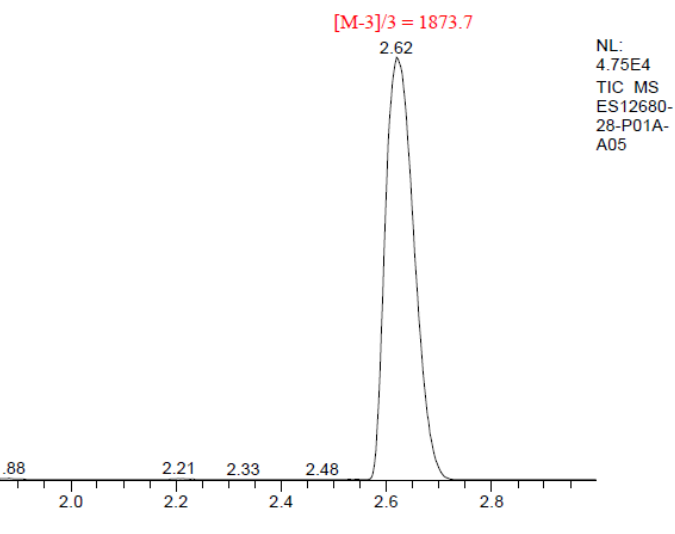

TIC MS

ES12680-

50

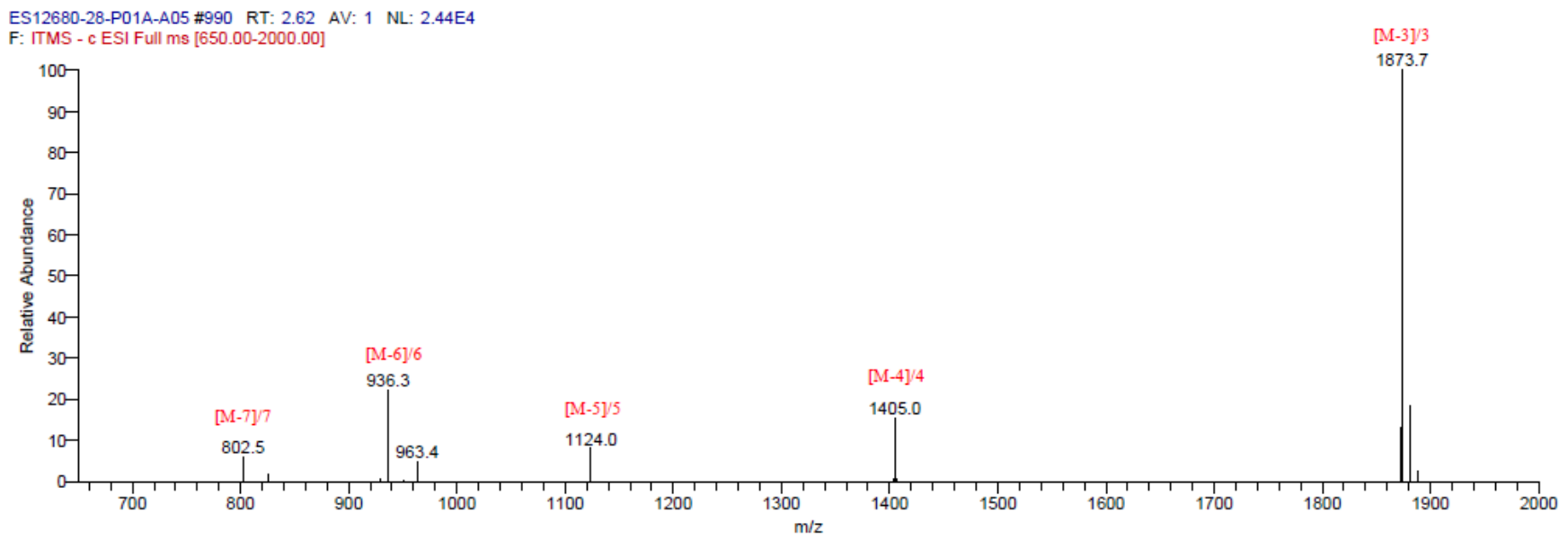

Figure S26. LC trace and mass of $\mathbf{4 h}$ 


\section{SI-6-24 LC Trace and Mass of 4i}

Following General Procedure 3

Yield: $39.03 \%$

Exact mass: 5622.01

Triply charged mass [M-3]/3, calculated: 1873; observed: 1873.3 .<smiles>CC1CC[C@H]1NC(=O)COc1ccc(C(=O)Nc2ccc(C3CCN(C(=O)OC(C)(C)C)CC3)cn2)cc1</smiles>
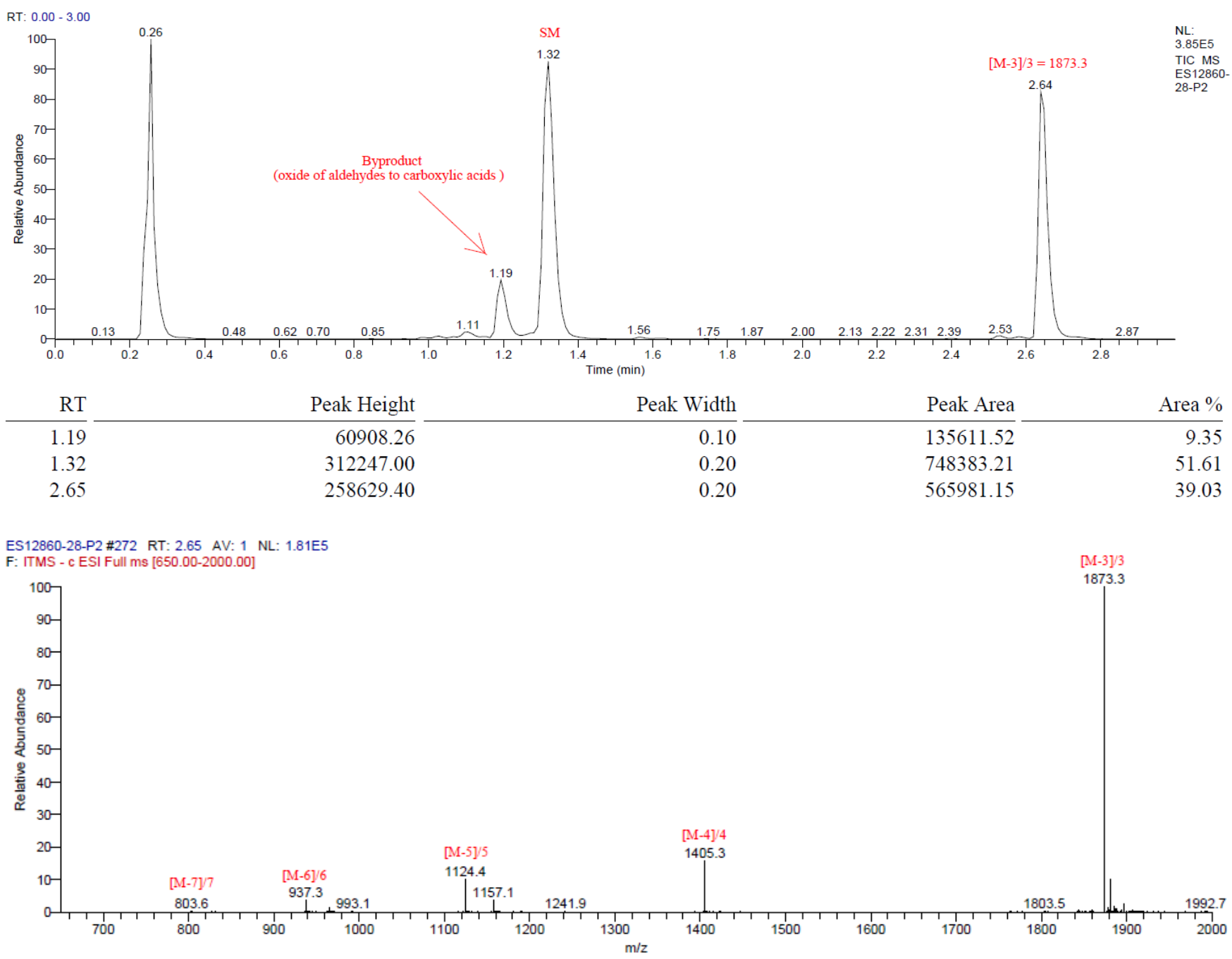

Figure S27. LC trace and mass of $\mathbf{4 i}$ 


\section{SI-6-25 LC Trace and Mass of 4j}

Following General Procedure 3

Yield: $80.82 \%$

Exact mass: 5497.82

Triply charged mass [M-3]/3, calculated: 1831.6; observed: 1832.0.<smiles>CCCOc1ccc(NC(=O)c2ccc(OCC(=O)NCC3C4CC[C@H](C4)[C@H]3C)cc2)nn1</smiles>
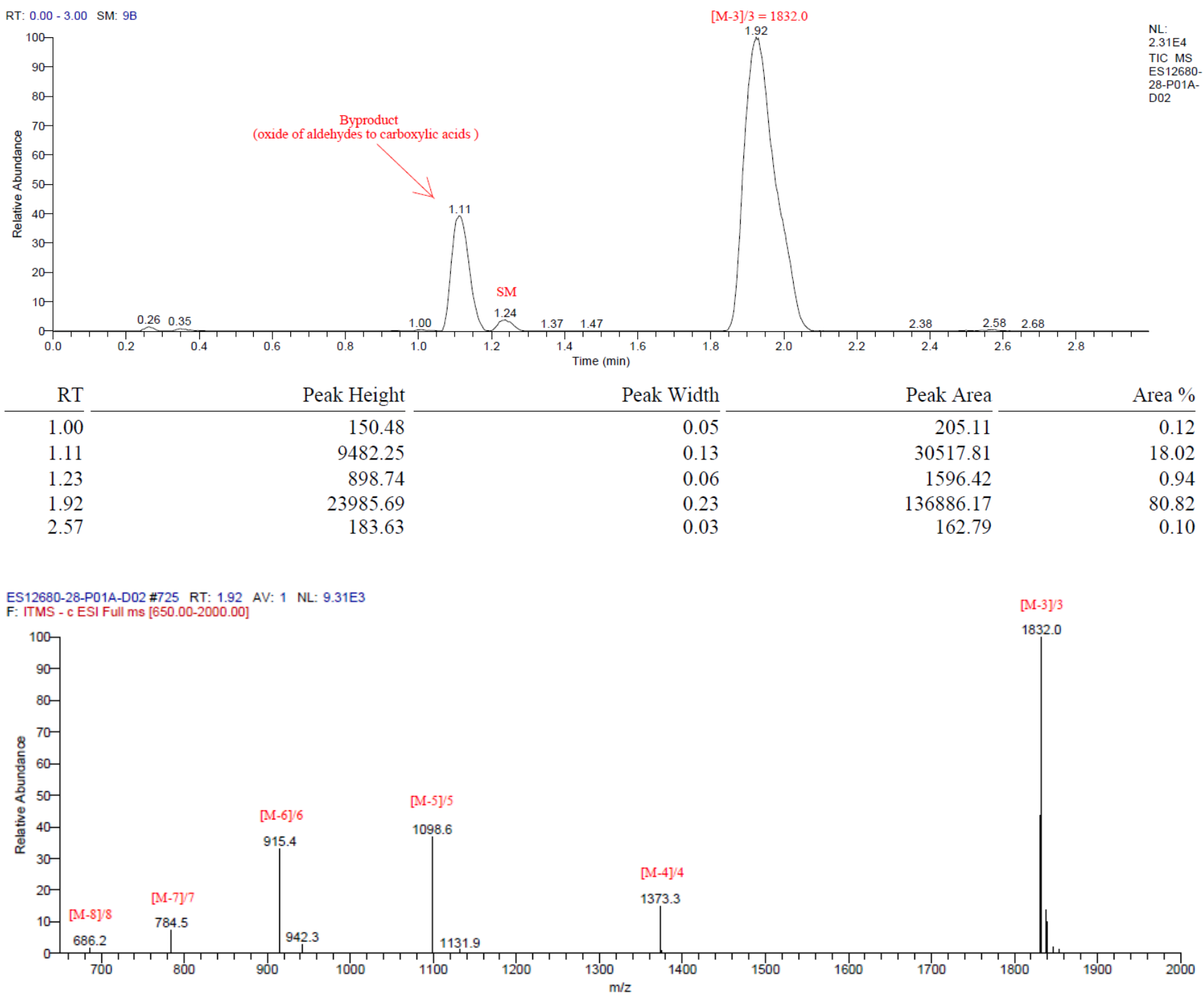

Figure S28. LC trace and mass of $\mathbf{4 j}$ 


\section{SI-6-26 LC Trace and Mass of 4k}

\section{Following General Procedure 3}

Yield: $71.01 \%$

Exact mass: 5439.74

Triply charged mass [M-3]/3, calculated: 1812.3; observed: 1811.9.
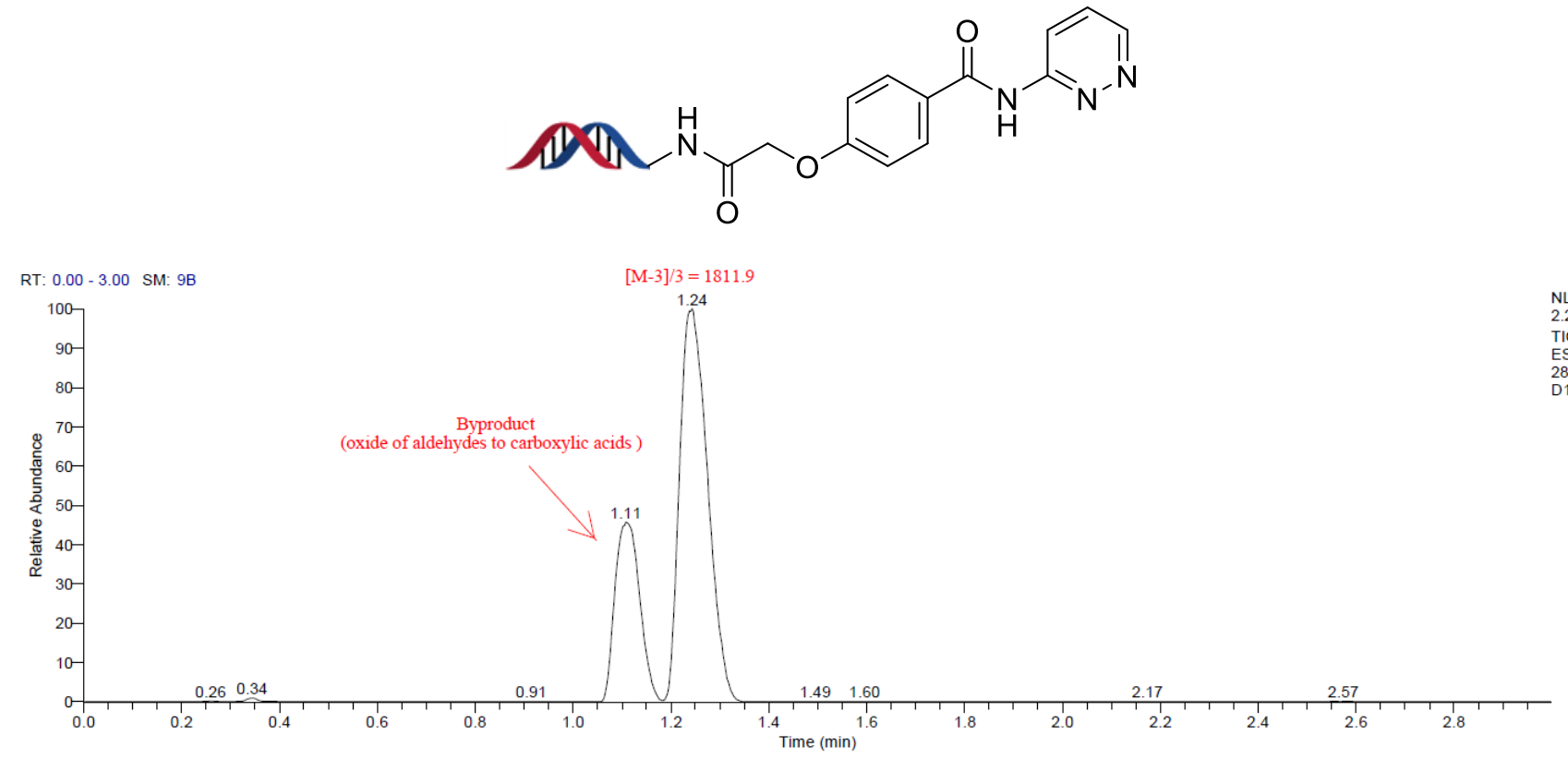

\begin{tabular}{|c|c|c|c|c|}
\hline RT & Peak Height & Peak Width & Peak Area & Area \% \\
\hline 1.11 & 10464.48 & 0.12 & 36460.83 & 28.99 \\
\hline 1.24 & 23698.82 & 0.18 & 89322.94 & 71.01 \\
\hline
\end{tabular}

ES12680-28-P01A-D12 \#467 RT: 1.24 AV: 1 NL: 6.63E3 F: ITMS - c ESI Full ms [650.00-2000.00]

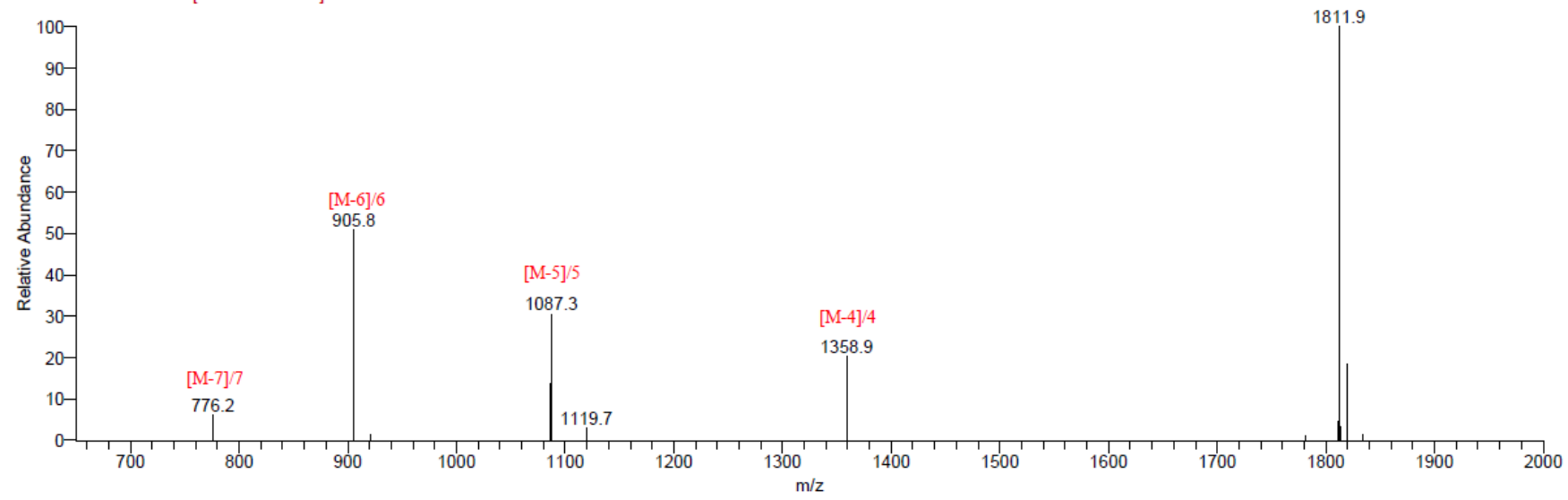

Figure S29. LC trace and mass of $\mathbf{4 k}$ 


\section{SI-6-27 LC Trace and Mass of 41}

Following General Procedure 3

Yield: $67.64 \%$

Exact mass: 5489.8

Triply charged mass [M-3]/3, calculated: 1828.9; observed: 1829.1.<smiles>O=C(COc1ccc(C(=O)Nc2cc3ccccc3nn2)cc1)NC[C@@H]1CC[C@H]2CC[C@H]1C2</smiles>
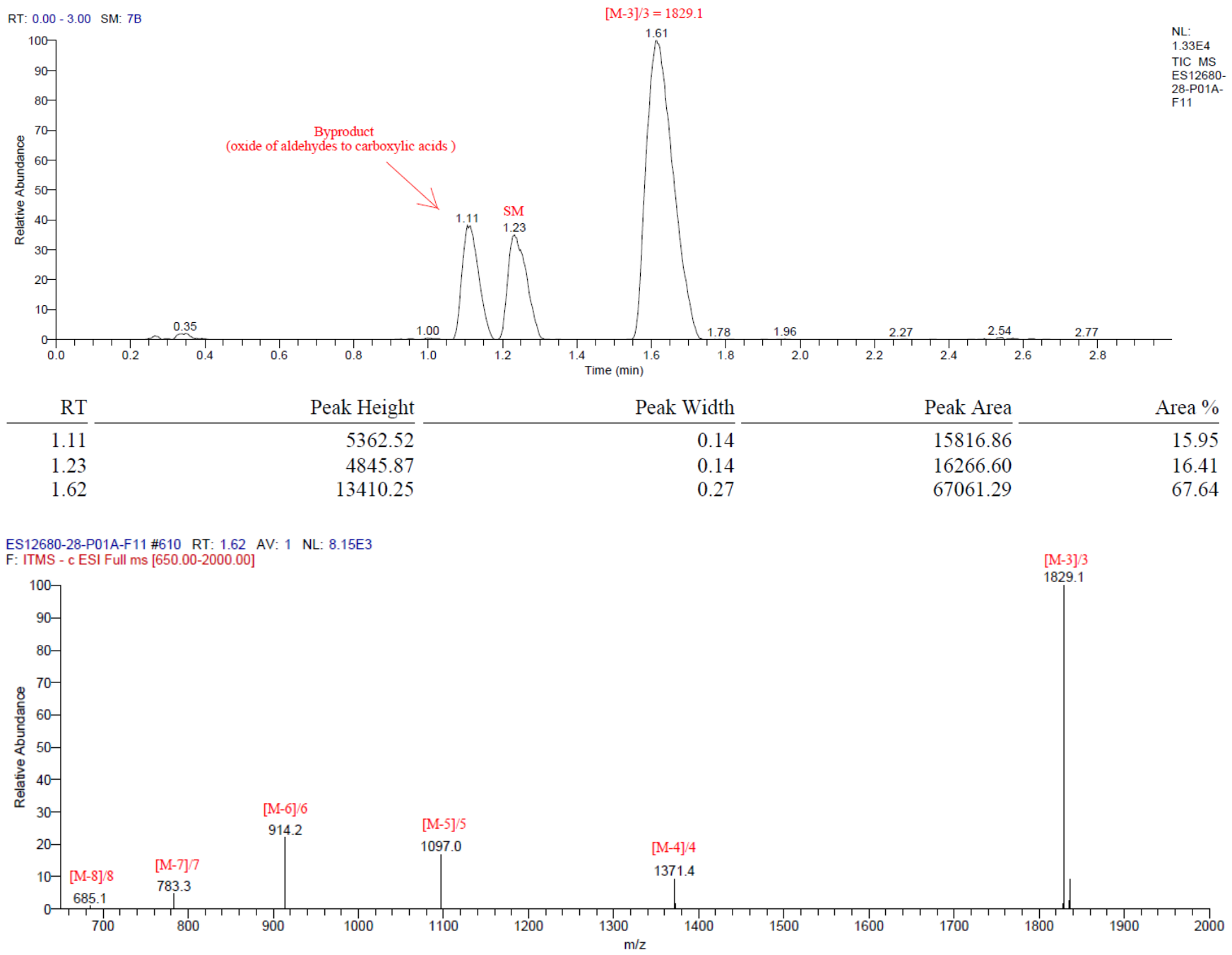

Figure S30. LC trace and mass of 41 


\section{SI-6-28 LC Trace and Mass of 4m}

Following General Procedure 3

Yield: $34.39 \%$

Exact mass: 5483.8

Triply charged mass [M-3]/3, calculated: 1826.9; observed: 1826.8 .
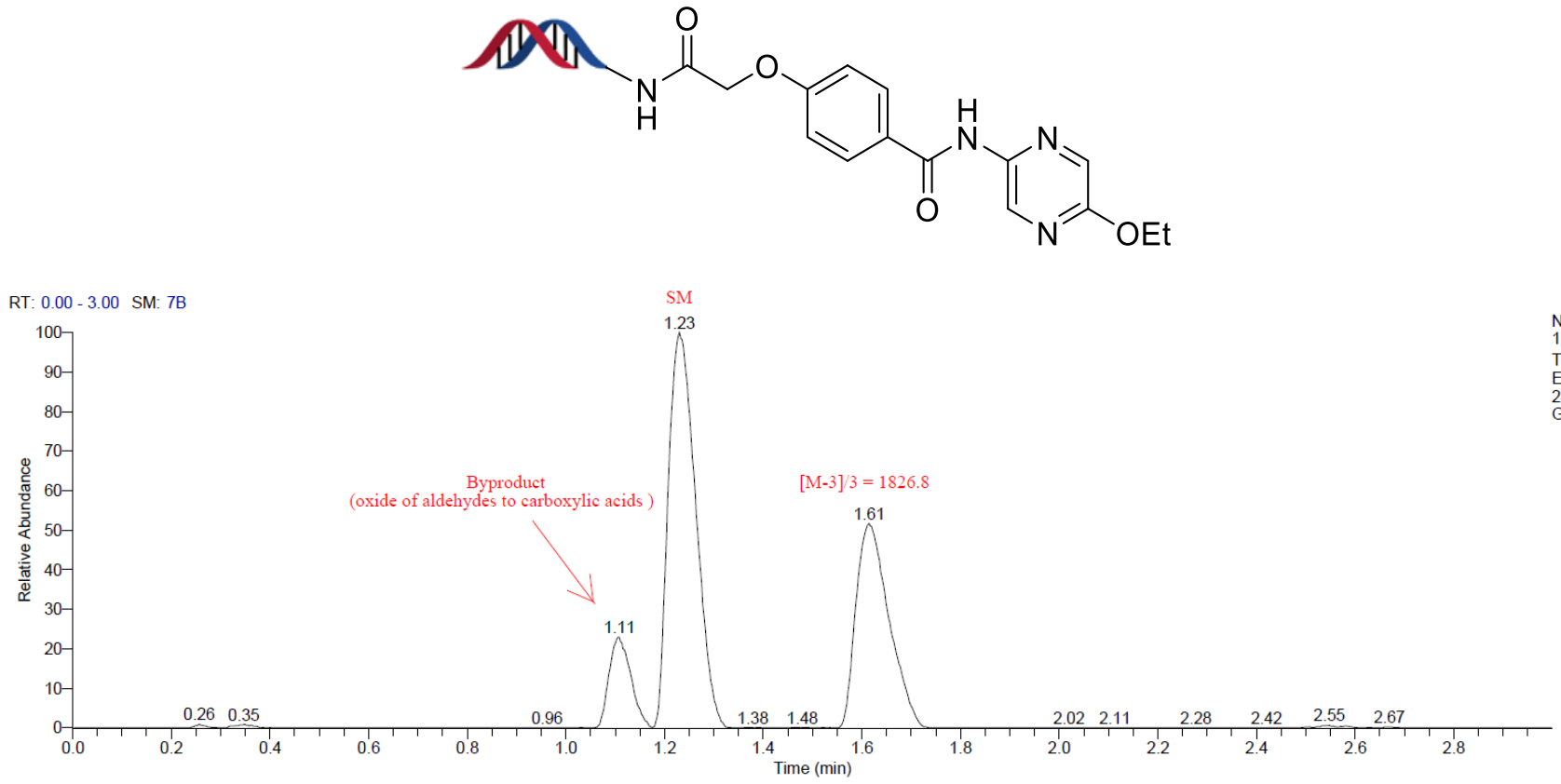

\begin{tabular}{|c|c|c|c|c|}
\hline RT & Peak Height & Peak Width & Peak Area & Area \% \\
\hline 1.11 & 4667.48 & 0.12 & 13929.77 & 10.09 \\
\hline 1.23 & 19788.08 & 0.18 & 76208.24 & 55.21 \\
\hline 1.61 & 10177.09 & 0.20 & 47468.06 & 34.39 \\
\hline 2.54 & 137.17 & 0.05 & 225.46 & 0.16 \\
\hline 2.58 & 94.83 & 0.09 & 202.85 & 0.15 \\
\hline
\end{tabular}

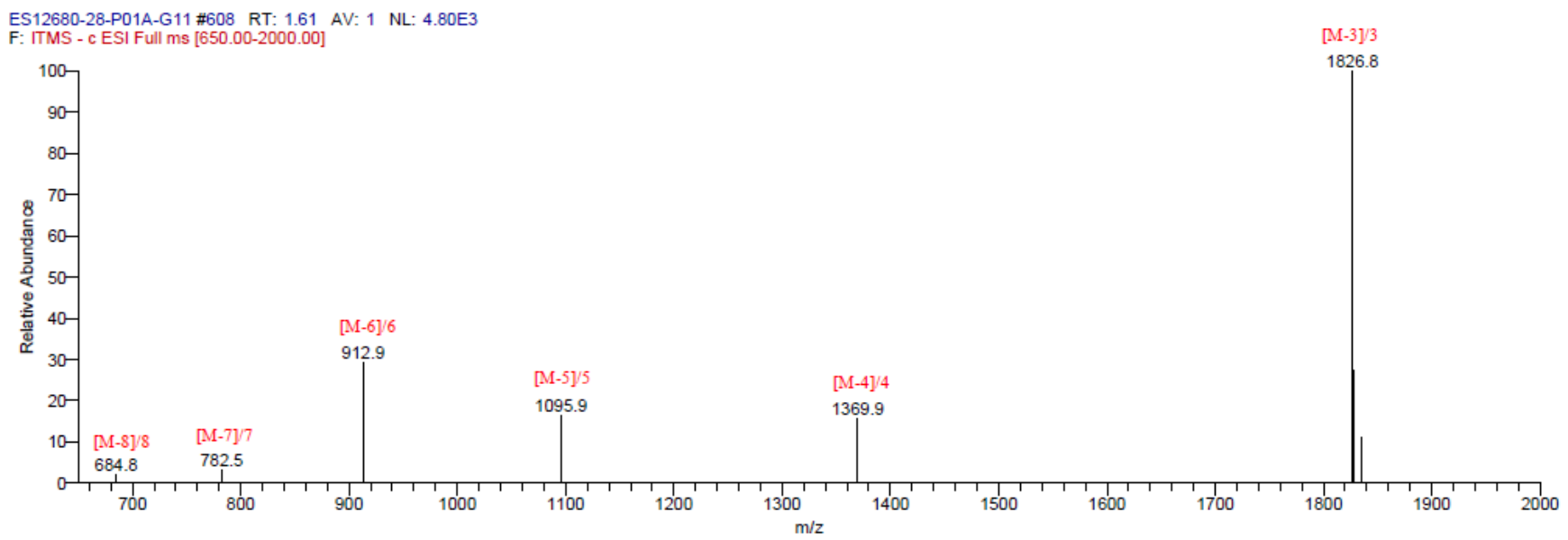

Figure S31. LC trace and mass of $\mathbf{4 m}$ 


\section{SI-6-29 LC Trace and Mass of 4n}

Following General Procedure 3

Yield: $51.95 \%$

Exact mass: 5570.72

Triply charged mass [M-3]/3, calculated: 1855.9; observed: 1855.5.<smiles>O=C(COc1ccc(C(=O)Nc2ncnc3c(Br)csc23)cc1)NC1CC2CCC1C2</smiles>
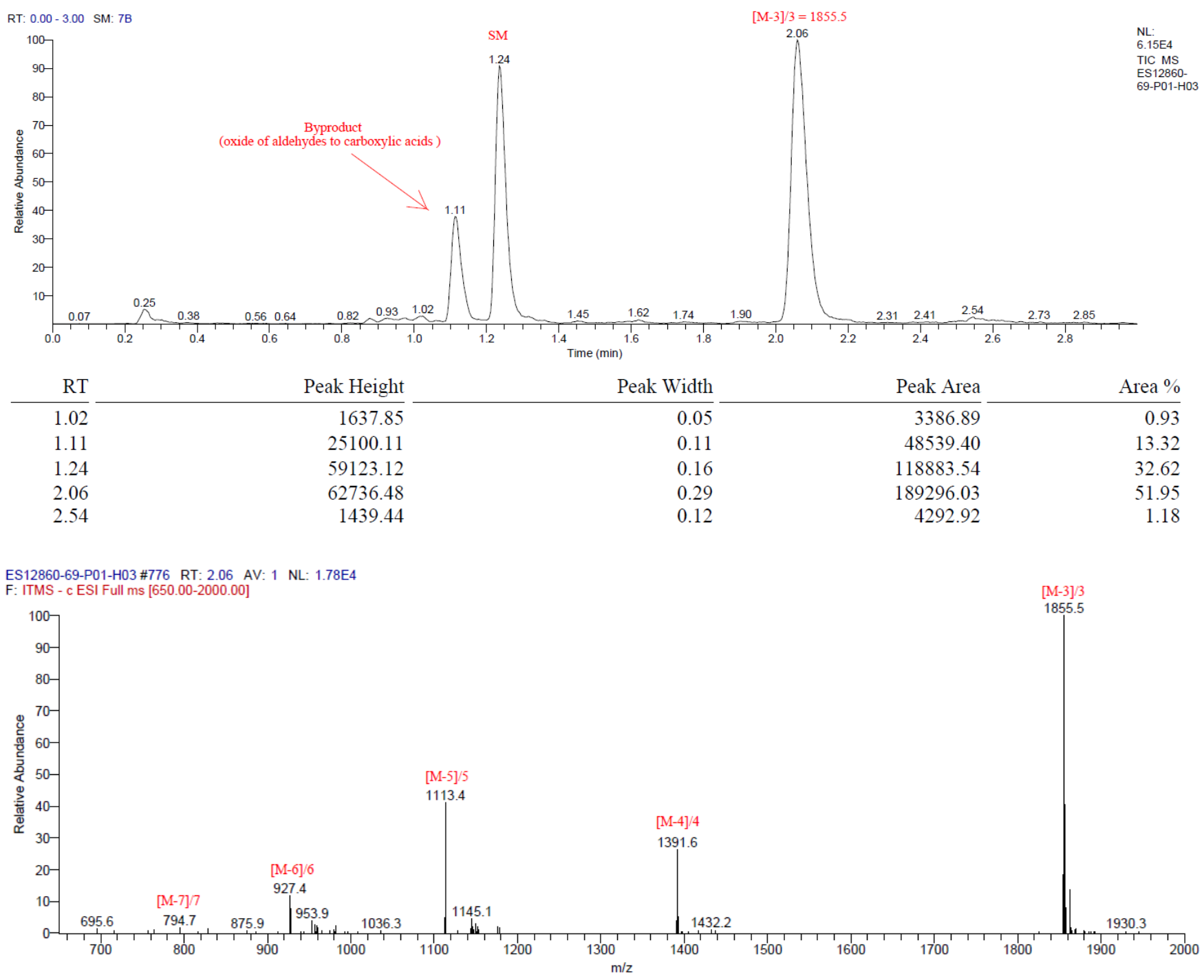

Figure S32. LC trace and mass of $4 \mathbf{n}$ 


\section{SI-6-30 LC Trace and Mass of 4o}

Following General Procedure 3

Yield: $35.27 \%$

Exact mass: 5529.89

Triply charged mass [M-3]/3, calculated: 1842.3; observed: 1842.4.
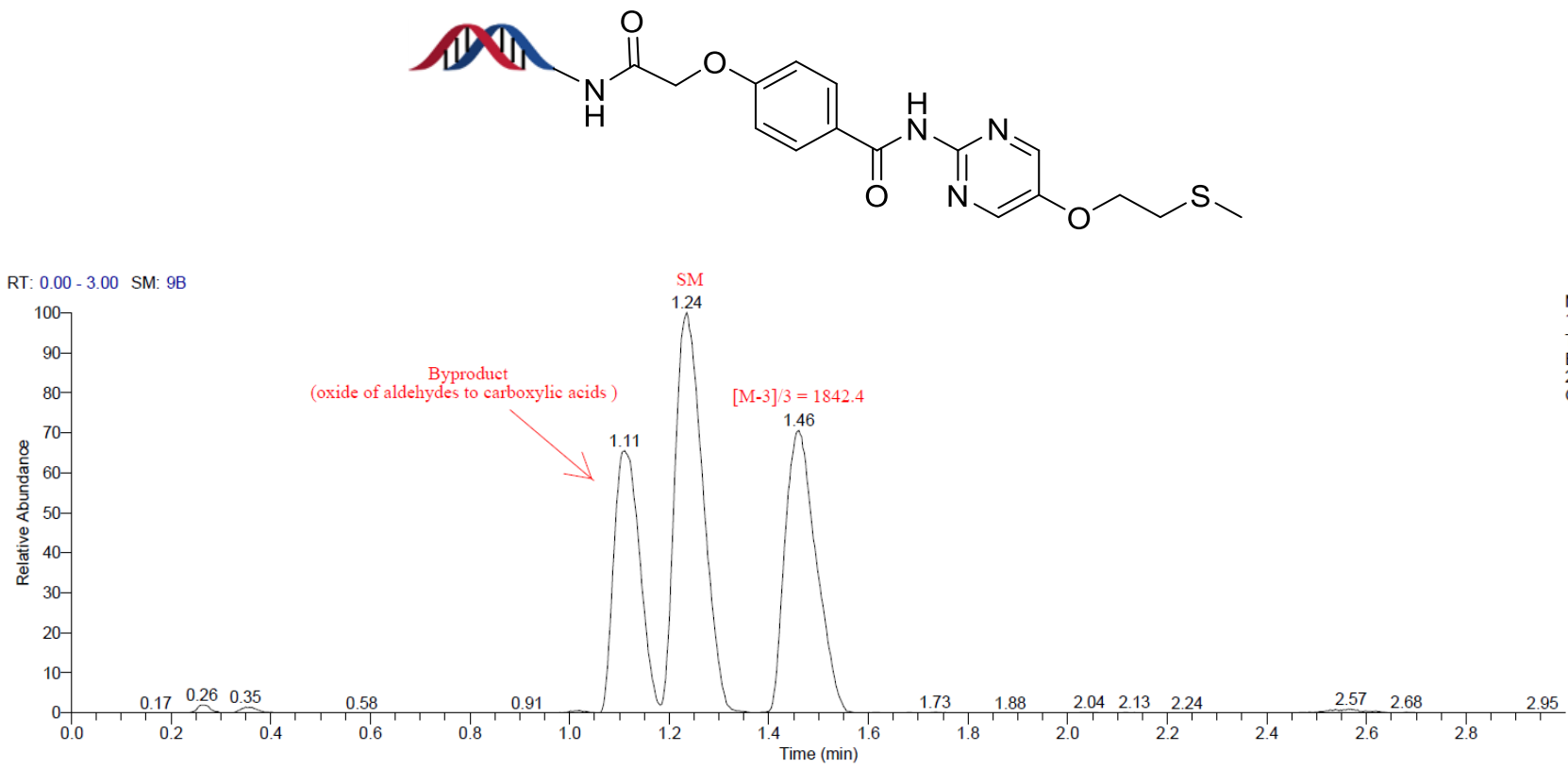

\begin{tabular}{|c|c|c|c|c|}
\hline RT & Peak Height & Peak Width & Peak Area & Area $\%$ \\
\hline 1.11 & 8659.37 & 0.07 & 24438.67 & 20.32 \\
\hline 1.24 & 14163.64 & 0.17 & 53403.87 & 44.41 \\
\hline 1.46 & 10078.75 & 0.17 & 42408.20 & 35.27 \\
\hline
\end{tabular}

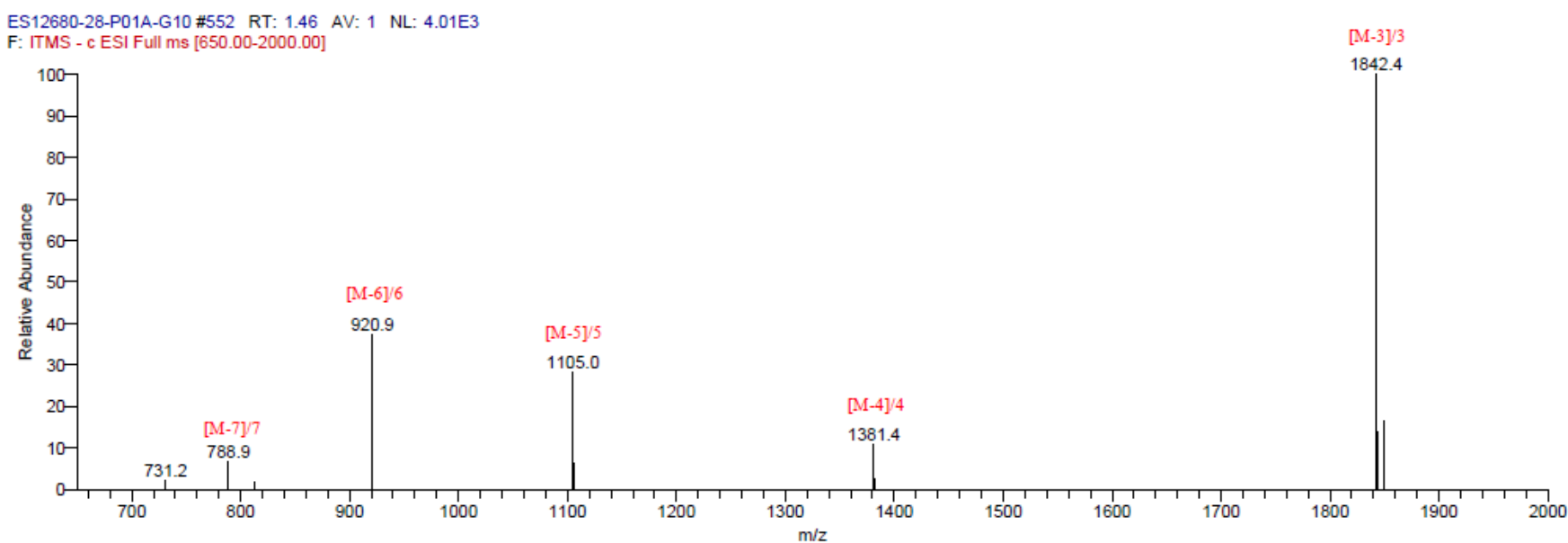

Figure S33. LC trace and mass of 40 


\section{SI-6-31 LC Trace and Mass of 4p}

Following General Procedure 3

Yield: $76.37 \%$

Exact mass: 5596.76

Triply charged mass [M-3]/3, calculated: 1864.6; observed: 1864.8.<smiles>Cc1n[nH]c(NC(=O)c2ccc(OCC(=O)NCC3C4CC[C@H]3C4C)cc2)c1-c1cccc(Br)c1</smiles>

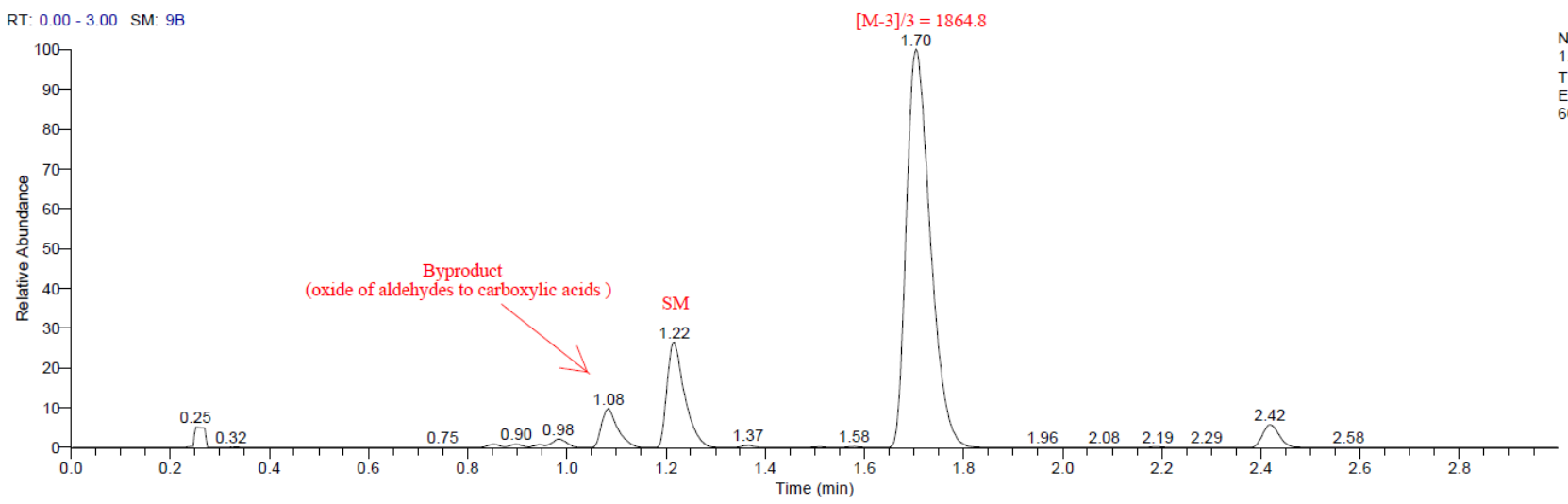

\begin{tabular}{rrrrr} 
RT & Peak Height & Peak Width & Peak Area & Area \% \\
\hline 0.99 & 2895.28 & 0.06 & 3633.33 & 0.66 \\
1.08 & 14257.14 & 0.11 & 27808.15 & 5.04 \\
1.21 & 37646.65 & 0.14 & 82074.51 & 14.88 \\
1.71 & 130066.36 & 0.19 & 421342.10 & 76.37 \\
2.42 & 7885.36 & 0.10 & 16852.88 & 3.05
\end{tabular}

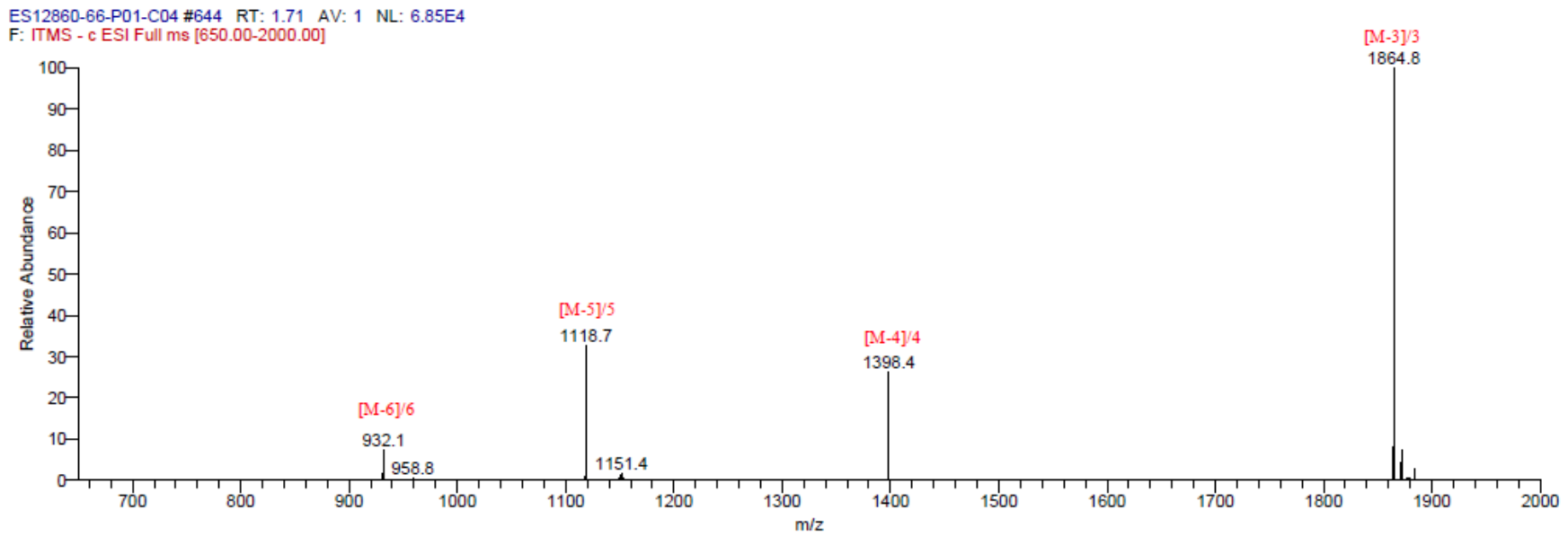

Figure S34. LC trace and mass of $\mathbf{4 p}$ 


\section{SI-6-32 LC Trace and Mass of 4q}

Following General Procedure 3

Yield: $64.7 \%$

Exact mass: 5570.72

Triply charged mass [M-3]/3, calculated: 1855.9; observed: 1856.0.
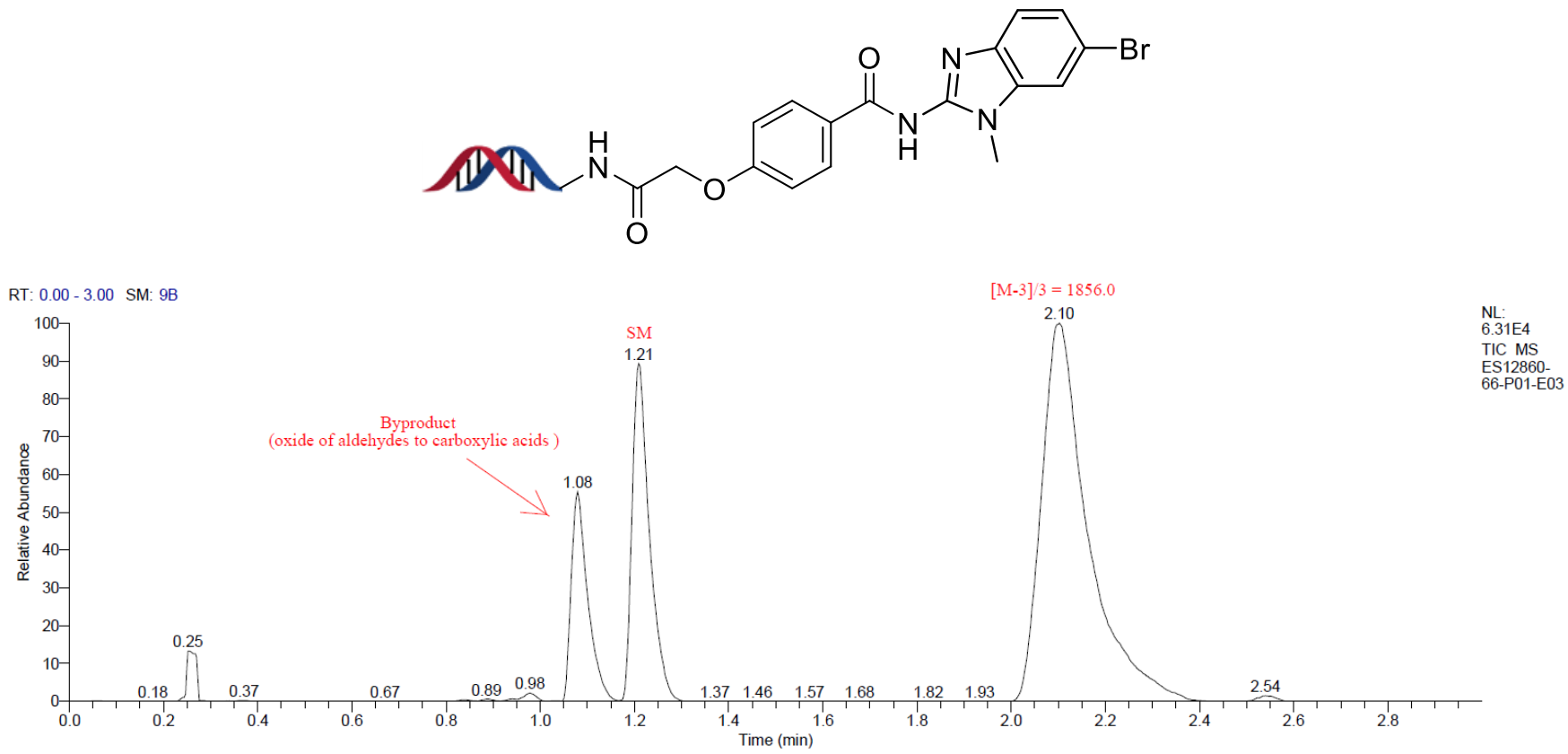

\begin{tabular}{rrrrr} 
RT & Peak Height & Peak Width & Peak Area & Area \% \\
\hline 0.98 & 1478.83 & 0.06 & 2459.04 & 0.37 \\
1.08 & 39674.60 & 0.12 & 85288.23 & 12.87 \\
1.21 & 63026.84 & 0.15 & 144367.62 & 21.79 \\
2.10 & 65277.70 & 0.35 & 428615.90 & 64.70 \\
2.54 & 1076.53 & 0.07 & 1722.56 & 0.26
\end{tabular}

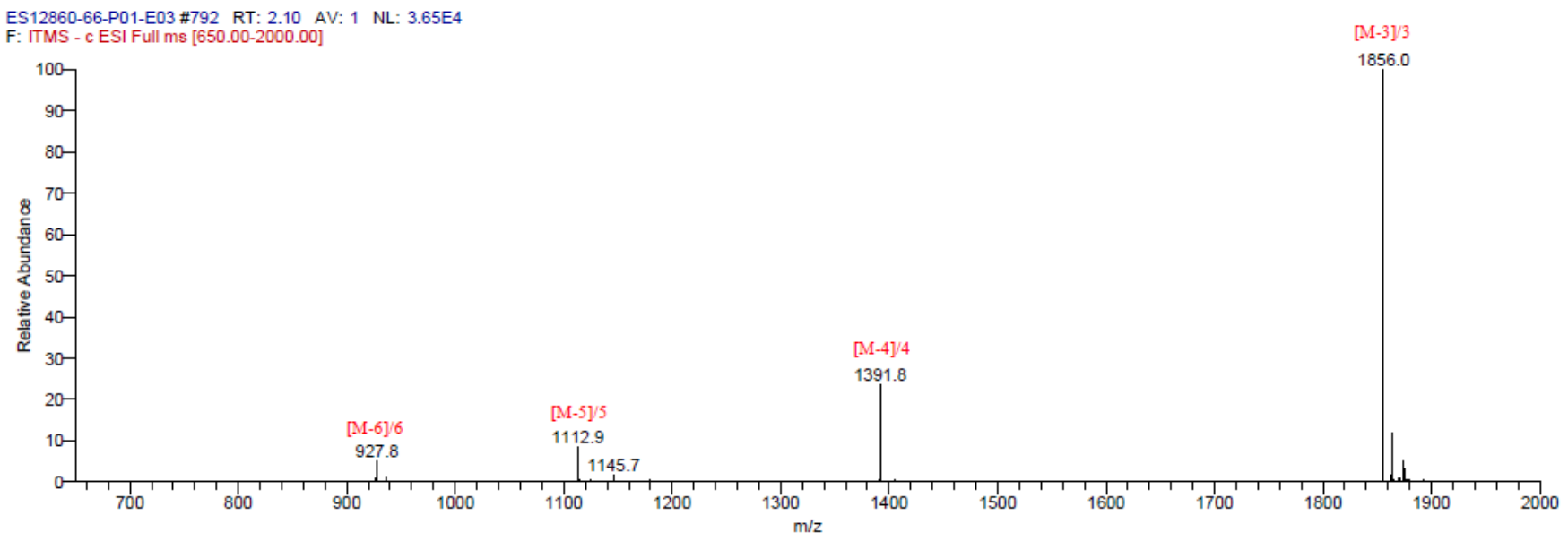

Figure S35. LC trace and mass of $\mathbf{4 q}$ 


\section{SI-6-33 LC Trace and Mass of 4r}

Following General Procedure 3

Yield: $46.72 \%$

Exact mass: 5557.68

Triply charged mass [M-3]/3, calculated: 1851.6; observed: 1851.7.
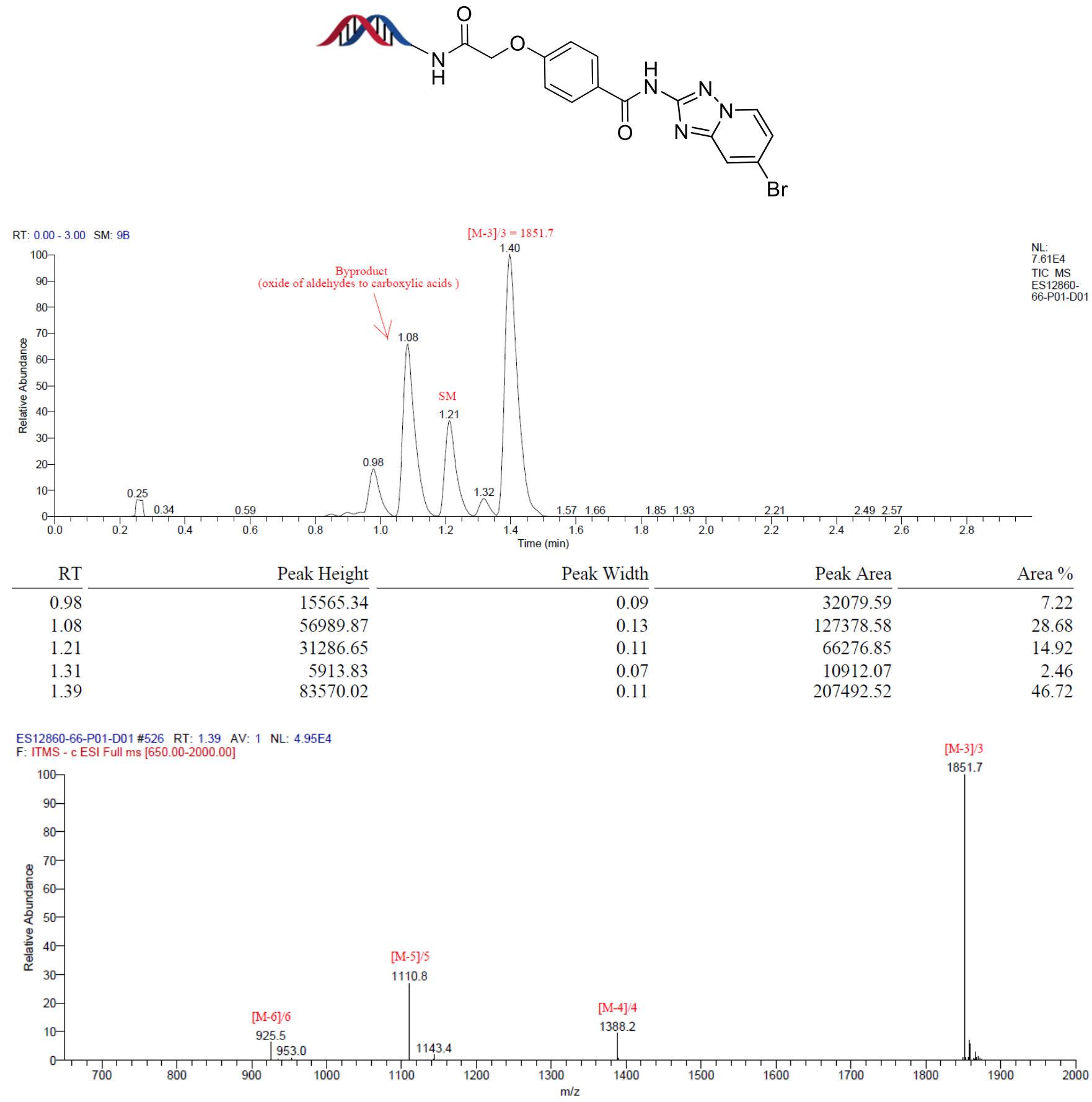

Figure S36. LC trace and mass of $\mathbf{4 r}$ 


\section{SI-6-34 LC Trace and Mass of 1q}

Following General Procedure 2

Yield: $89.23 \%$

Exact mass: 5282.6

Triply charged mass [M-3]/3, calculated: 1759.9; observed: 1760.3.
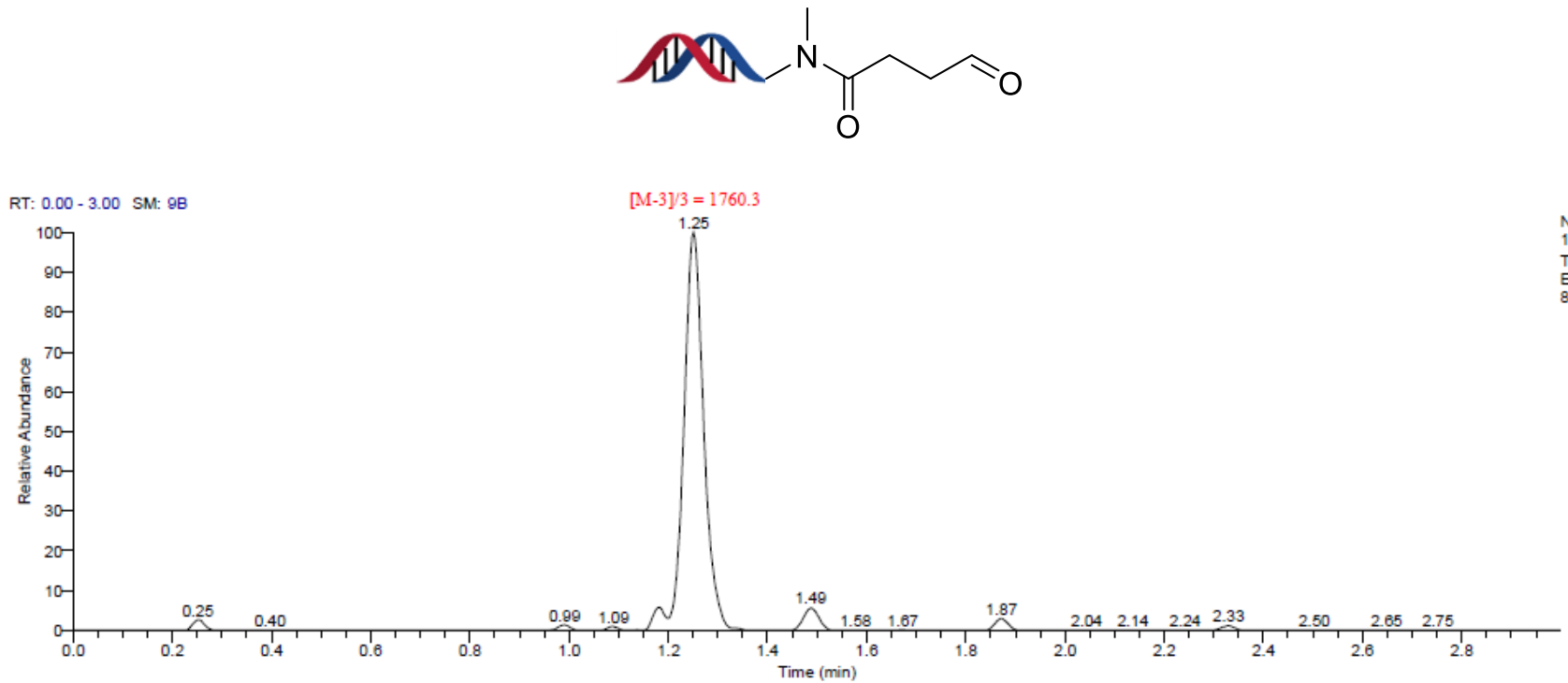

\begin{tabular}{|c|c|c|c|c|}
\hline $\mathrm{RT}$ & Peak Height & Peak Width & Peak Area & Area \% \\
\hline 0.99 & 2160.43 & 0.06 & 2926.72 & 0.79 \\
\hline 1.18 & 8457.62 & 0.05 & 12363.54 & 3.34 \\
\hline 1.25 & 130655.03 & 0.12 & 330500.90 & 89.23 \\
\hline 1.49 & 7485.38 & 0.09 & 15005.53 & 4.05 \\
\hline 1.87 & 4083.14 & 0.07 & 6772.30 & 1.83 \\
\hline 2.33 & 1655.51 & 0.08 & 2841.94 & 0.77 \\
\hline
\end{tabular}

ES12860-82-P1 \#472 RT: 1.25 AV: 1 NL: $5.32 E 4$

F: ITMS - c ESI Full ms [650.00-2000.00]

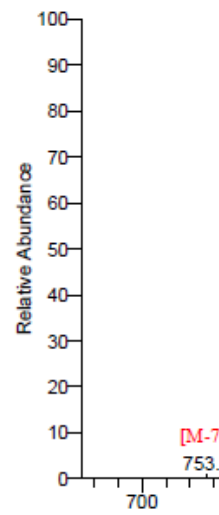

1655.51

08

6772.30

1.83
0.77

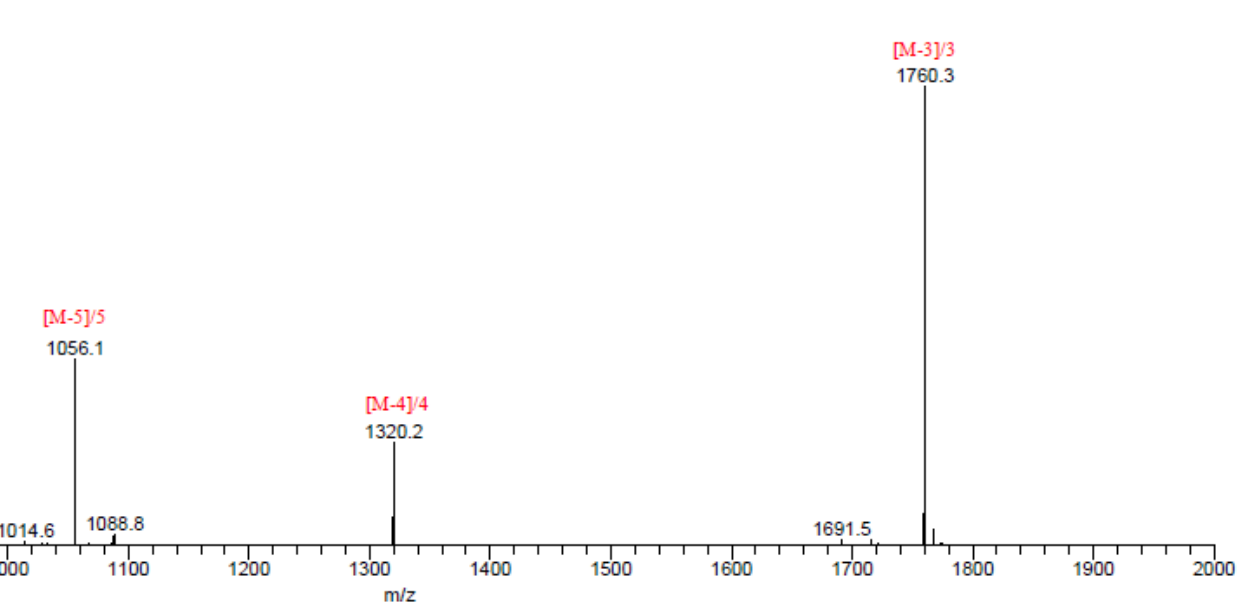

Figure S37. LC trace and mass of 1q 


\section{SI-6-35 LC Trace and Mass of 5a}

Following General Procedure 3

Yield: $55.91 \%$

Exact mass: 5374.67

Triply charged mass [M-3]/3, calculated: 1790.6; observed: 1790.9.
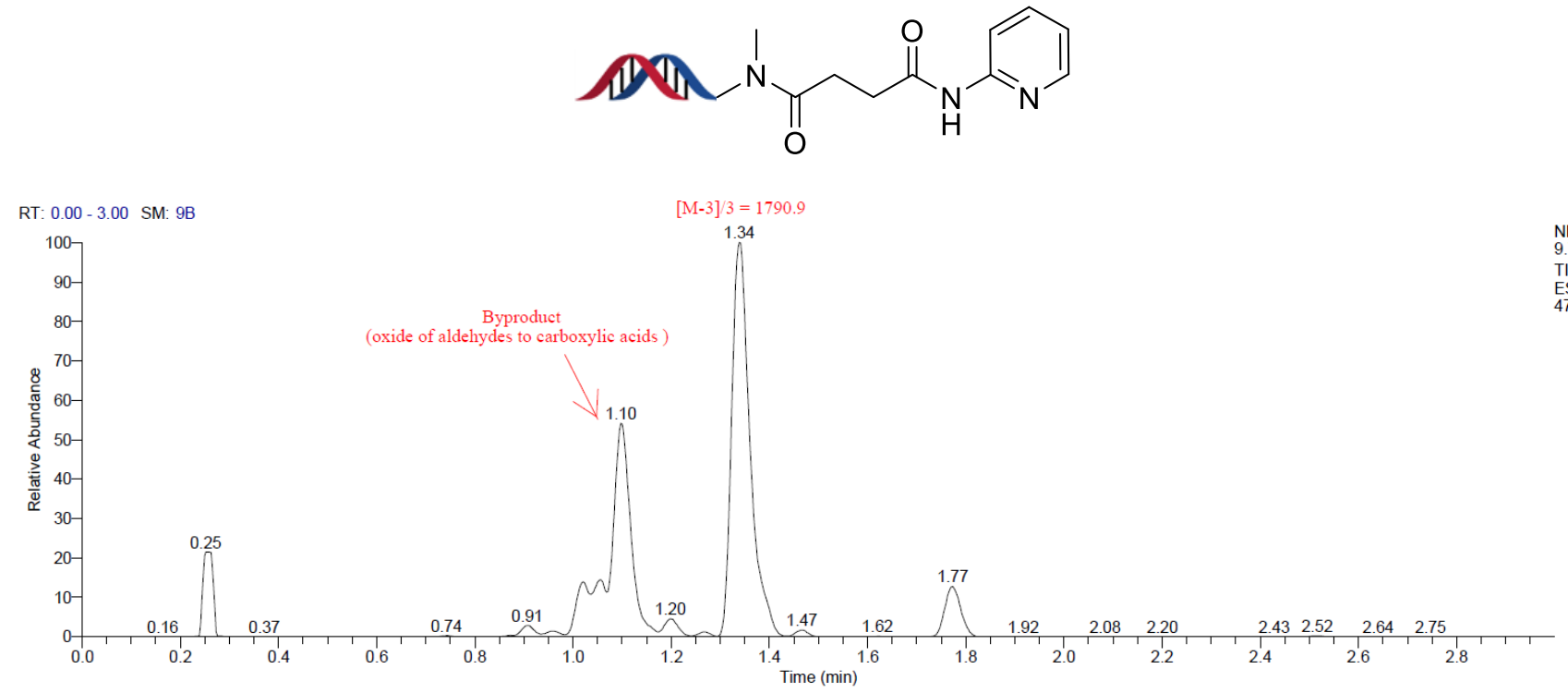

\begin{tabular}{|c|c|c|c|c|}
\hline RT & Peak Height & Peak Width & Peak Area & Area \% \\
\hline 1.02 & 14919.50 & 0.05 & 26832.58 & 5.89 \\
\hline 1.06 & 16468.79 & 0.03 & 25657.35 & 5.63 \\
\hline 1.10 & 59022.27 & 0.07 & 120156.47 & 26.38 \\
\hline 1.34 & 109101.65 & 0.14 & 254680.86 & 55.91 \\
\hline 1.77 & 13800.03 & 0.11 & 28230.09 & 6.20 \\
\hline
\end{tabular}

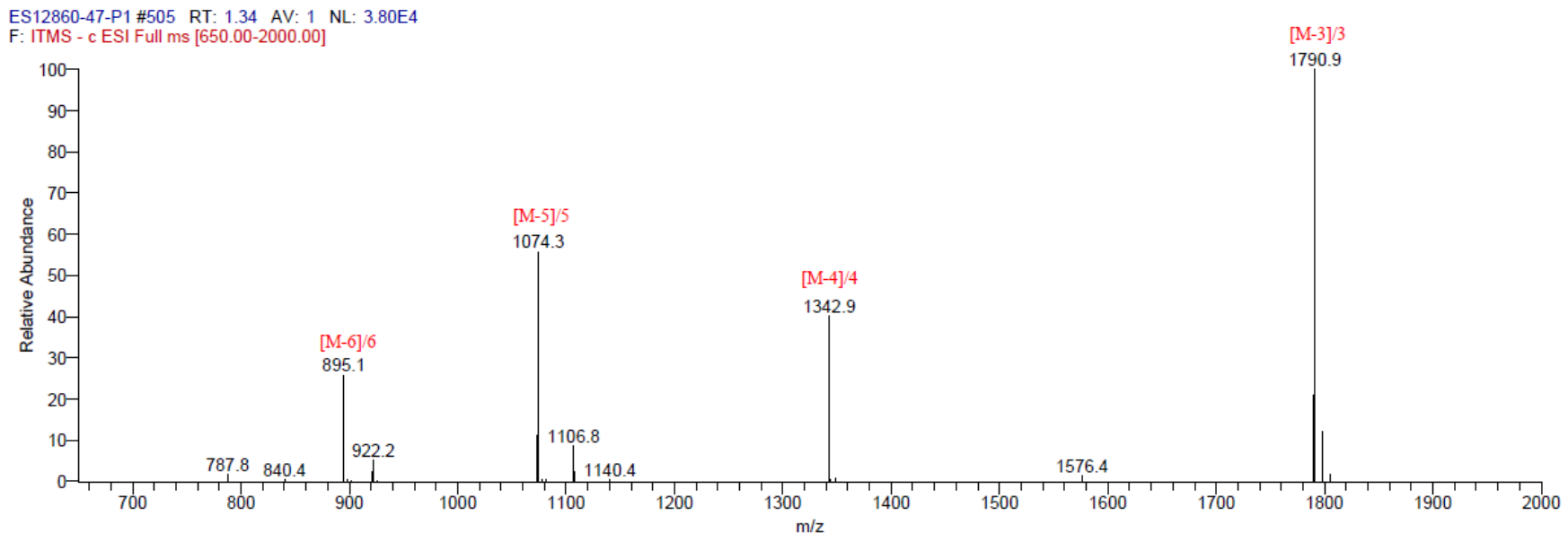

Figure S38. LC trace and mass of $\mathbf{5 a}$ 


\section{SI-6-36 LC Trace and Mass of 5p}

Following General Procedure 3

Yield: $80.97 \%$

Exact mass: 5532.69

Triply charged mass [M-3]/3, calculated: 1843.2; observed: 1843.9.
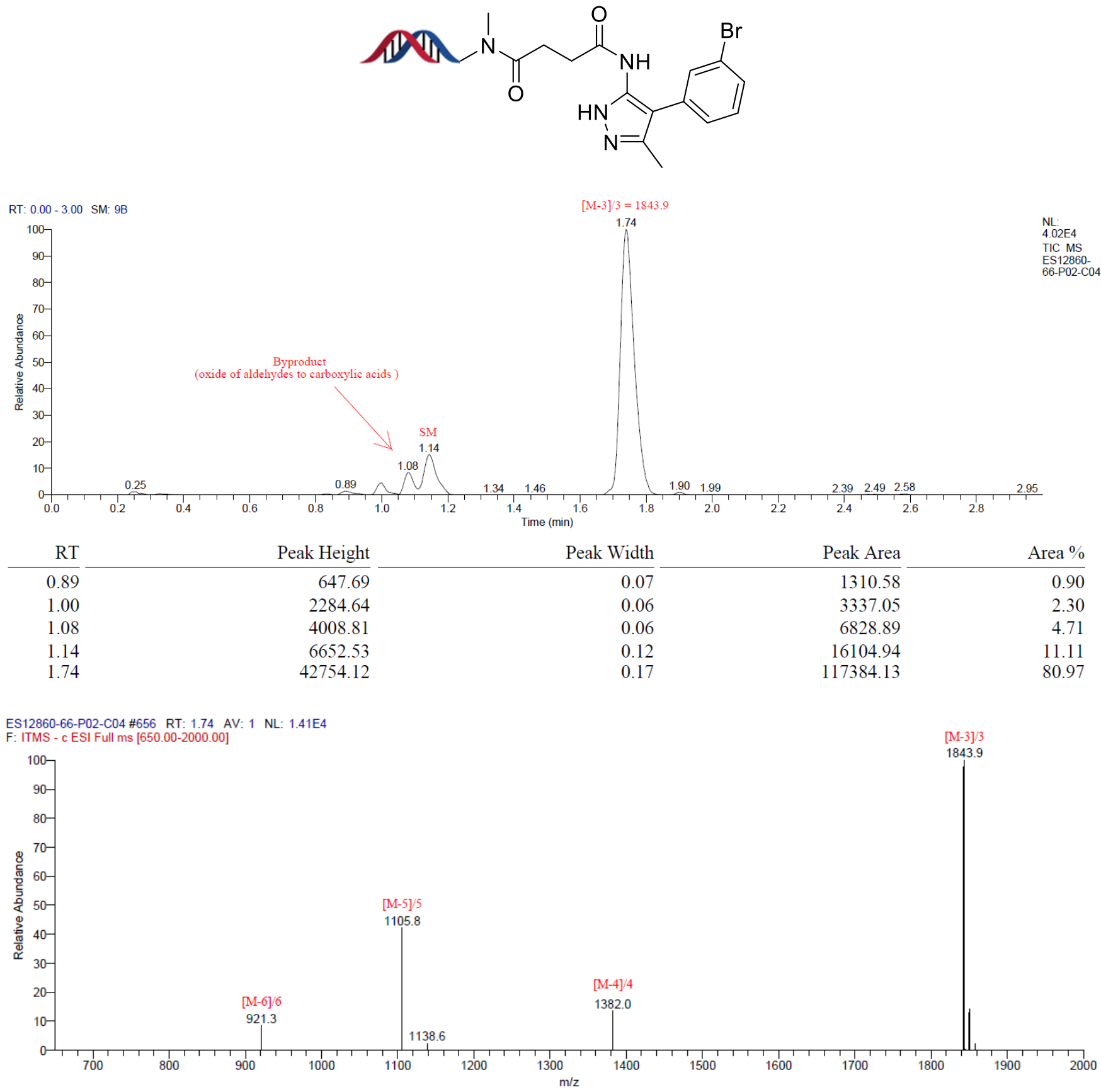

Figure S39. LC trace and mass of $\mathbf{5 p}$ 


\section{SI-6-37 LC Trace and Mass of 5q}

Following General Procedure 3

Yield: $59.97 \%$

Exact mass: 5506.65

Triply charged mass [M-3]/3, calculated: 1834.6; observed: 1834.6.<smiles>CN(C[C@@H]1CC[C@H]2CC[C@H]1C2)C(=O)CCC(=O)Nc1nc2ccc(Br)cc2n1C</smiles>
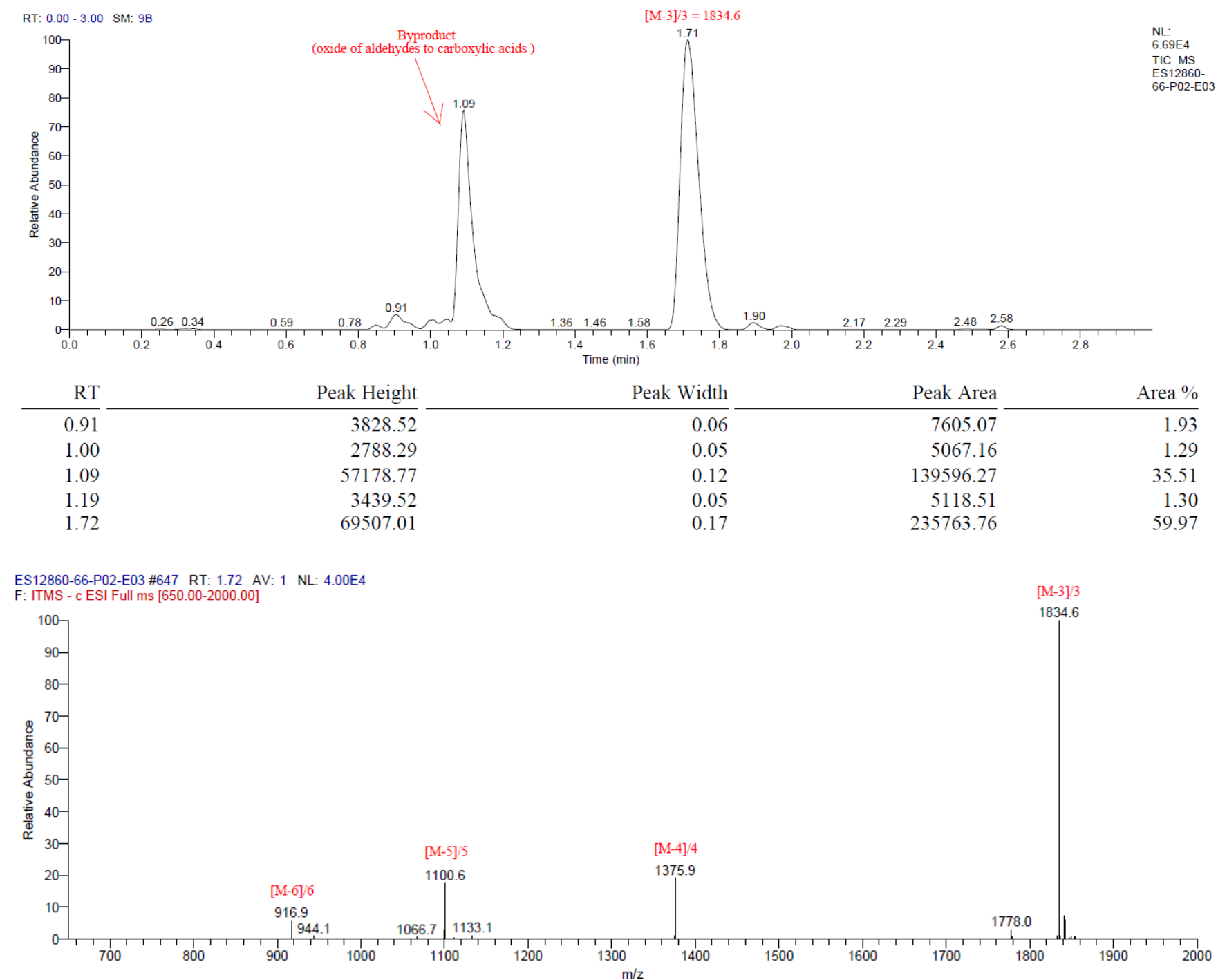

Figure S40. LC trace and mass of $\mathbf{5 q}$ 


\section{SI-6-38 LC Trace and Mass of 5s}

Following General Procedure 3

Yield: $54.07 \%$

Exact mass: 5520.67

Triply charged mass [M-3]/3, calculated: 1839.2; observed: 1839.9.<smiles>CCn1c(NC(=O)CCC(=O)N(C)CN2C3CC[C@H]2C3)nc2ccc(Br)cc21</smiles>

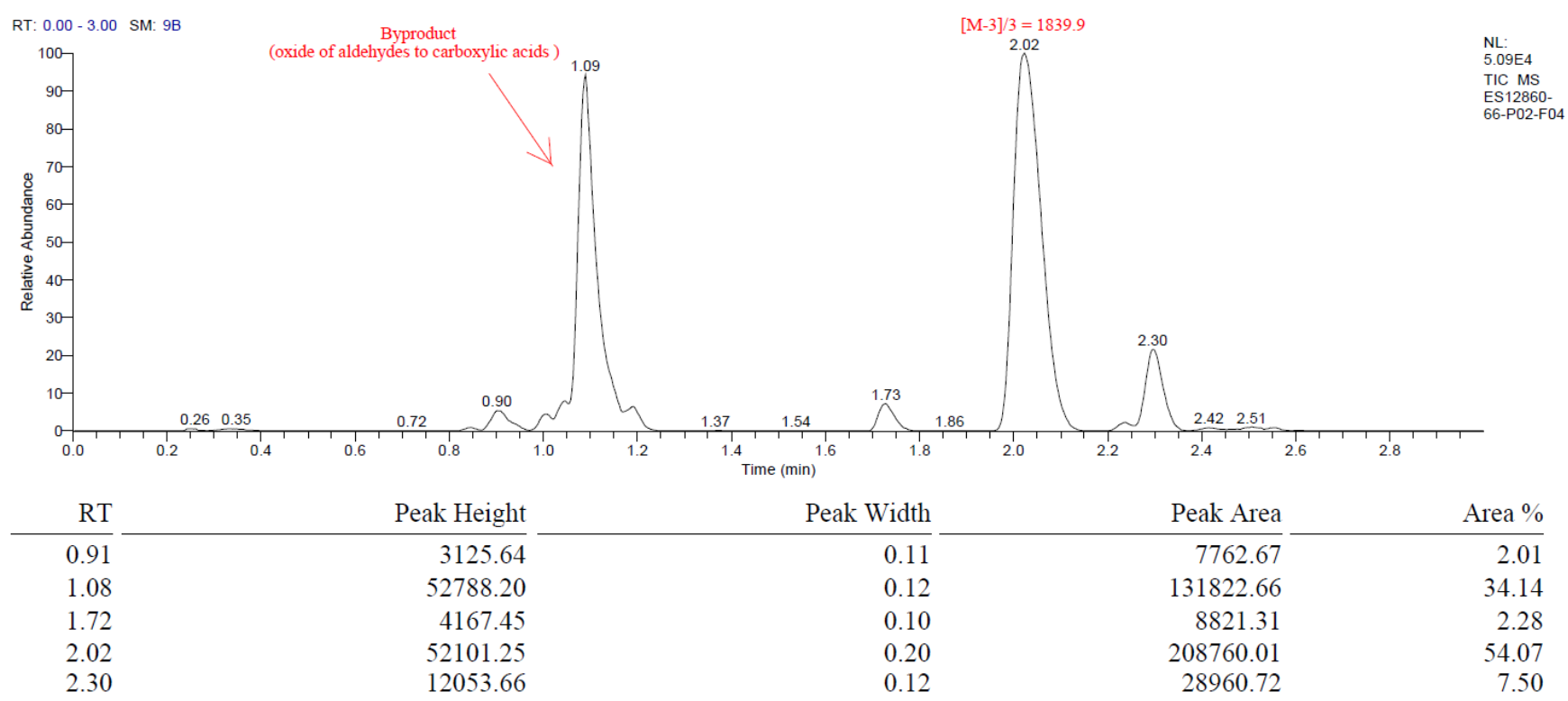

ES12860-66-P02-F04 \#763 RT: 2.02 AV: 1 NL: $1.30 E 4$

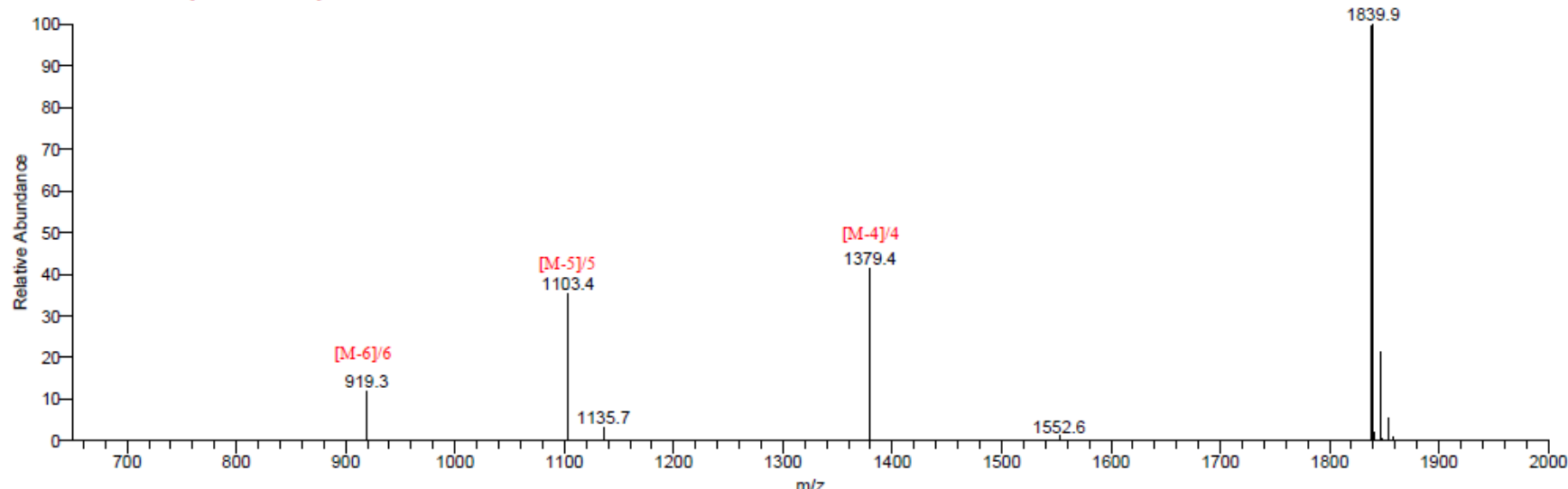

Figure S41. LC trace and mass of $5 \mathrm{~s}$ 


\section{SI-6-39 LC Trace and Mass of 5t}

Following General Procedure 3

Yield: $53.04 \%$

Exact mass: 5456.59

Triply charged mass [M-3]/3, calculated: 1817.9; observed: 1818.0.
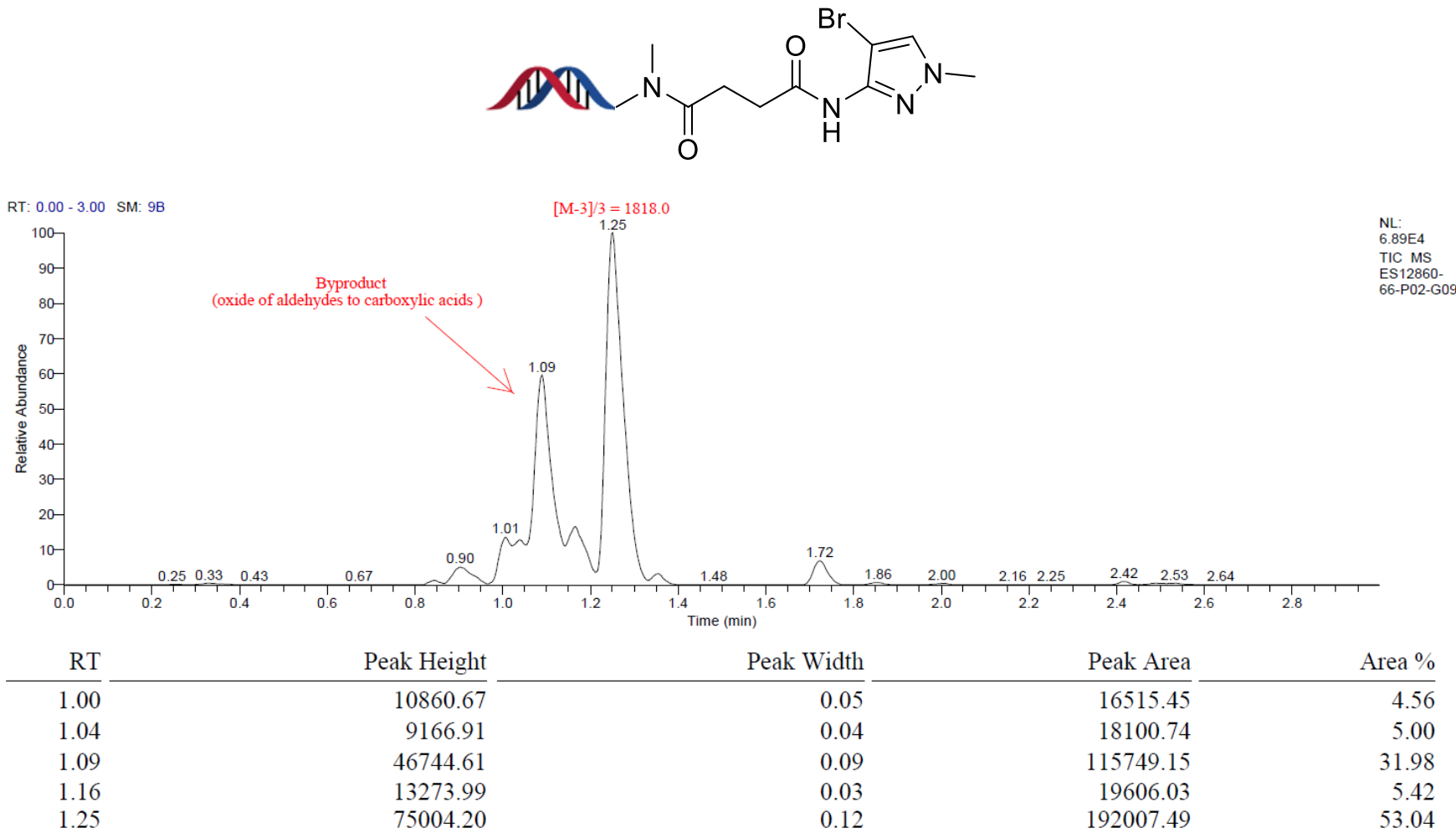

ES12860-66-P02-G09 \#470 RT: 1.25 AV: 1 NL: $4.53 E 4$

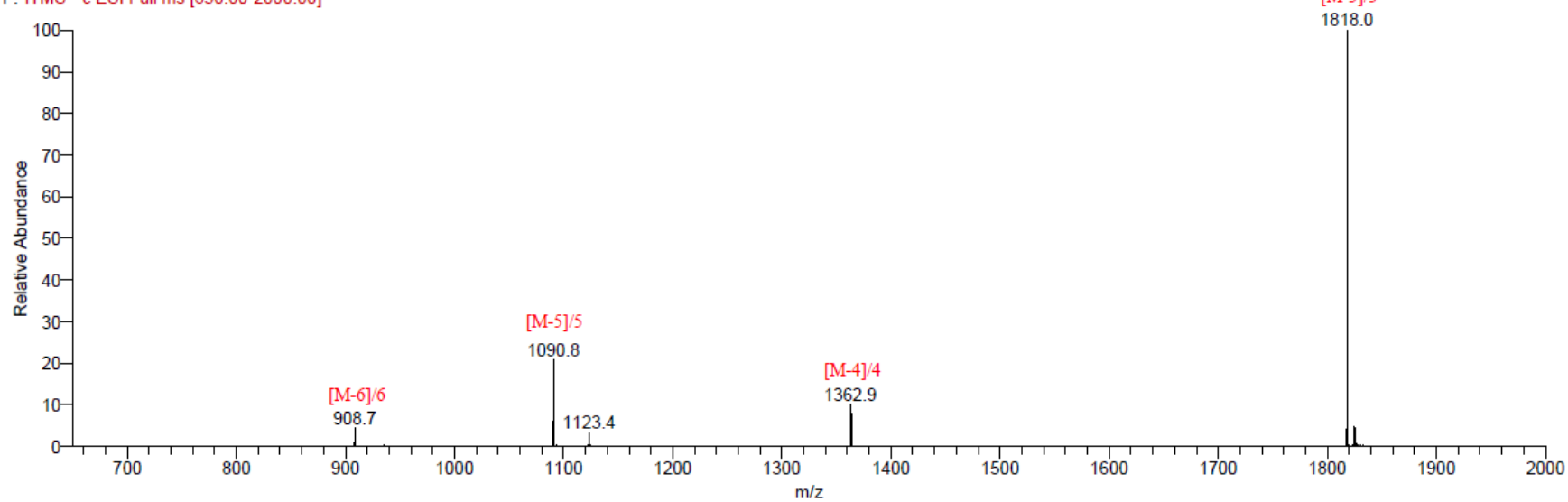

Figure $\mathbf{S 4 2}$. LC trace and mass of $\mathbf{5 t}$ 


\section{SI-6-40 LC Trace and Mass of 5u}

Following General Procedure 3

Yield: $42.77 \%$

Exact mass: 5492.62

Triply charged mass [M-3]/3, calculated: 1829.87; observed: 1830.2.<smiles>CN(C[C@@H]1CC[C@H]2CC[C@H]1C2)C(=O)CCC(=O)Nc1nc2c(Br)cccc2[nH]1</smiles>
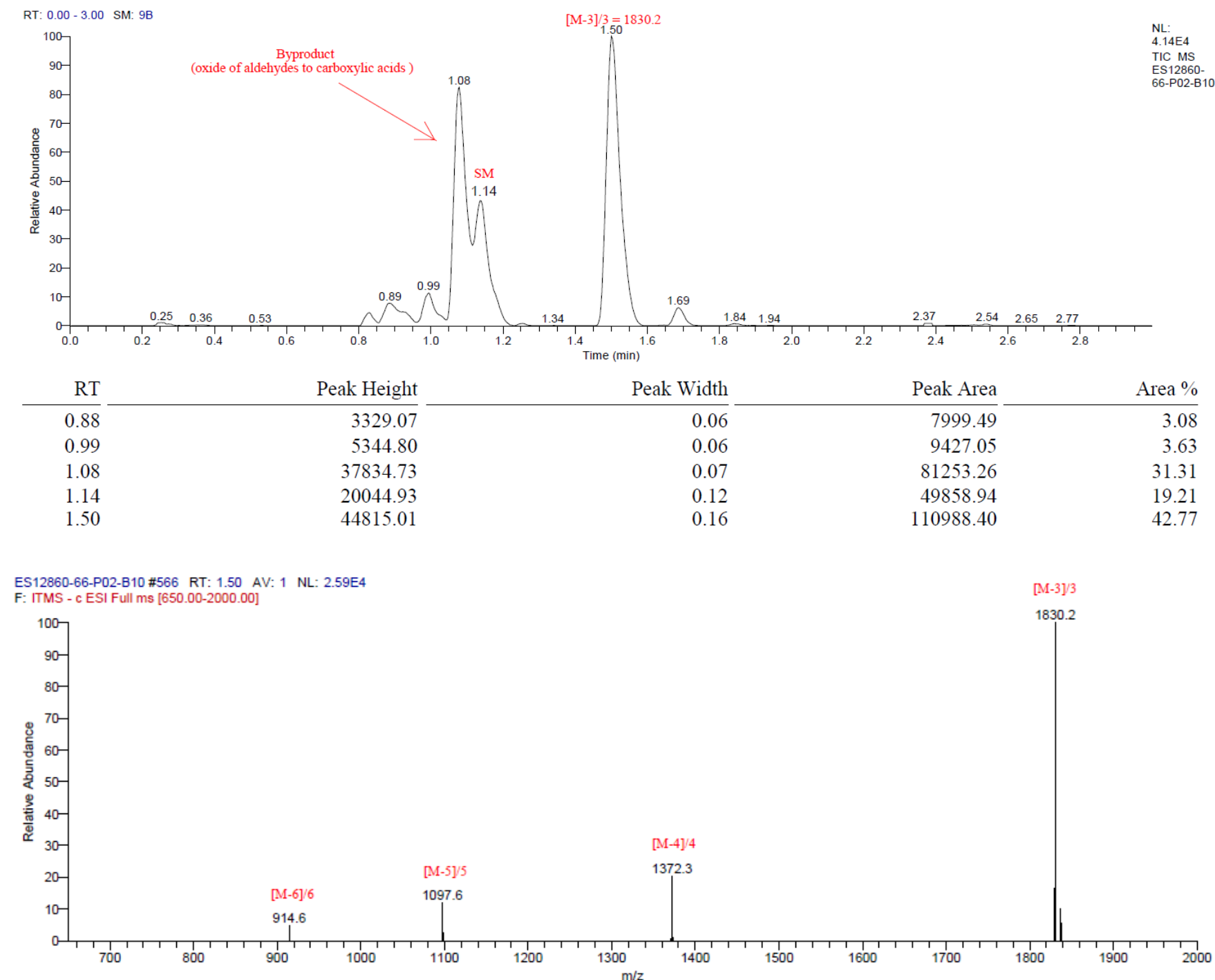

Figure S43. LC trace and mass of $\mathbf{5 u}$ 


\section{SI-6-41 LC Trace and Mass of 5v}

Following General Procedure 3

Yield: $38.71 \%$

Exact mass: 5539.62

Triply charged mass [M-3]/3, calculated: 1845.5; observed: 1845.6.
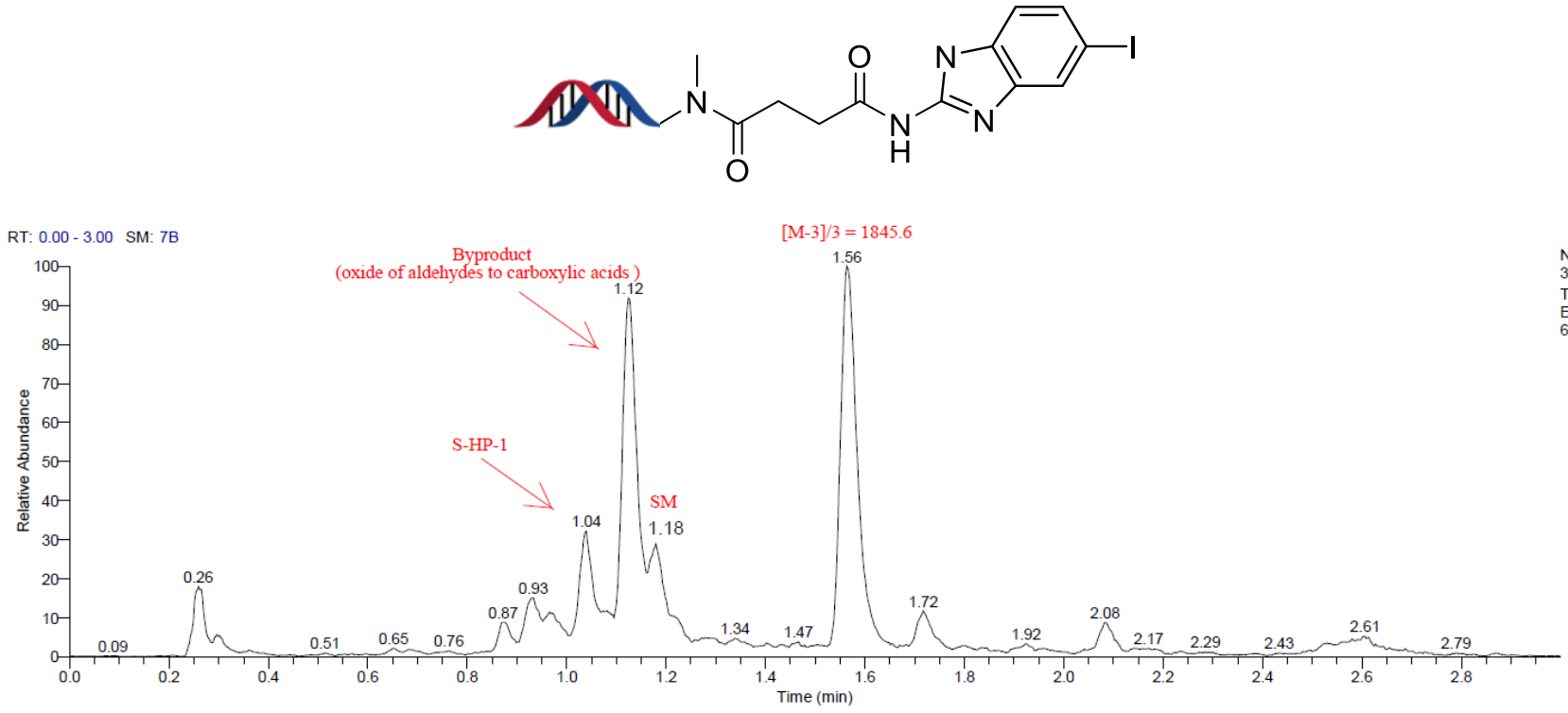

\begin{tabular}{rrrrr} 
RT & Peak Height & Peak Width & Peak Area & Area \% \\
\cline { 5 - 5 } \cline { 3 - 5 } & 4277.40 & 0.11 & 15650.07 & 8.09 \\
1.04 & 9776.77 & 0.09 & 23171.79 & 11.97 \\
1.12 & 29721.31 & 0.07 & 60198.20 \\
1.18 & 8672.55 & 0.11 & 19586.39 \\
1.56 & 32017.25 & 0.25 & 74922.09 & 31.11
\end{tabular}

ES12860-69-P02-E03 \#590 RT: 1.56 AV: 1 NL: $1.72 E 4$

F: ITMS - c ESI Full ms [650.00-2000.00]
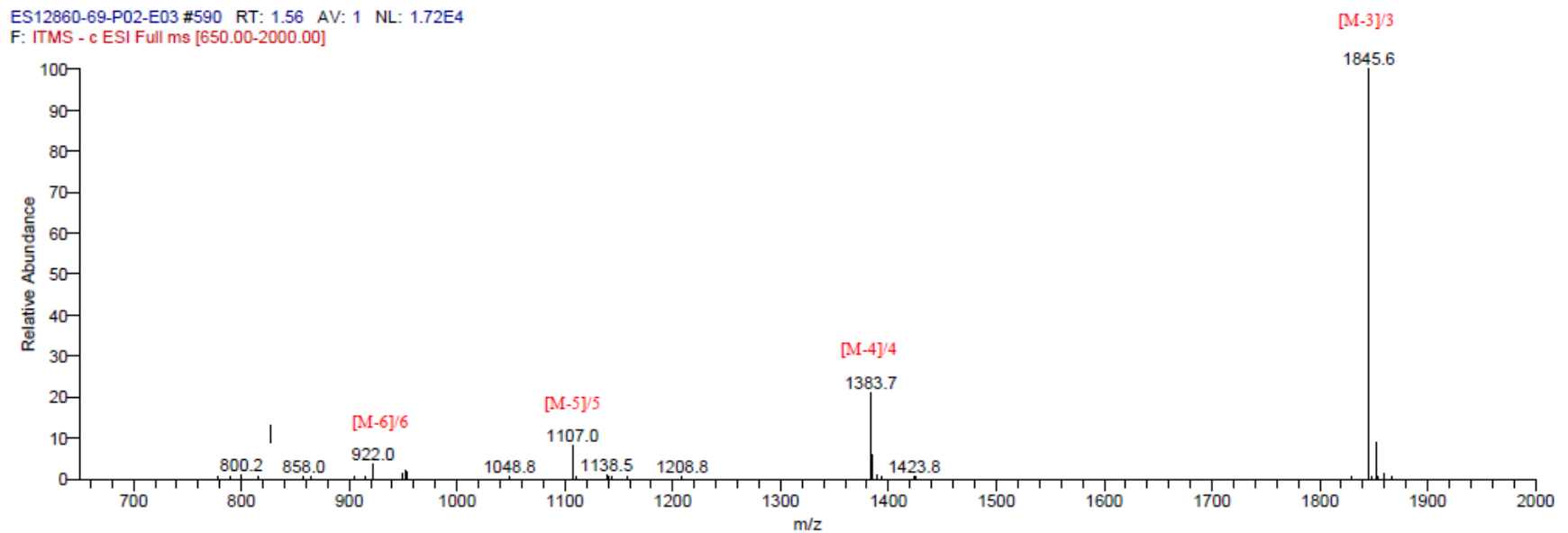

Figure S44. LC trace and mass of $5 v$ 


\section{SI-6-42 LC Trace and Mass of 5w}

Following General Procedure 3

Yield: $34.93 \%$

Exact mass: 5493.6

Triply charged mass [M-3]/3, calculated: 1830.2; observed: 1829.9.
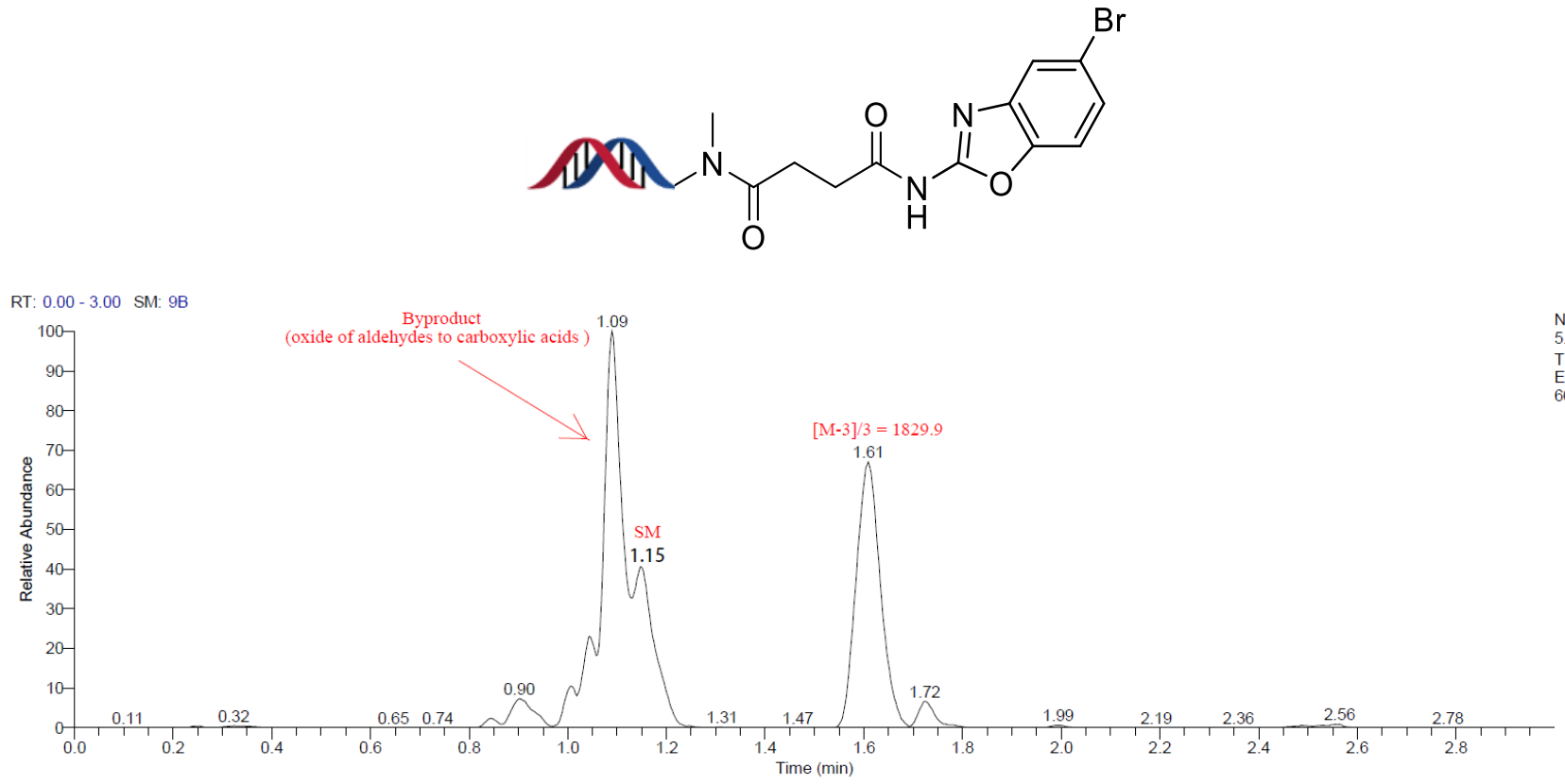

\begin{tabular}{|c|c|c|c|c|}
\hline RT & Peak Height & Peak Width & Peak Area & Area \% \\
\hline 1.00 & 6713.67 & 0.05 & 10073.12 & 2.85 \\
\hline 1.04 & 13595.09 & 0.04 & 22115.58 & 6.25 \\
\hline 1.09 & 60252.92 & 0.07 & 132844.42 & 37.56 \\
\hline 1.15 & 23591.89 & 0.12 & 65113.73 & 18.41 \\
\hline 1.61 & 38158.99 & 0.15 & 123520.62 & 34.93 \\
\hline
\end{tabular}

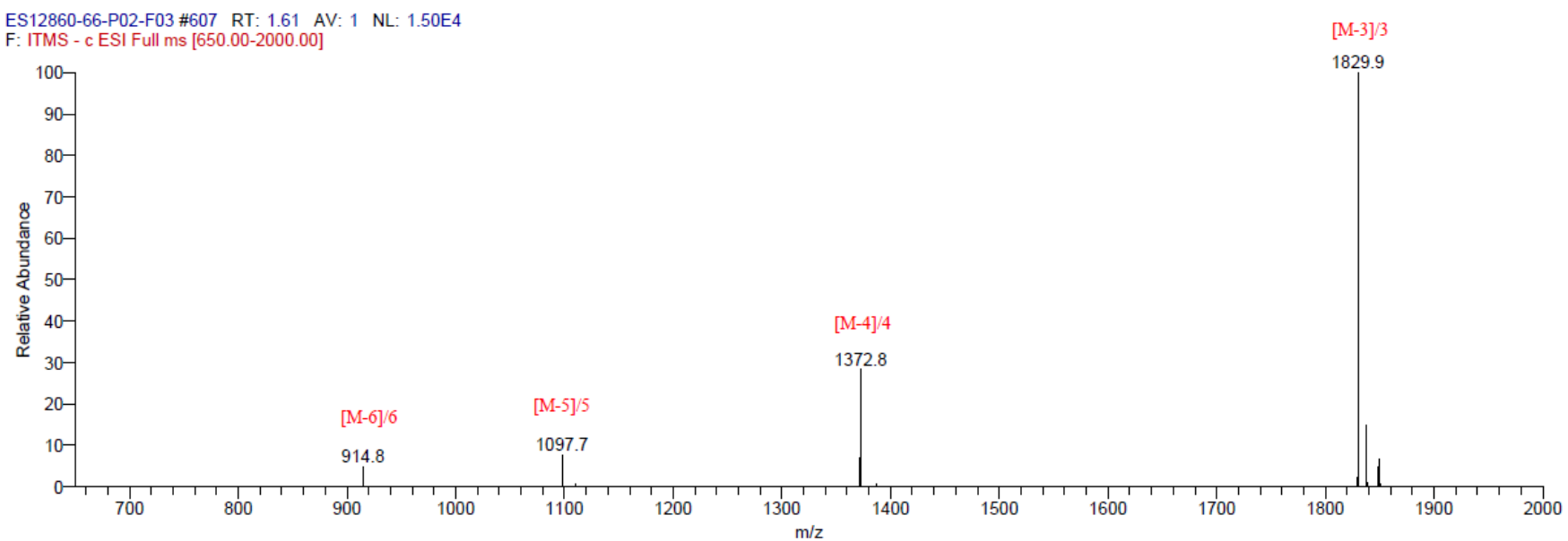

Figure S45. LC trace and mass of $\mathbf{5 w}$ 


\section{SI-6-43 LC Trace and Mass of 5x}

Following General Procedure 3

Yield: $32.22 \%$

Exact mass: 5483.61

Triply charged mass [M-3]/3, calculated: 1826.8; observed: 1826.2.<smiles>COc1cc(Br)cnc1NC(=O)CCC(=O)N(C)CN1C2CCC1C2</smiles>

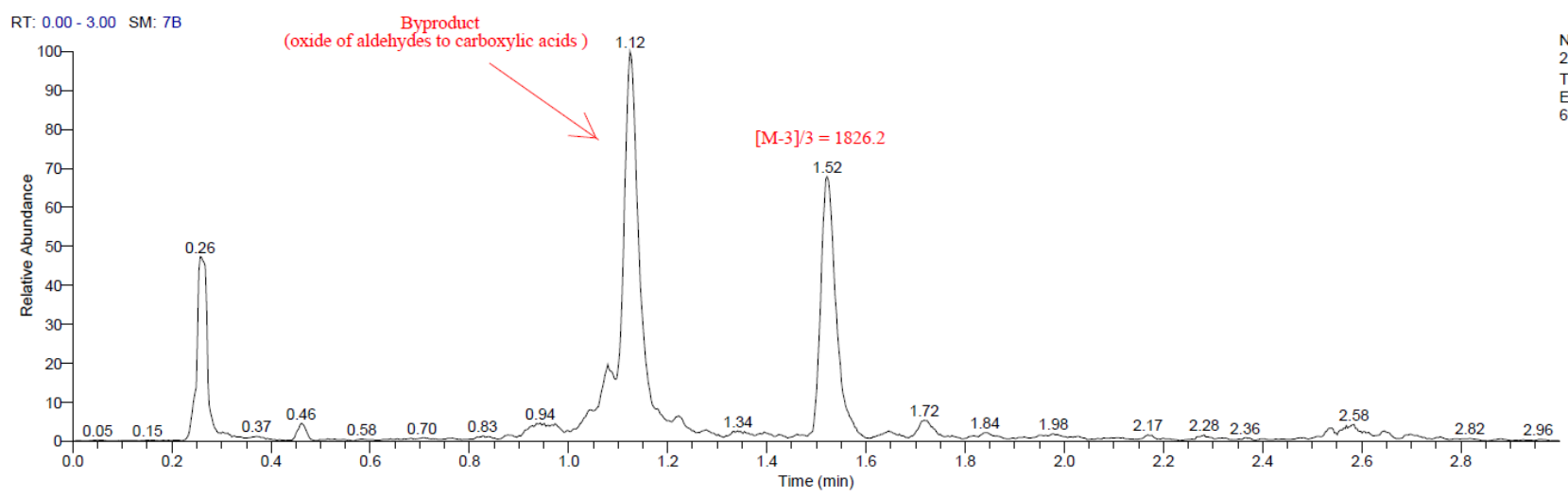

\begin{tabular}{rrrrr} 
RT & Peak Height & Peak Width & Peak Area & Area \% \\
\hline 0.94 & 1054.67 & 0.13 & 4661.33 & 3.84 \\
1.12 & 28426.36 & 0.20 & 71614.87 & 59.06 \\
1.52 & 19746.94 & 0.15 & 39069.16 & 32.22 \\
1.72 & 1454.67 & 0.11 & 2979.86 & 2.46 \\
2.58 & 1172.44 & 0.08 & 2940.09 & 2.42
\end{tabular}

ES12860-69-P02-G05 \#574 RT: 1.52 AV: 1 NL: 5.65E3

F: ITMS - c ESI Full ms [650.00-2000.00]

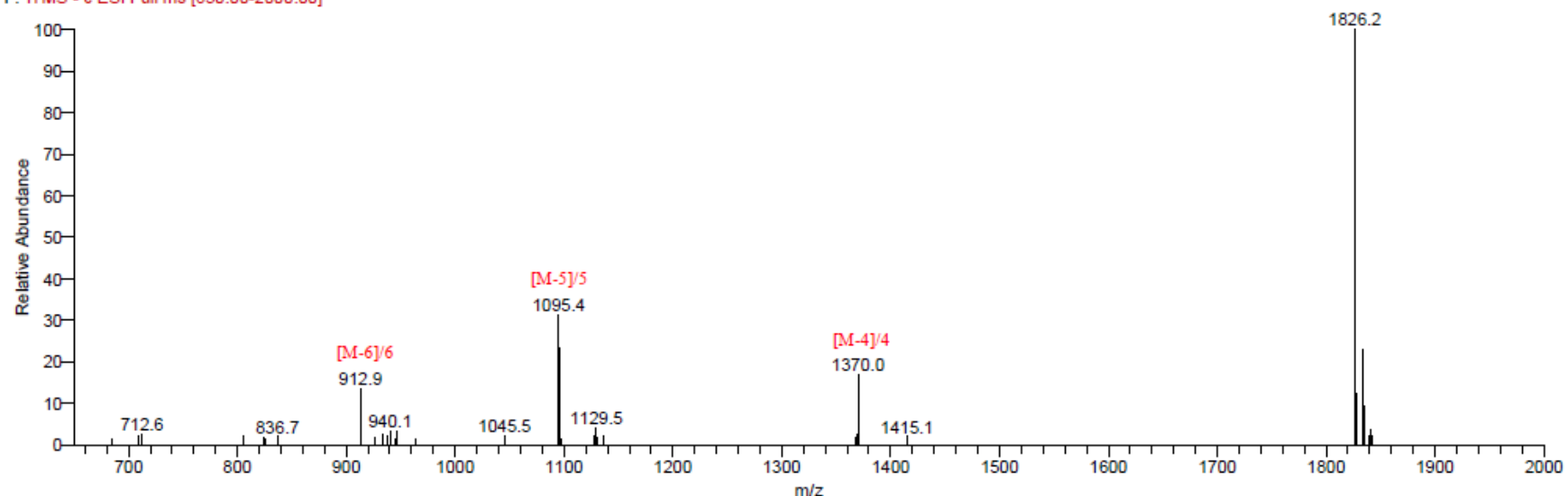

Figure S46. LC trace and mass of $5 x$ 


\section{SI-6-44 LC Trace and Mass of 5y}

Following General Procedure 3

Yield: $43.69 \%$

Exact mass: 5467.61

Triply charged mass [M-3]/3, calculated: 1821.5; observed: 1821.8 .<smiles>Cc1cc(Br)cnc1NC(=O)CCC(=O)N(C)CN1C2CCC1C2</smiles>

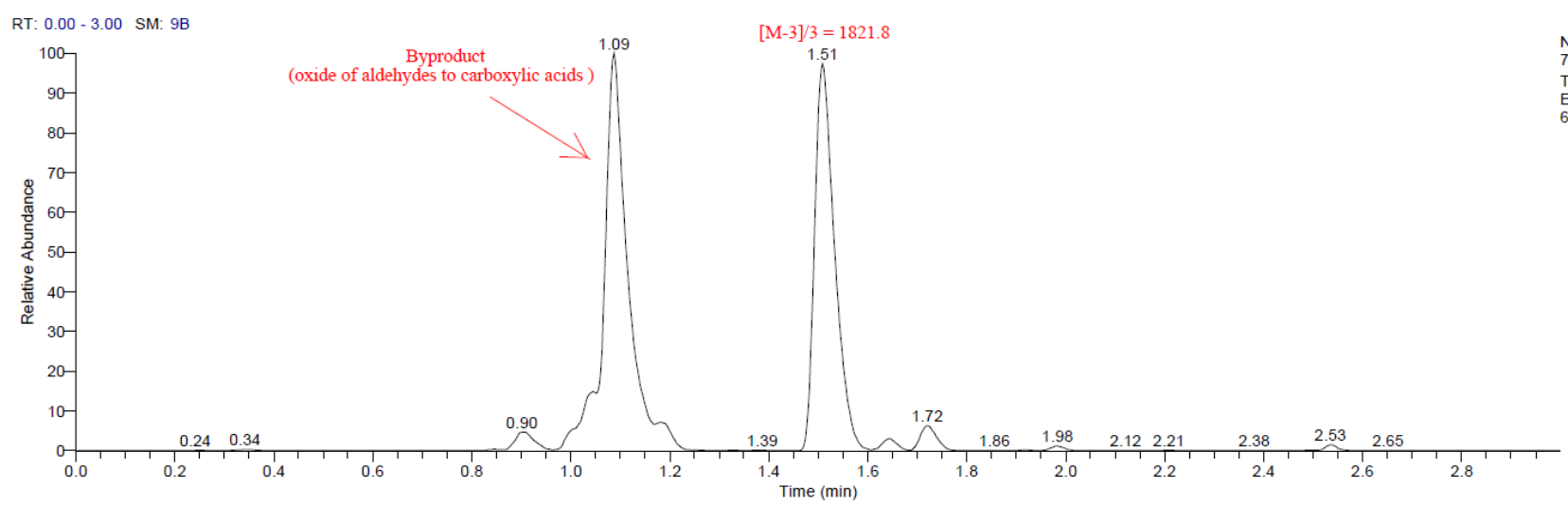

\begin{tabular}{|c|c|c|c|c|}
\hline $\mathrm{RT}$ & Peak Height & Peak Width & Peak Area & Area $\%$ \\
\hline 1.04 & 12289.97 & 0.04 & 21559.32 & 4.59 \\
\hline 1.08 & 82251.20 & 0.12 & 221489.18 & 47.13 \\
\hline 1.19 & 5848.31 & 0.07 & 10520.81 & \\
\hline 1.51 & 78816.03 & 0.15 & 205312.49 & 43.69 \\
\hline 1.72 & 5391.25 & 0.11 & 11086.31 & 2. \\
\hline
\end{tabular}

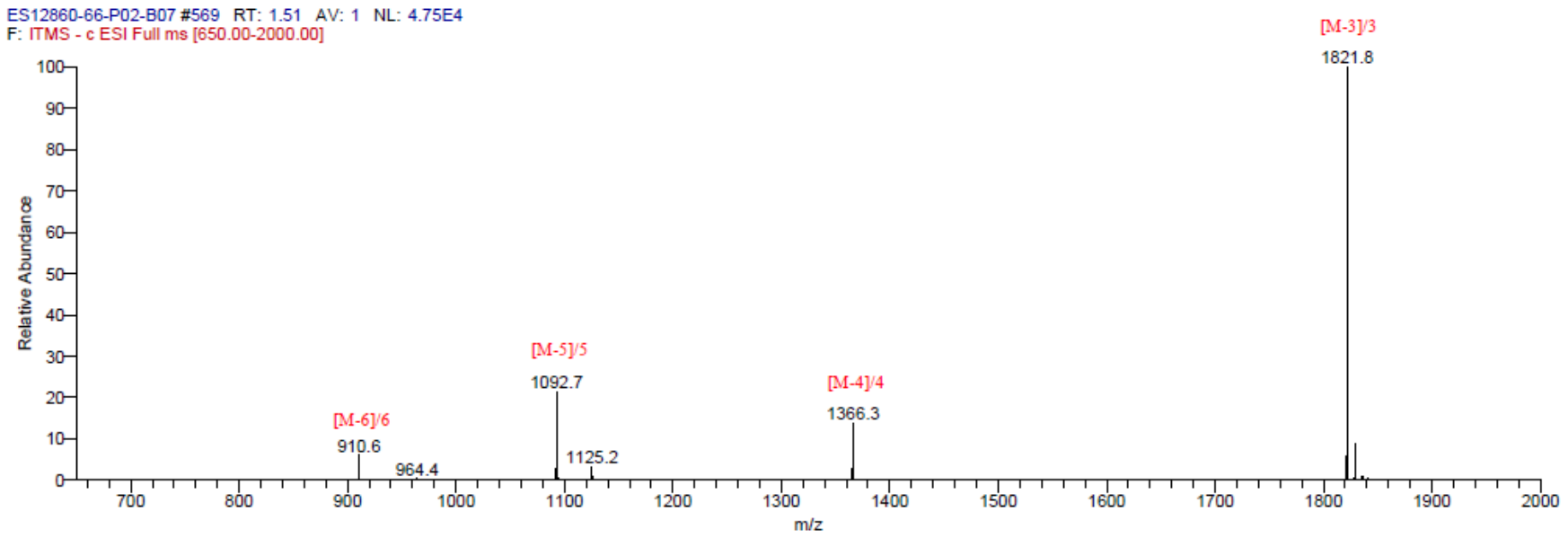

Figure S47. LC trace and mass of $\mathbf{5 y}$ 


\section{SI-6-45 LC Trace and Mass of 5z}

Following General Procedure 3

Yield: $67.24 \%$

Exact mass: 5503.64

Triply charged mass [M-3]/3, calculated: 1833.6; observed: 1833.3.<smiles>CN(CCCC(=O)Nc1cc2c(Br)cccc2cn1)C(=O)CN1CC2CCC1C2</smiles>

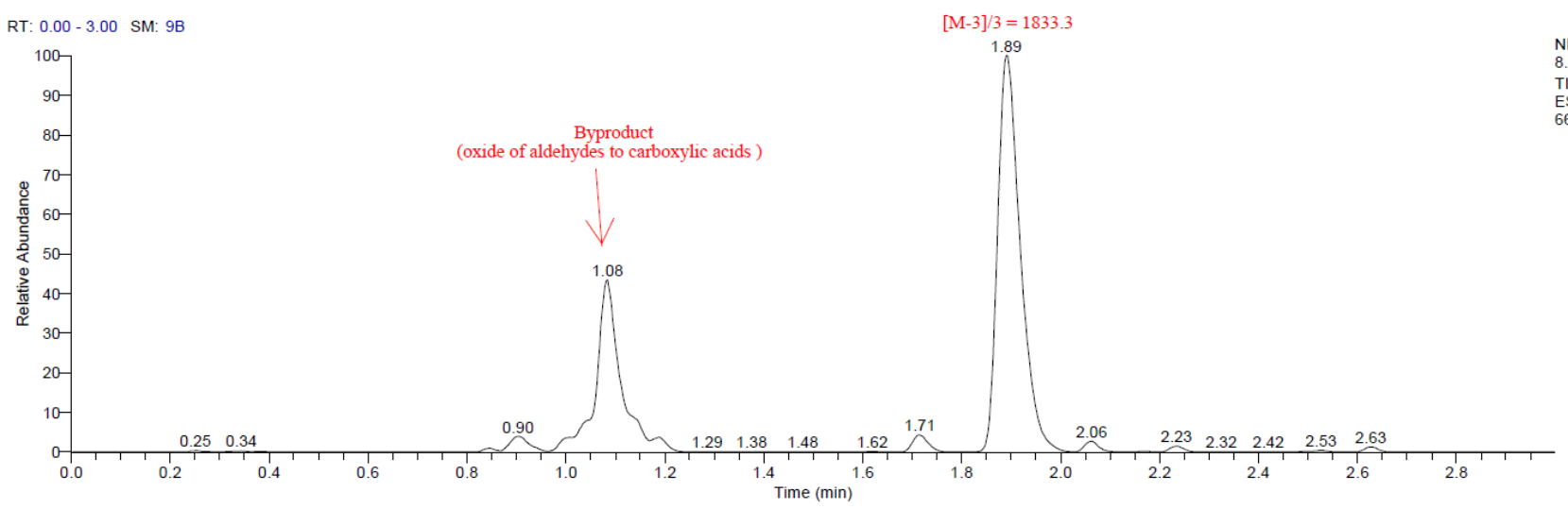

\begin{tabular}{rrrrr} 
RT & Peak Height & Peak Width & Peak Area & Area \% \\
\cline { 2 - 5 } & 3626.73 & 0.10 & 8893.49 & 2.33 \\
1.04 & 7091.04 & 0.04 & 12517.63 & 3.28 \\
1.08 & 38892.69 & 0.08 & 90935.33 & 23.81 \\
1.14 & 7854.61 & 0.04 & 12800.79 & 3.35 \\
1.89 & 84721.24 & 0.21 & 256828.92 & 67.24
\end{tabular}

ES12860-66-P02-B08 \#713 RT: 1.89 AV: 1 NL: $2.64 E 4$

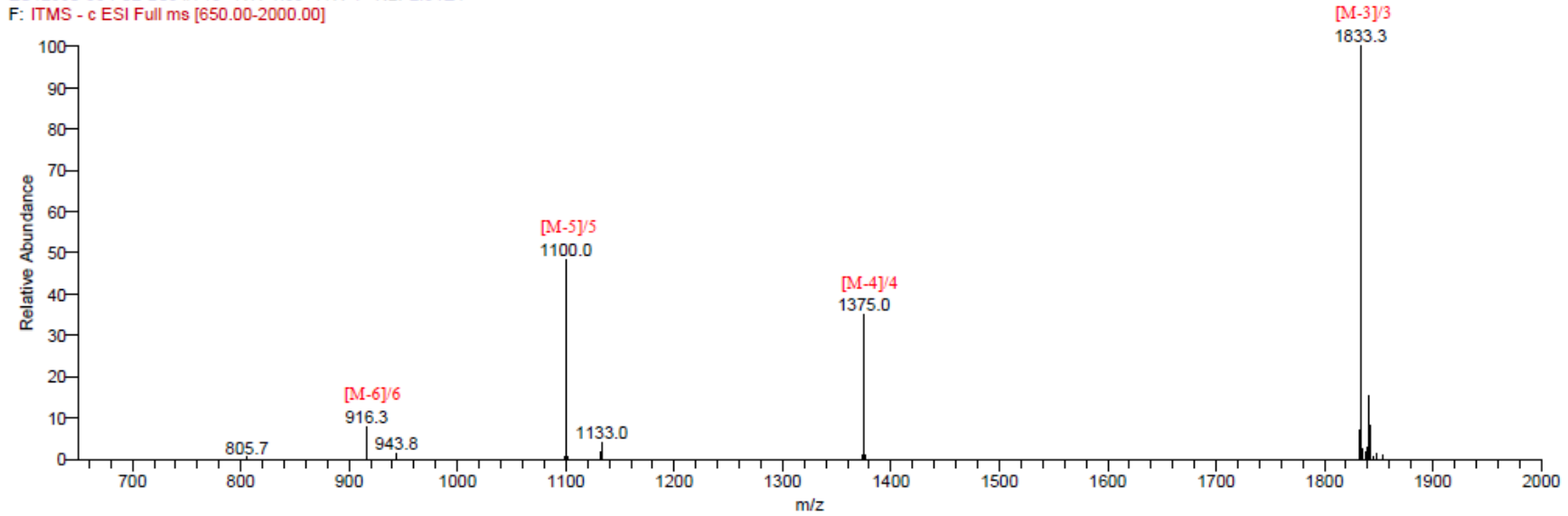

Figure S48. LC trace and mass of $5 z$ 


\section{SI-6-46 LC Trace and Mass of 5aa}

Following General Procedure 3

Yield: $65.03 \%$

Exact mass: 5503.64

Triply charged mass [M-3]/3, calculated: 1833.6; observed: 1833.7.<smiles>CN(CCCC(=O)Nc1cc2cc(Br)ccc2cn1)C(=O)CN1CC2CCC1C2</smiles>

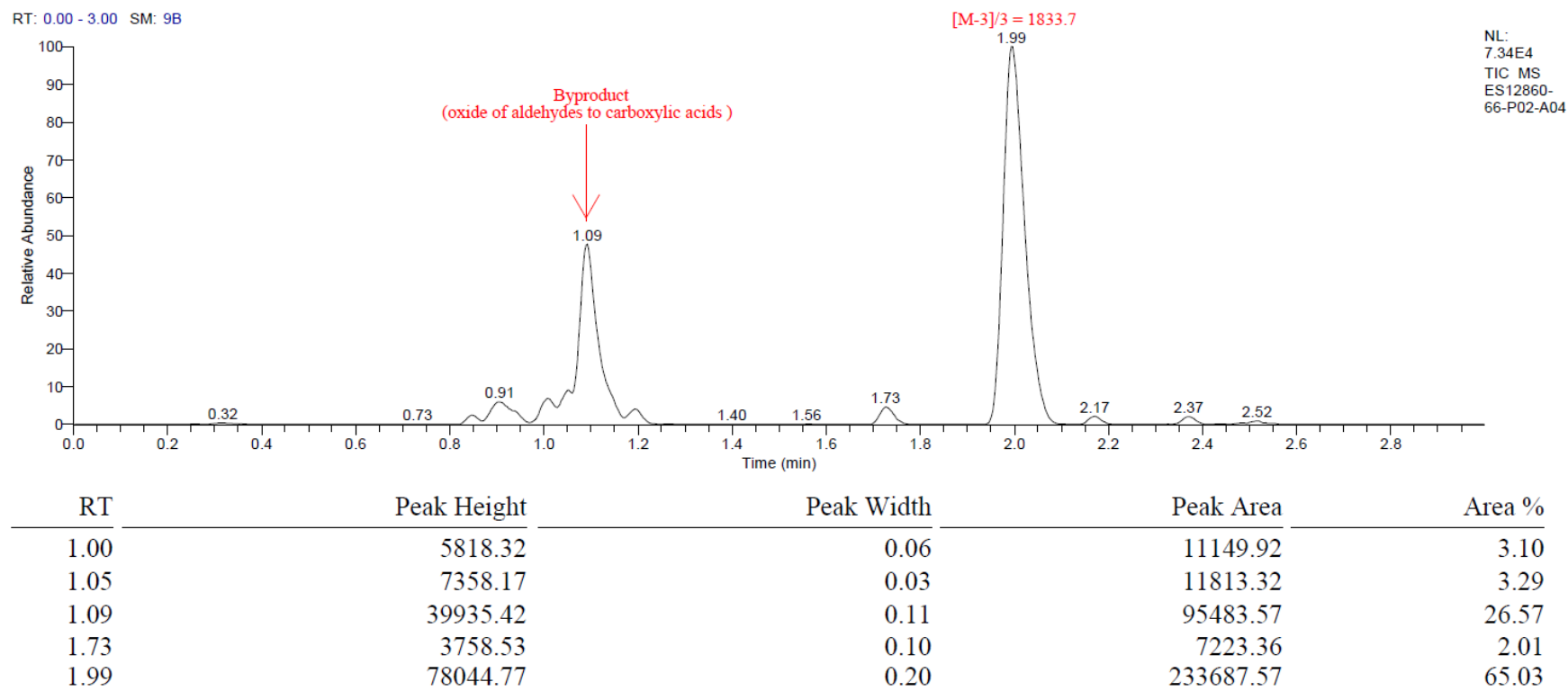

ES12860-66-P02-A04 \#752 RT: 1.99 AV: 1 NL: 4.86E4

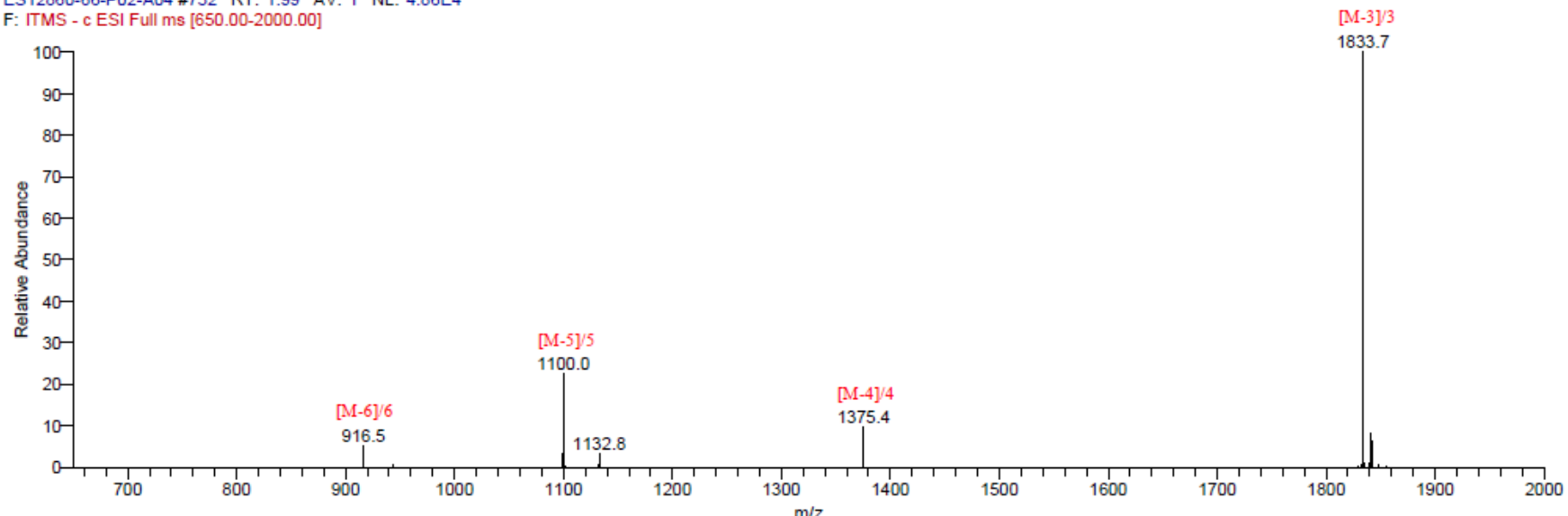

Figure S49. LC trace and mass of 5aa 


\section{SI-6-47 LC Trace and Mass of 9}

Following General Procedure 1

Yield: $89.75 \%$

Exact mass: 5419.69

Triply charged mass [M-3]/3, calculated: 1805.6; observed: 1805.5.<smiles>O=Cc1cc(OCCCC(=O)NCC2CC3CCC2C3)ccc1[N+](=O)[O-]</smiles>

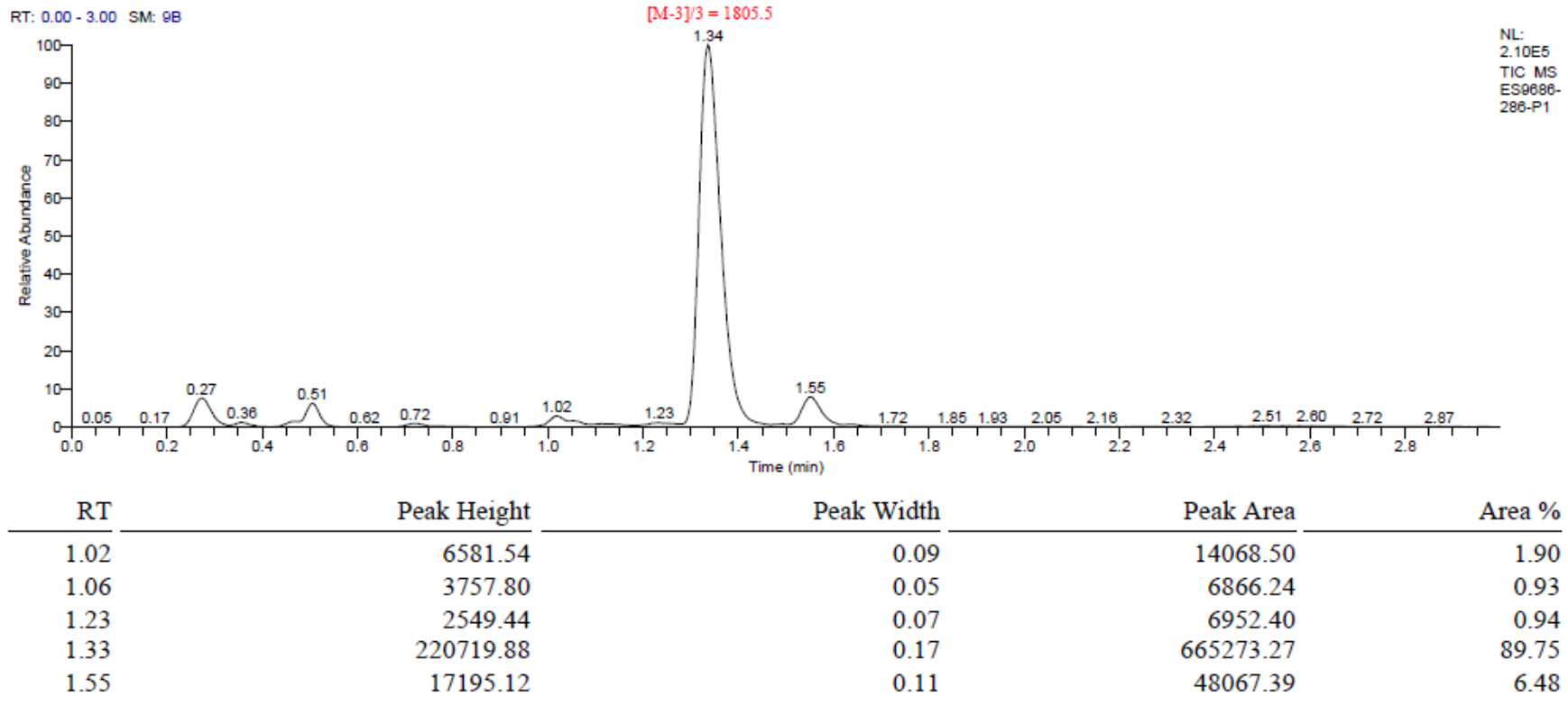

ES9686-286-P1 \#503 RT: 1.33 AV: 1 NL: 9.67E4

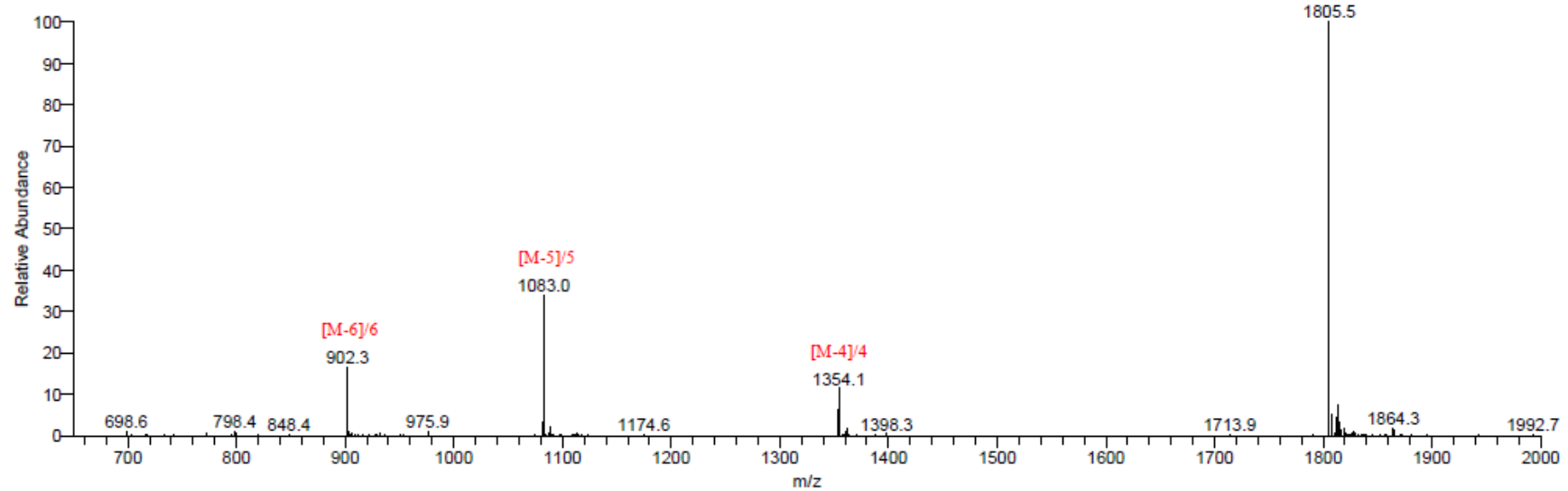

Figure S50. LC trace and mass of 9 


\section{SI-6-48 LC Trace and Mass of 10}

Following General Procedure 3

Yield: $79.02 \%$

Exact mass: 5546.25

Triply charged mass [M-3]/3, calculated: 1847.8; observed: 1848.1 .
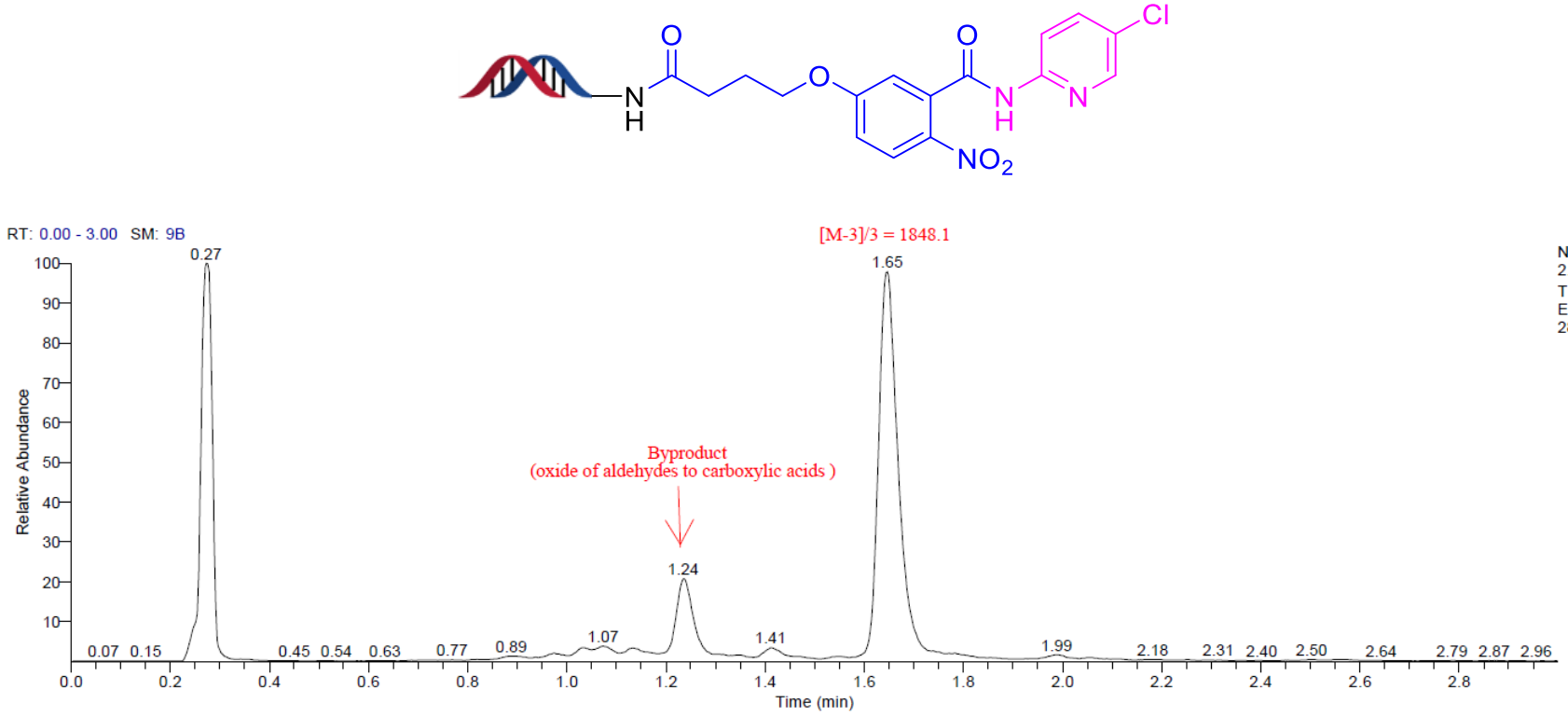

\begin{tabular}{|c|c|c|c|c|}
\hline RT & Peak Height & Peak Width & Peak Area & Area \% \\
\hline 1.03 & 5519.99 & 0.05 & 10255.07 & 1.51 \\
\hline 1.08 & 5947.64 & 0.06 & 14321.46 & 2.11 \\
\hline 1.13 & 5610.63 & 0.08 & 15249.48 & 2.24 \\
\hline 1.24 & 43893.53 & 0.18 & 102918.98 & 15.13 \\
\hline 1.64 & 215852.78 & 0.23 & 537531.76 & 79.02 \\
\hline
\end{tabular}

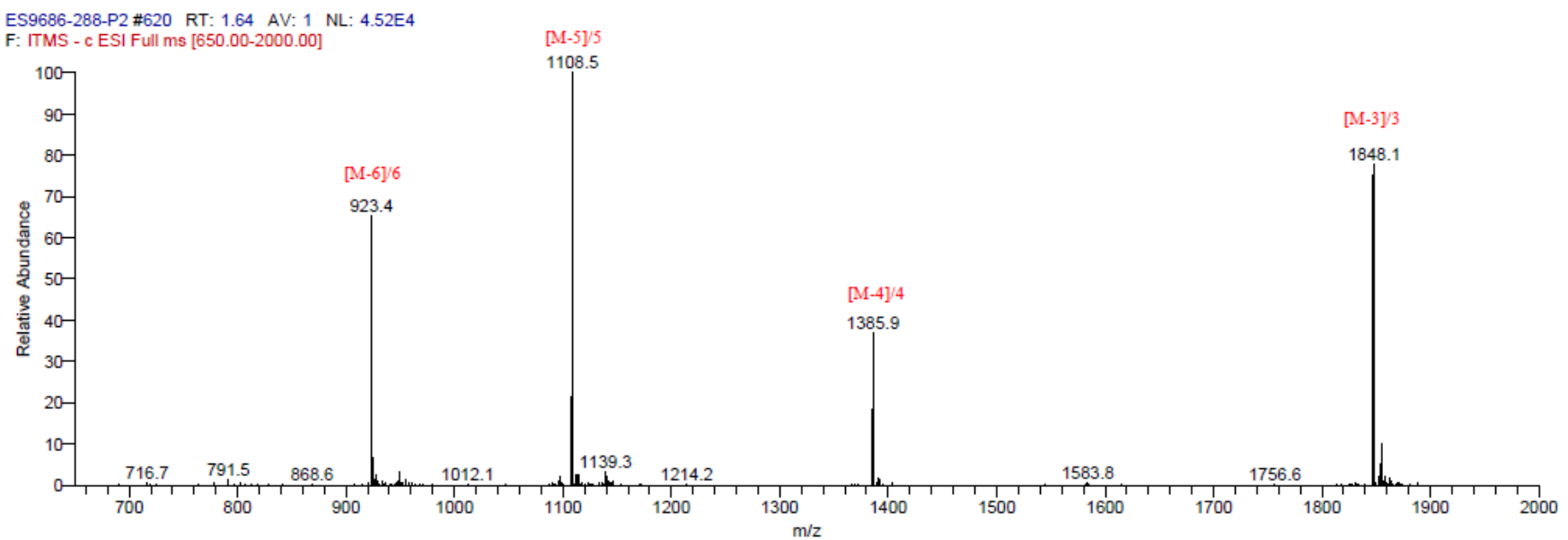

Figure S51. LC trace and mass of $\mathbf{1 0}$ 


\section{SI-6-49 LC Trace and Mass of 11}

Yield: $51.36 \%$

Exact mass: 5516.25

Triply charged mass [M-3]/3, calculated: 1837.8; observed: 1837.5.<smiles>Nc1ccc(OCCCC(=O)NCC2CC3CCC2C3)cc1C(=O)Nc1ccc(Cl)cn1</smiles>

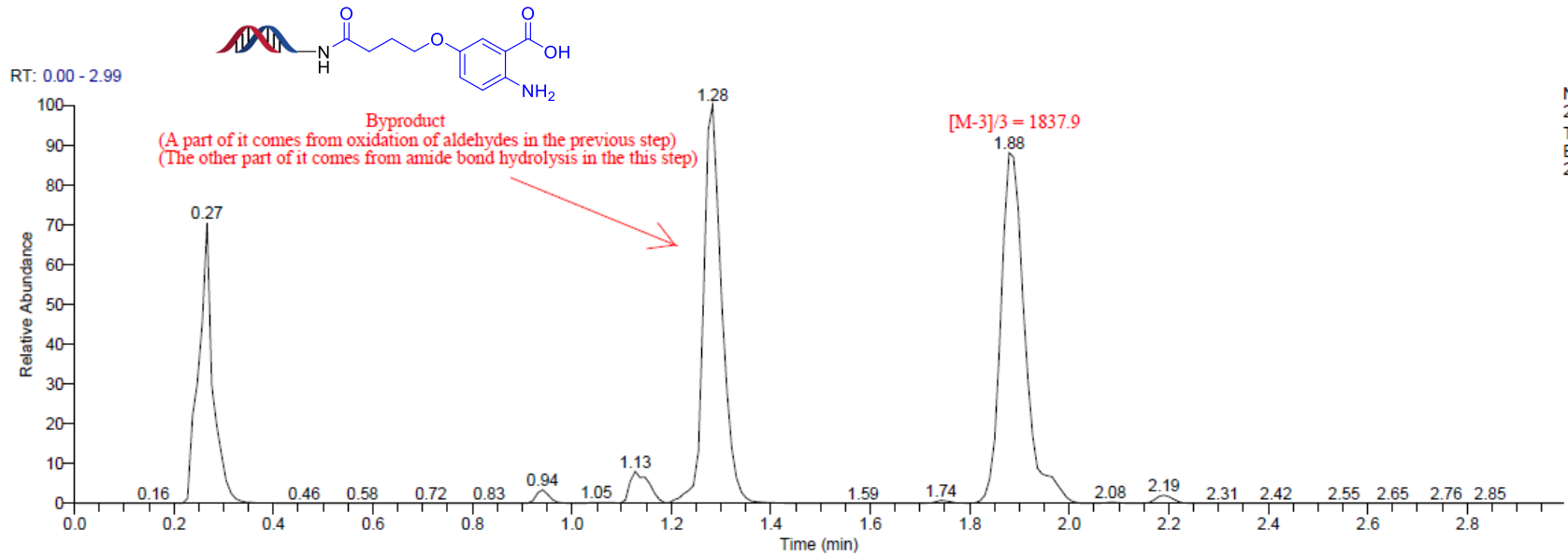

\begin{tabular}{|c|c|c|c|c|}
\hline RT & Peak Height & Peak Width & Peak Area & Area \% \\
\hline 1.07 & 400.09 & 0.08 & 1169.15 & 0.09 \\
\hline 1.13 & 15656.06 & 0.11 & 47898.96 & 3.58 \\
\hline 1.28 & 208240.25 & 0.19 & 586089.48 & 43.80 \\
\hline 1.74 & 1460.19 & 0.11 & 3396.34 & 0.25 \\
\hline 1.89 & 191153.42 & 0.25 & 687256.43 & 51.36 \\
\hline 2.08 & 594.23 & 0.09 & 1196.12 & 0.09 \\
\hline 2.19 & 4261.78 & 0.13 & 11154.58 & 0.83 \\
\hline
\end{tabular}

ES9686-292-P2 \#194 RT: 1.89 AV: 1 NL: $1.06 E 5$ F: ITMS - c ESI Full ms [650.00-2000.00]
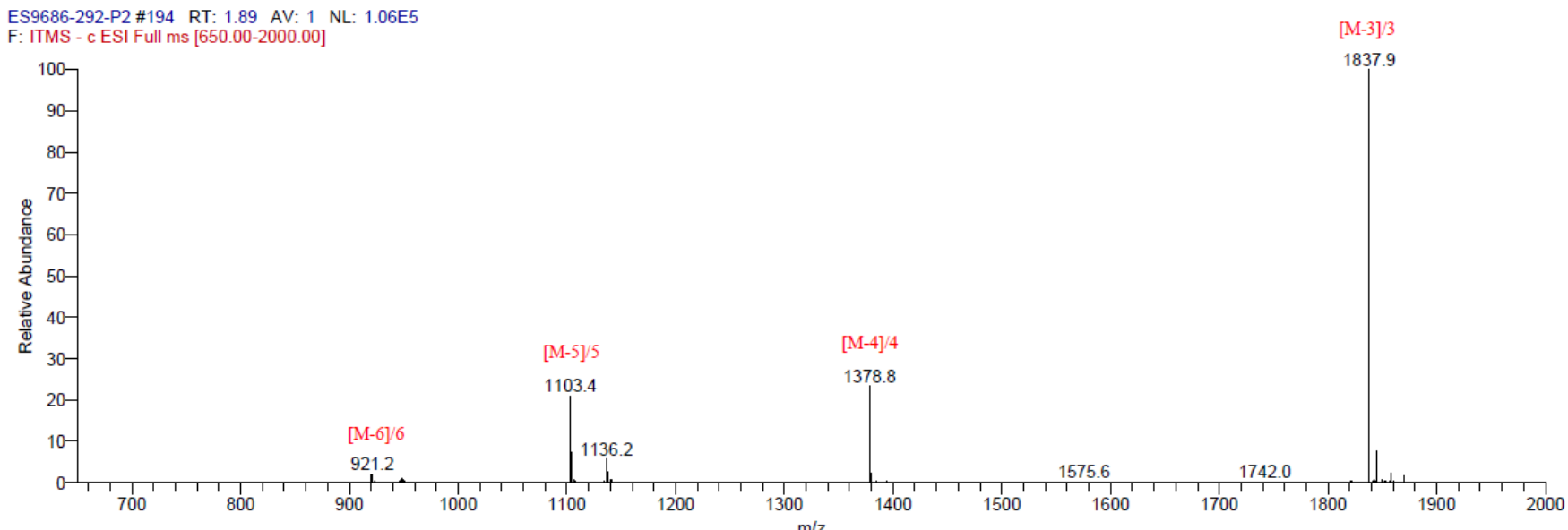

Figure S52. LC trace and mass of crude $\mathbf{1 1}$ 


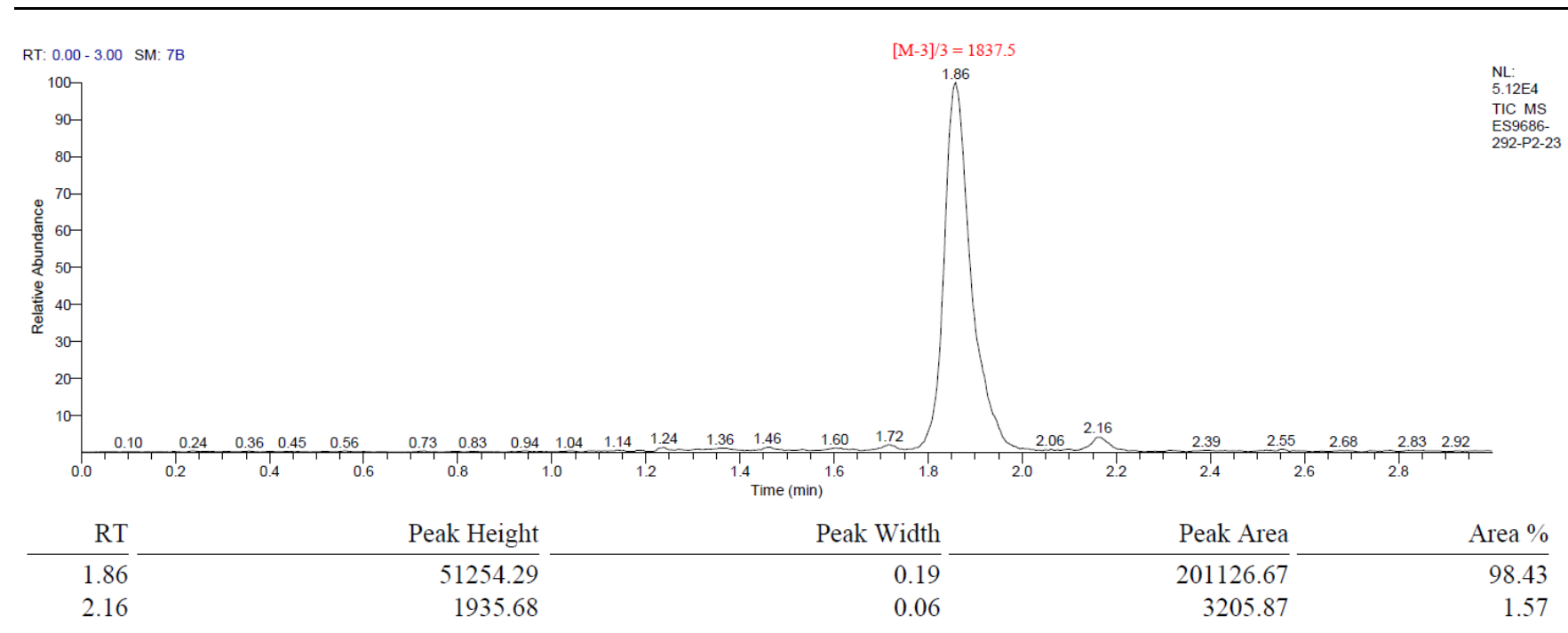

ES9686-292-P2-23 \#701 RT: 1.86 AV: 1 NL: 3.12E4

F: ITMS - c ESI Full ms [650.00-2000.00]
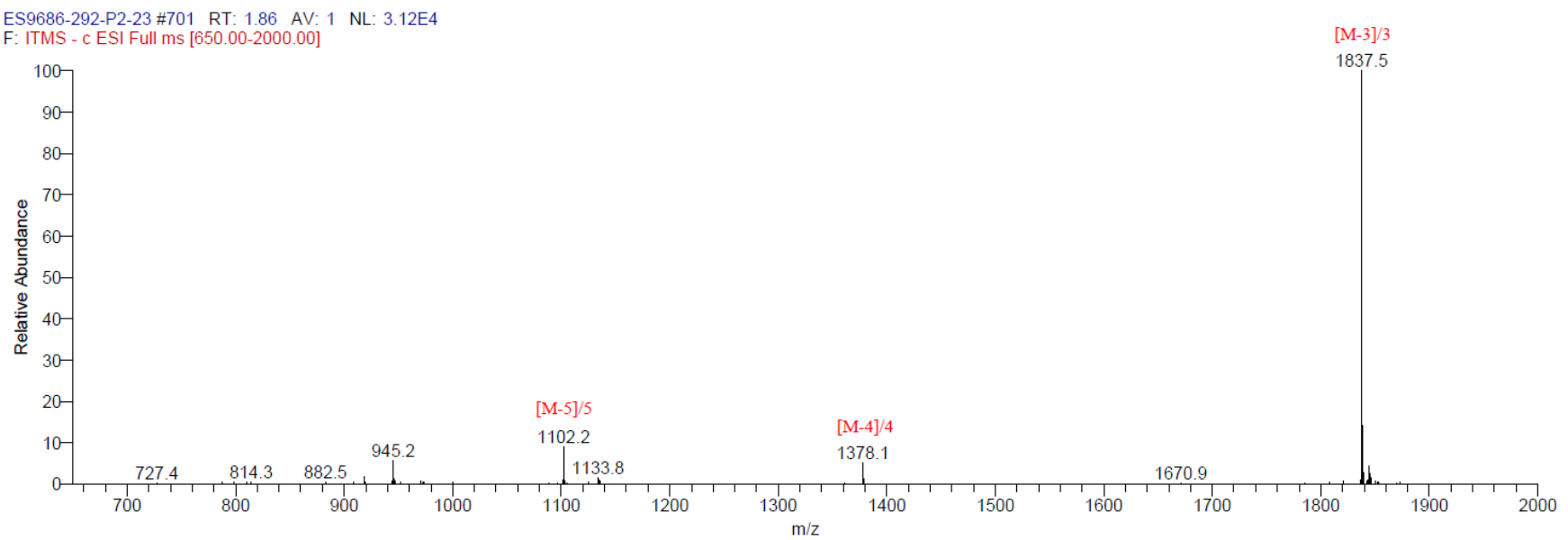

Figure S53. LC trace and mass of 11 after prep-HPLC 


\section{SI-6-50 LC Trace and Mass of 12}

Yield: $83.16 \%$

Exact mass: 5690.46

Triply charged mass [M-3]/3, calculated: 1895.8; observed: 1895.9.

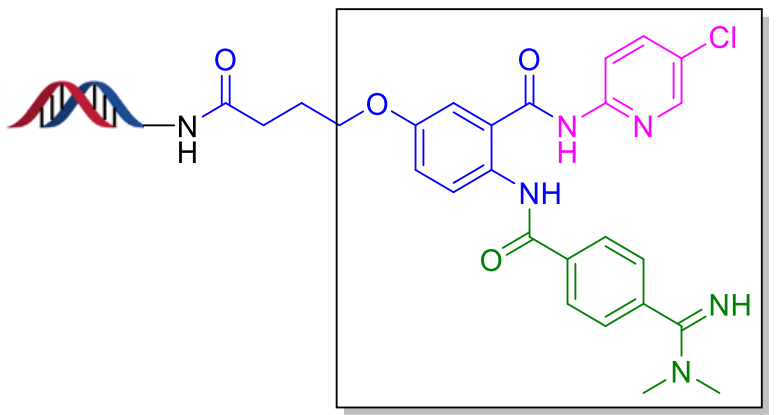

Betrixaban

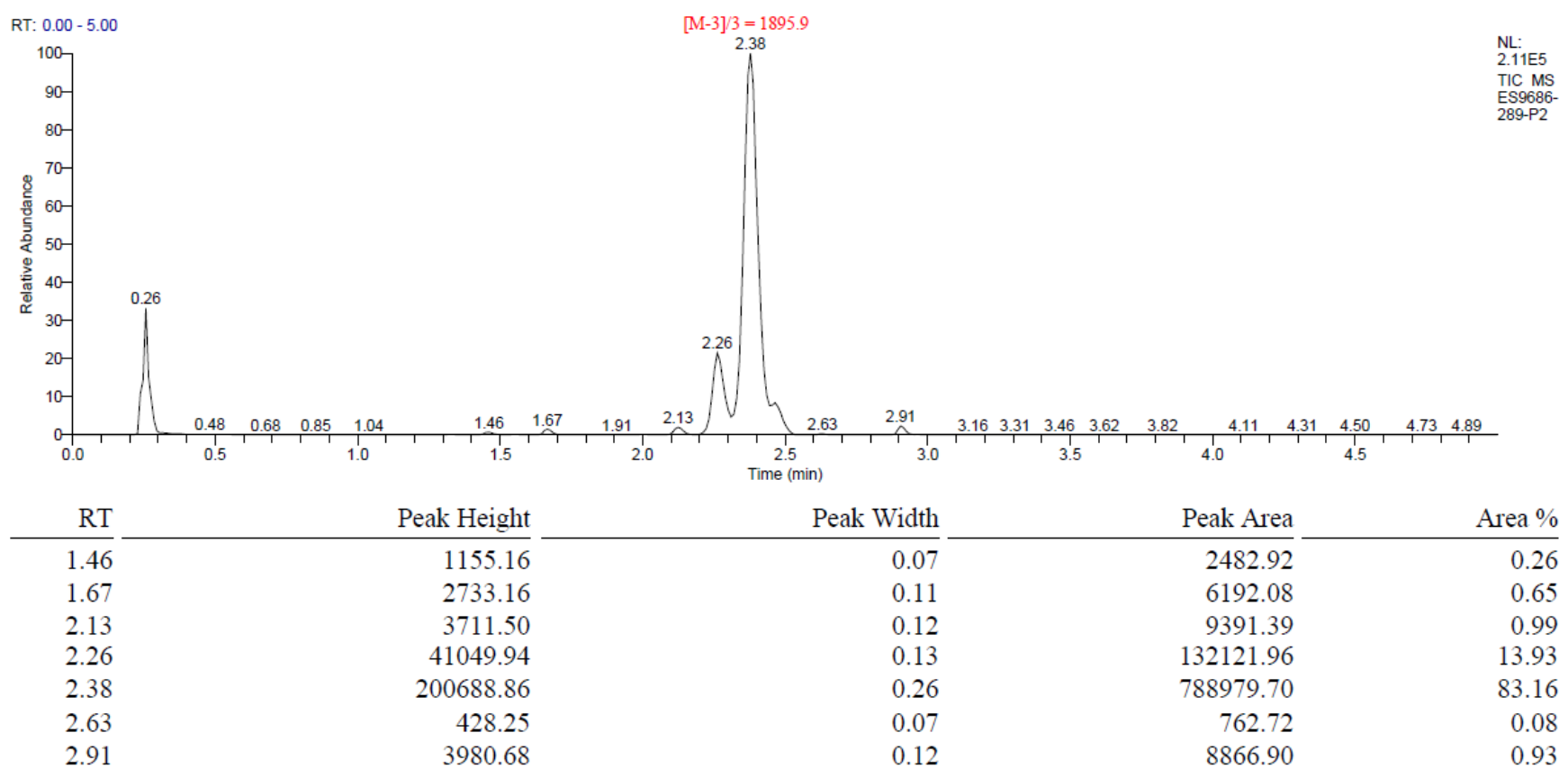

ES9686-289-P2 \#244 RT: 2.38 AV: 1 NL: $9.77 E 4$

F: ITMS - c ESI Full ms [650.00-2000.00]

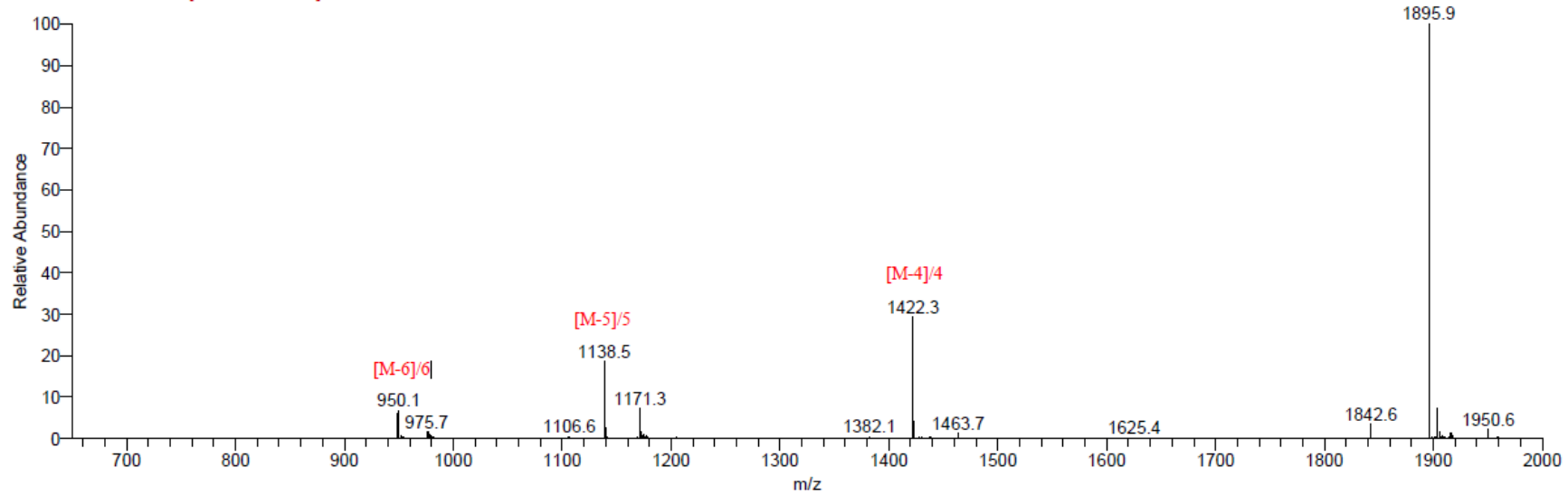

Figure S54. LC trace and mass of 12 


\section{SI-6-51 LC Trace and Mass of 13}

Yield: $70.44 \%$

Exact mass: 5674.41

Triply charged mass [M-3]/3, calculated: 1890.5; observed: 1890.5 .<smiles>O=C(CCCOc1ccc(NCc2ccc(-c3nnn[nH]3)cc2)c(C(=O)Nc2ccc(Cl)cn2)c1)NCc1ccccc1</smiles>
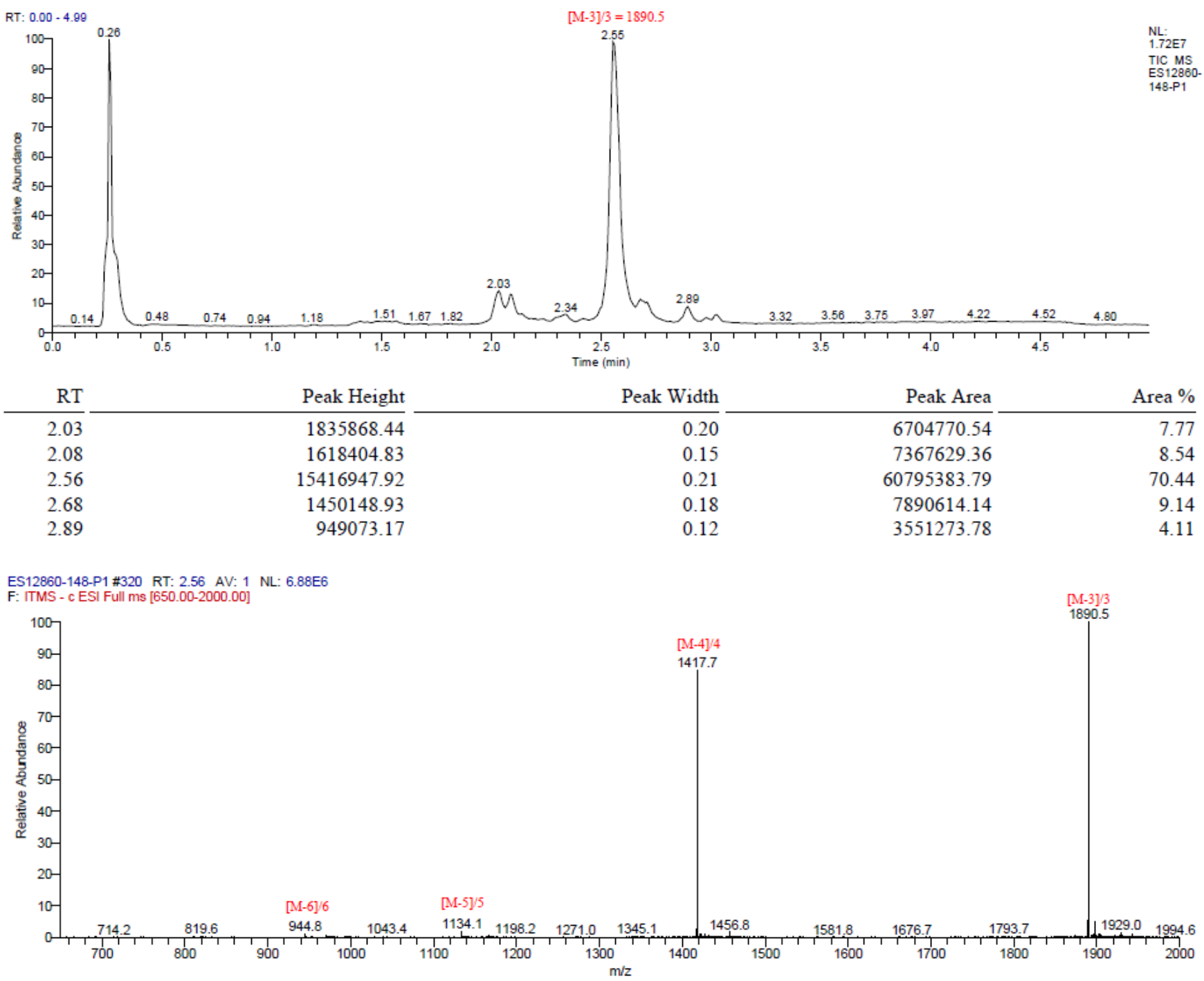

Figure S55. LC trace and mass of $\mathbf{1 3}$ 